APAE Memo No. 214

Copy No.

AEC Research and

Development Report UC-81,

Reactors, Power

(Special Distribution)

\title{
EVALUATION OF \\ LOW IMPURITY CORE MATERIAL \\ IN THE SM-2
}

\author{
Issued August 14, 1959 \\ Prepared By \\ Guyon P. Pancer \\ John L. Zegger
}

Approved By

William S. Brown - Supervisor, Radiochemistry Laboratory

Dennis D. Foley - Head of Materials Technology

Prepared under

Contract No. AT $(30-3)-326$

for the USAEC

New York Operations Office

ALCO PRODUCTS, INCORPORATED

Post Office Box 414

Schenectady 1, New York 


\section{DISCLAIMER}

This report was prepared as an account of work sponsored by an agency of the United States Government. Neither the United States Government nor any agency Thereof, nor any of their employees, makes any warranty, express or implied, or assumes any legal liability or responsibility for the accuracy, completeness, or usefulness of any information, apparatus, product, or process disclosed, or represents that its use would not infringe privately owned rights. Reference herein to any specific commercial product, process, or service by trade name, trademark, manufacturer, or otherwise does not necessarily constitute or imply its endorsement, recommendation, or favoring by the United States Government or any agency thereof. The views and opinions of authors expressed herein do not necessarily state or reflect those of the United States Government or any agency thereof. 


\section{DISCLAIMER}

Portions of this document may be illegible in electronic image products. Images are produced from the best available original document. 


\section{A.E.C.LEGAL NOTICE}

This report was prepared as an account of Government sponsored work. Neither the United States, nor the Commission, nor any person acting on behalf of the Commission:

A. Makes any warranty or representation, expressed or implied, with respect to the accuracy, completeness, or usefulness of the information contained in this report, or that the use of any information, apparatus, method, or process disclosed in this report may not infringe privately owned rights:

or

B. Assumes any liabilities with respect to the use of, or for damages resulting from the use of any information, apparatus, method, or process disclosed in this report.

As used in the above, "person acting on behalf of the Commission" includes any employee or contractor of the Commission, or employee of such contractor, to the extent that such employee or contractor of the Commission, or employee of such contractor prepares, disseminates, or provides access to, any information pursuant to his employment or contract with the Commission, or his employment with such contractor.

\section{ALCO LEGAL NOTICE}

"This report was prepared by Alco Products, Incorporated in the course of work under, or in connection with, Contract No. AT $(30-3)-326$, issued by United States Atomic Energy Commission, New York Operations Office; and subject only to the rights of the United States, under the provisions of this contract, Alco Products, Incorporated makes no warranty or representation, express or implied, and shall have no liability with respect to the use thereof or with respect to whether any such use will infringe the rights of others."

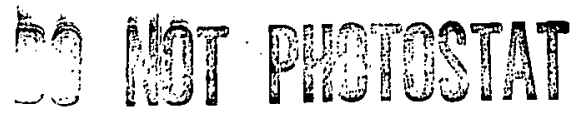




\section{DISTRIBUTION}

COPIES

$1-2$ New York Operations Office .

U. S. Atomic Energy Commission

376 Hudson . Street

New York 14, New York

Attention: Chief, Army Reactors Branch, NYOO

$3-5$

U. S. Atomic Energy Commission

Army Reactors Branch

Division of Reactor. Development

Washington 25, D. C.

Attention:-Chief, Water Systems Project Branch

Office, Ass't Director (Army Reactors)

6

U. S. Atomic Energy Commission

Chief, Patents Branch

Washington 25, D. C。

Attention:- Roland Anderson

7.

U. S. Atomic Energy Commission

Chief, New York Patent Group

Brookhaven National Laboratory

Upton, New York

Attention: Harman Potter

8

U. S. Atomic Energy Commission

Idaho Operations Office

Phillips Petroleum Company, NRTS

Technical Library

P. O.: Box 1250

Idaho Falls, Idaho

Attention: Technical Liais on Officer Army Reactors

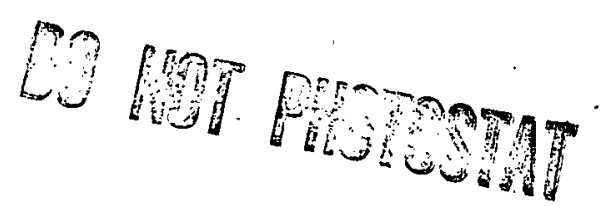

9-11 Nuclear Power Field Office

USAERDL

Fort Belvoir, Virginia

Attention: Chief, Nuclear Power Field Office 
COPIES

12

13

14

15

$16-17$

\section{DISTRIBUTION (CONT ${ }^{\circ}$ D)}

Union Carbide Nuclear Corporation

Oak Ridge National Laboratory

Y-12 Building 9704-1

P.O. Box. "Y"

Oak Ridge, Tennessee

Attention: A. L. Boch

The Martin Company

P.O. Box 5042

Middle.River, Maryland

Attention: AEC Contract Document Custodian

Combustion Engineering, Inc.

P.O. Box 2558

Idaho Falls, Idaho

Attention: Mr。W. B. Allred, Project Manager SL-1

U.S. Atomic Energy Commission

Reference Branch

Technical Information Services Extension

P.O. Box 62

Oak Ridge, Tennessee

Alco Products, Inc.

P. O Box 145

Fort Belvoir, Virginia

Attention: H. L. Weinberg

18

Dr。 $\mathbf{R}_{0} \cdot$ L。 Murray

Nor th Carolina State-College

P. O. Box 5596

State College Station

Raleigh, Nor th. Carolina

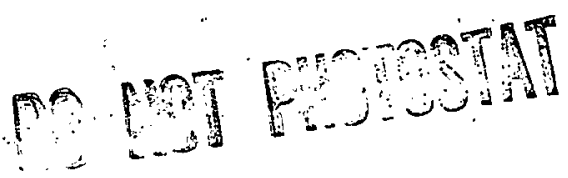




\section{DISTRIBUTION (CONT'D)}

\section{COPIES}

19

Dr. Lawrence R. Quarles

Dean, School of Engineering

University of Virginia

Charlottesville, Virginia

Attention: : Dr。J。L.Meem, Jr。

20

K. Kasschau

21

J. F. Haines

22

D. D. Foley

23

J. G. Gallagher

24

J. P. Tully

25

C. A. Bergmann

26

P. E. Bobe

27

W. S. Brown

28

B. J. Byrne

29

R. J. Clark

30

T. F. Connolly

31

R. A. Hasse

32

R. W. Kelleman

33.

G. W. Knighton

34

G. P. Pancer.

35

$\mathbf{R}_{\text {. }}$. Do Robertson

36

J. L. Zegger

$37-41$

File 


\section{ABSTRACT}

The worth of reduced cobalt and tantalum impurity concentrations of AISI Type 347 stainless steel in the SM-2 core cladding and structural material was evaluated on the basis of material costs involved and accessibility for maintenance. 
TABLE OF CONTENTS

$\underline{\text { PAGE }}$

1.0 INTRODUCTION $\ldots \ldots-\ldots, \ldots$

2. 0 SUMMARY AND CONCLUSIONS - $-\ldots \ldots$

3.0 THEORETICAL EQUATIONS AND CALCULATED RESULTS - : 7

3.1 Activity Buildup Equations _... 7

3. 2 Dose Rate Equations - _ _ _ _.

3. 3 Estimated Radiation Levels in the Steam Generator

Water Box-............................ 20

4. 0 DISCUSSION OF RESULTS $\ldots \ldots \ldots$

4. 1 Economic Considerations of Low Impurity Core

Materials _...

4.1.1 Low Impurity Reflector Material-.....

4. 1. 2 Low Impurity Core Material- _- $\ldots \ldots \ldots \ldots-35$

4. 2 Maintenance Aspects of Reduced Impurity Levels_- _ -43

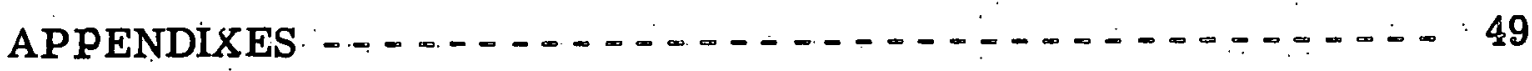

APPENDIX A - NUCLIDE DATA _..........

APPENDIX B - PHYSICAL DATA $\ldots \ldots \ldots \ldots$

APPENDIX C - CONVERSION FACTOR $\Psi \ldots \ldots \ldots$

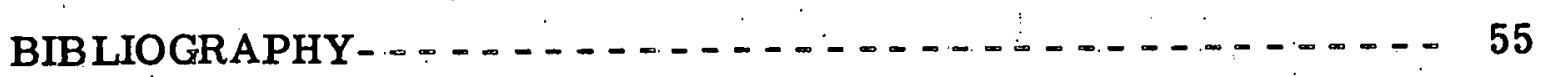

ix 


\section{LIST OF.ILLUSTRATIONS}

FIGURE

$1:$

2
TITLE

$\underline{\text { PAGE }}$

SM-2 Steam Generator (Water Box) Dose

Rate over 20-Year Period for 41-Inch

Reactor Vessel _.........

Relative Contribution and Dose Rate in

the SM-2 Steam Generator

Calculated Dose Rates in the SM-2 Steam

Generator for Various Core Impurity

Concentrations

Change in Steam Generator Dose Rate for

Various Cobalt Impurity Levels in the Core

Cladding Material

Premium Cost Required for Various Reductions in Steam Generator Dose Rate $\cdots \cdots \cdots \infty \ldots$

Percent Increase in Material Cost of Core Cladding Material for Various Reductions in Steam Generator Dose Rate $=\ldots \ldots \ldots$

SM -2 Steam Generator Dose Rate for Core Cladding Impurity Level of 0.025 Percent Cobalt, 0.01 Percent Tantalum, and Reflector Impurity Level of 0.025 Percent Cobalt, 0.1.Percent Tantalum $-\div \ldots,-\infty-\infty-\infty 45$ 


\section{LIST OF TABLES}

TABLE

TITLE

PAGE

Relative Contributions to the SM-2 Steam Generator Dose Rate Over 20-Year Period for 41 -Inch Reactor Vessel - Cobalt ( 0.01 Fitercent), Tantalum (0.01 percent) in Core; Nominal Cobalt (0.1 Per cent), Tantalum (0.1 Percent) in Reflector $\ldots \ldots \ldots \ldots$

Calculated SM-2 Steam Generator Dose Rates for Various Impurity Levels in the Core and Reflector Material (Type 347 Stainless Steel)

"Productive Labor. Exposure Time" in the SM-2 Steam Generator for Various Core and Reflector Impurity Levels $\ldots \ldots \ldots \infty . \infty \ldots \ldots+\ldots$ 


\subsection{INTRODUCTION}

The buildup of radioactive corrosion product and fission product deposits on the primary system surfaces of nuclear reactors may restrict the normal operation of the installation. Continued buildup can seriously limit accessibility and may even prevent necessary maintenance.

The buildup of activity is due primarily to the activation of core cladding and structural material and its subsequent release by corrosion. The material of construction for the Army Package Power Reactor (SM-1) core is AISI Type 304 stainless steel with minor amounts of Stellite, Haynes-25 alloy, Armco 17-4PH and AISI Type 410 stainless steel. The observed dose rates from the system surfaces of this reactor after shutdown are the result of contributions from the long-lived nuclides of cobalt60 and -58 , manganese -54 , iron -59 , and chromium-51. Almost 75 percent of the dose rate after two years of reactor operation is due to cobalt-60 and $-58.1$

The proposed core cladding and structural material for the $\mathrm{SM}-2$ is AISI Type 347 stainless steel. The use of this material may result in higher radiation levels than in the $S M-1$ because of the higher power level and the added contribution to the dose rate from tantalum-182. This nuclide is formed by an $(n-\gamma)$ reaction on the tantalum which is present as an impurity associated with the columbium additive to the stainless steel. It is possible to reduce the contribution to the dose rate from tantalum-182 and cobalt -60 through the procurement of low impurity stainless steel. A number of steel mills have indicated their willingness to supply AISI Type 347 stainless steel with guaranteed limits of 0.01 percent maximum cobalt and 0.01 to 0.02 per cent maximum tantalum. However, in order to evaluate the consequences of low impurity core materials, it is necessary to determine the contribution to the dose rate from uncontrollable nuclides such as cobalt-58, iron-59, manganese-54, and chromium-51. It may be possible to reduce the dose rate contribution from cobalt-60 and tantalum-182 to a point that may be insignificant when compared to the contribution from the uncontrollable nuclides.o. Changes in coolant chemistry or improvements in purification methods may reduce the deposition of all nuclides.

The feasibility of reducing cobalt and tantalum impurity levels in the SM-2 will depend upon the monetary premium involved, the magnitude of the reduction in dose rates, and the effect of such a reduction on access and maintenance. In this report, the maintenance problem is confined to the steam generator. This component contains the greatest non-core primary. surface area and is one of those areas most likely to require maintenance. 


\subsection{SUMMARY AND CONCLUSIONS}

A set of equations was derived and used to calculate the dose rate due to activated corrosion products in the SM-2 steam generator water box over a 20-year period (20 core lives). The calculations were made for a 41inch reactor vessel configuration utilizing AISI Type 347 stainless steel as cladding and reflector material. Since.SM-2 water chemistry conditions are similar to the SM-1, dose rate calculations were based on SM $\propto 1$ activity buildup experience.

The cobalt and tantalum impurity concentrations assumed in the stainless steel were varied to permit an evaluation of various impurity concentrations. As a result of the investigation the following conclusions were reached:

1. The use of nominal cobalt and tantalum concentrations ( 0.1 percent) in the cladding and reflector material will result in a steam generator gamma dose rate of approximately 5 Roentgens per hour after 1 year and 19 Roentgens per hour after 20 years.

2. The use of 0.02 percent cobalt and 0.1 percent tantalum in the reflector and core support material can be justified.

3. With 0.02 percent cobalt and 0.1 percent tantalum in the reflector and core support material, lowering the core cladding cobalt impurity level to 0.002 percent or lower will reduce the steam generator dose rate to a maximum of 75 to 80 percent, depending on the tantalum impurity level.

4. The practical impurity level, determined on the basis of both material economics and reduction in dose rate, would be 0.025 percent max. cobalt and 0.01 percent max. tantalum in the core cladding; 0.025 percent max. cobalt and 0.1 percent max. tantalum in the reflector and core support material.

5. It may not be possible to reduce the SM-2 steam generator dose rate by impurity level reduction to a point where accessibility to the water box is no longer a problem.

With AISI Type 347 stainless steel of nominal cobalt and tantalum concentrations ( 0.1 percent) used in the cladding and reflector material, approximately 88 percent of the 20 -year dose rate will be the consequence of activation of these controllable impurities. The remaining 12 percent will be due to the activation of the constituents of the stainless steel, e.g. iron, nickel, manganese. By reducing the controllable impurities, the gamma dose rate from the steam generator can be greatly reduced. The contribution to the 
dose rate from the normal stainless steel constituents then becomes relatively more significant. For example; by reducing the cobalt and tantalum . impurity concentration in the core cladding to 0.01 percent, the dose rate contribution from the normal stainless steel constituents will increase to 36 percent of the total dose rate.

The use of 0.02 percent cobalt and 0.1 percent tantalum in the reflector and core support material can be justified. The major contributor to the dose rate from these components is cobalt $60,:$ As these components will not be removed during the 20-year plant lifetime, a significant reduction in the steam generator dose rate can be achieved by decreasing the cobalt impurity level to a practical value A value of 0.02 percent cobalt impurity concentration can be açhieved at a relatively small increase in material cost. The negligible dose rate contribution from the tantalum impurity in the stainless steel reflector does not warrant a reduction in the tantalum impurity level.

For a reflector impurity concentration of 0.02 percent cobalt and 0.1 percent tantalum, lowering the cobalt impurity level in the core cladding to 0.002 percent or lower will reduce the dose rate obtained from the use of nominal cladding impurity levels to a maximum of 75 to 80 percent depending upon the tantalum impurity level. This maximum reduction can be achieved at an increase in material cost of 514 percent. However, an optimum reduction in dose rate of 65 percent can be achieved at a cost increase of 175 percent." The 175 percent increase in cost would be the same for impurity levels of either 0.1 percent tantalum -0.015 percent cobalt or 0.01 percent tantalum -0.0225 percent cobalt. The lower tantalum impurity level may be more advantageous from a reactivity aspect.

It may not be possible to reduce the SM-2 steam generator dose rate by impurity level reduction to a point where accessibility to the water box is no longer a problem. From a Health Physics aspect, it would be desirable to reduce the cobalt and tantalum impurity level below the nominal value. However, extremely low levels cannot be justified. The practical level, determined on the basis of both material economics and reduction in dose rate, would be 0.025 percent max. cobalt and 0.01 percent max. tantalum in the core cladding; 0.025 percent max. cobalt and 0.1 percent max. tantalum in the reflector and core support material.

The deposition of activated corrosion products with its associated dose rate may be reduced by improved purification methods and changes in coolant chemistry (high $\mathrm{pH}$ ). At the present time there are insufficient data avallable to evaluate these effects. 
Methods must be provided to facilitate maintenance in the SM-2 steam generator. Two methods which should be considered are remote maintenance in the radiation area or decontamination to reduce the dose rate to safe working levels. The disadvantage of remote maintenance is that all types of failures must be anticipated. Decontamination should be considered only as a last resort. At the present time it is the only immediate solution to the problem. 


\subsection{THEORETICAL EQUATIONS AND CALCULATED RESULTS}

\subsection{Activity Buildup Equations}

A general set of equations was derived to determine the buildup of corrosion product activity in the primary system of pressurized water reactors. The equations are similar to a set of equations originally derived by Meem ${ }^{2}$ and modified by Bergmann 1 . Some of the constants used in the equations are based on SM-1 operating data, e. $g_{0}$, deposition probability, corrosion rate constant, and chemical composition of corrosion product scale. The equations are based on a mechanism associated with the formation, release, and deposition of activated corrosion products. The following assumptions are used as a basis for the mechanism:

(1) All active nuclides which deposit out on the primary system originate from activation by the thermal and fast flux of the core cladding, r eflectors and core support material. This neglects the possibility of inactive nuclides from out-of-core surfaces passing through the core area and becoming activated.

(2) The active nuclides are released from the core into the coolant by corrosion. The amount of corrosion or corrosion rate varies during the first 12 months of operation. After this period the corrosion rate is assumed constant. This assumption is based on experimental data from SM-1 operation?

(3) The phenomenon of recoil as a method of release of active nuclides from the core is neglected ${ }^{3}$.

(4) The various constituents of the stainless steel of the core do not corrode (release) in the same proportion as the base metal. The chemical composition of the insoluble corrosion products differ from the chemical composition of stainless steel 4 .

(5) A deposition probability constant, defined as the probability that one of the active nuclides released into the coolant will deposit on a surface, is found from choosing a value which best fits existing SM-1 data. The total deposition is directly proportional to the number of active nuclides in the primary coolant 1 .

(6) The activity deposits uniformly over the entire primary system (in-core and out-of-core surfaces).

(7) The possibility of an active nuclide being released into the coolant after it has deposited on the system surfaces is neglected. 
On the basis of these assumptions, the following mechanism for the buildup of activity is postulated.

The active nuclides in the core are produced by the thermal and fast flux: These active nuclides are subsequently lost from the core by three processes; decay, further activation to a stable or low energy emitting nuclide, and release from the core by corrosion. The nuclides, which are released by corrosion, will enter the coolant and circulate through the entire primary system. While circulating, the nuclides are removed from the coolant by decay, purification, and deposition on the surfaces of the primary system:: Once the nuclides have deposited on the surfaces of the system there is a final loss by decay. equation:

The buildup of activity in the core can be described by the following

$$
\mathrm{N}=\left.\frac{\mathrm{N}_{0}\left|\sum \sigma \phi\right|}{\left|\lambda+\sum \sigma_{\mathrm{a}} \phi\right|}\right|_{1}=\mathrm{e}^{\left.-\mid \lambda+\sum \sigma_{\mathrm{a}} \phi\right)_{\mathrm{t}}} \mid
$$

where

$$
\begin{aligned}
N_{0} & =\text { number of atoms of the parent nuclide } \\
\sum \sigma \phi & =\text { cross section and flux for thermal and fast neutrons. } \\
\lambda & =\text { decay constant } \\
\sum \sigma_{2} \phi & =\text { loss factor accounting for further activation by the } \\
N & =\text { number of active nuclides in the core. }
\end{aligned}
$$

During the first twelve months of operation when a varying corrosion rate is assumed, the rate of change of the number of active nuclides released. to the coolant can be expressed as follows:

$$
\frac{\mathrm{dN}}{\mathrm{dt}}=\frac{\Psi_{\mathrm{c}} \mathrm{P} \sum \sigma \phi}{\mathrm{s}\left(\lambda+\sum \sigma_{\mathrm{a}} \phi\right)}\left(1-\mathrm{e}^{-\left(\lambda+\sum \sigma_{\mathrm{a}} \phi\right)}\right)\left(\mathrm{Ke} \mathrm{e}^{-\beta_{t}}\right)
$$


where

$$
\begin{aligned}
& \mathrm{Ke}-\mathrm{Bt}_{\mathrm{t}}=\text { is the variable corrosion rate expression }(\mathrm{K} \text { and } \beta \\
& \text { were derived from SM-1 experimental data) } \\
& A_{C} \quad=\text { total surface area of the core cladding and reflectors } \\
& \mathbf{P} / \mathbf{S} \quad=\text { the percent abundance of the parent nuclides in the } \\
& \text { corrosion products } \\
& \Psi \quad=\text { conversion factor (See Appendix C) } \\
& \mathrm{N}^{\prime}: \quad=\text { number of active atoms released into the coolant }
\end{aligned}
$$

The rate of change with time of the number of active nuclides in the water is now given by:

$$
\frac{d N^{\prime \prime}}{d t}=\frac{\Psi_{A_{c}} P K \sum \sigma \phi}{v s\left(\lambda+\sum \sigma_{a} \phi\right)} e^{-\beta t} \cdot\left(1-e^{-\left(\lambda+\sum \sigma_{a} \phi \mid t\right)}-\left(b_{t}+\alpha+\lambda\right) N^{\prime \prime}\right.
$$

where

$$
\begin{aligned}
& \left(D_{t}+\alpha+\lambda\right) N^{\prime} \quad \because \quad \begin{array}{c}
\text { the removal from the coolant by deposition, } \\
\text { purification and decay }
\end{array} \\
& \text { D } \quad \text { deposition probability }\left(\mathrm{cm}^{-2}-\sec ^{-1}\right) \\
& \text { At } \quad=\text { total surface area of primary system } \\
& \alpha \quad=\text { purification system factor }\left(\sec ^{-1}\right) \\
& \mathrm{V} \quad=\text { total volume of the system } \\
& \text { N" } \quad=\text { number of active atoms per unit volume in the coolant } \\
& \text { Let } G=\left(D A_{t}+\alpha+\lambda\right) \\
& \text { E } \quad \cdots=\left(\sum \sigma_{\mathrm{a}} \phi+\lambda+\beta\right) \\
& \text { Q } \quad=\frac{\Psi_{\mathrm{A}_{\mathrm{c}} \mathrm{PK}} \sum \sigma \phi}{\operatorname{Vs}\left(\lambda+\sum \sigma_{\dot{\mathrm{a}}} \phi\right)}
\end{aligned}
$$


Substituting and solving equation. (3)

$$
N^{\prime}=Q\left[\frac{e^{-\beta t}-e^{-G t_{1}}+e^{-G t}-e^{-E t}}{|G-\beta|}\right]
$$

where $\mathrm{N}^{\prime \prime}$ has the units of atoms $/ \mathrm{cm}^{3}$

The rate of buildup on the surfaces of the primary system for the first twelve months of reactor operation is.now found from:

$$
\frac{d N_{1}}{d t}=D^{\prime} N^{\prime} \lambda N_{1}
$$

where $\mathrm{N}_{1}=$ number of active atoms per unit area on the on the primary system surface

Substituting the value of $\mathrm{N}^{\prime \prime}$ (equation 7 ) into equation (8) and solving:

$$
\begin{gathered}
N_{1}=D V Q\left[\frac{e^{-\beta t}-e^{-\lambda t}+\frac{e^{-G t}-e^{-\lambda t}}{|G-\beta|(\lambda-\beta)}+}{\mid G-E)(\lambda-G)}\right. \\
\left.\therefore \frac{e^{-\lambda t}-e^{-G t}}{|G-\beta|(\lambda-G)}+\frac{e^{-\lambda t}-e^{-E t}}{\mid G-E) \mid \lambda-E)}\right]_{0 \leq t \leq 12 \text { months }}
\end{gathered}
$$

where $\mathrm{N}_{1}$ has the units atoms $/ \mathrm{cm}^{2}$

As stated above, beyond twelve months the corrosion rate is constant. Ther efore the expression $\mathrm{Ke}^{-} \beta^{\mathrm{t}}$ is replaced by $\mathrm{C}\left(\mathrm{mgs} / \mathrm{dm}^{2}-\mathrm{mo}\right)$ in equation (2). 
Following the same argument as above; the number of active nuclides per unit area on the system surfaces, defined as $\mathrm{N}_{2}$, from twelve months to some time ( $t$ ) plus 12 months is given by:

$$
\begin{aligned}
& N_{2}=D V Q_{1}\left\{\left[\frac{\left(1-e^{-\lambda t}\right)}{\lambda G}+\frac{\left(e^{-G t}-e^{-\lambda t}\right)}{|G-\lambda||\lambda-G|}+\frac{\left(e^{-\lambda t}-e^{-G t} \mid\right.}{G(\lambda-G)}-\frac{\mid t e-\lambda t)}{|G-\lambda|}\right]=12\right. \text { months } \\
& -\left[\frac{\left(1-e^{-\lambda t}\right)}{\lambda G}+\frac{\left(e^{-G t}-e^{-\lambda(t)}\right.}{(G-\lambda)(\lambda-G)}+\frac{\left(e^{-\lambda t}-e^{G t}\right)}{G(\lambda-G)}-\frac{\left(t e^{-\lambda t}\right)}{\mid G-\lambda)}\right] \mid
\end{aligned}
$$

where $Q_{1}=\frac{\Psi_{\mathrm{c}} \mathrm{PC} \cdot{ }}{\operatorname{vs}\left|\lambda+\sum \sigma_{\mathrm{a}} \phi\right|}$

The total activity in the system at any time $(t)$ beyond 12 months would be

$$
\mathrm{N}_{3}=\mathrm{N}_{1}+\mathrm{N}_{2}
$$

The SM-2 core has been designed for a one calendar year lifetime. Therefore at the end of one year any deposited activity will be decaying while new nuclides are being formed and deposited from the replacement core. In applying equation (11) to determine the buildup in the SM-2, a modification must be made.

Since the core is replaced after each year of operation, the value of $\mathrm{N}_{2}$ would be zero when equation (11) is used to calculate the buildup due to the core only. The number of active atoms per unit area from i plus the present core, referred to as $\mathbf{N}_{4}$, is 


$$
\begin{aligned}
\mathbb{N}_{4} & =N_{1}^{\prime}(t-i)+N_{1}(t=1 \mathrm{yr}) \sum_{1} e^{-\lambda(t-i)} \\
& =1,2,3, \ldots n \\
N_{1} & =\text { equation }(9) \text { at time }(t-i) \\
N_{1} & =\text { equation }(9) \text { at time } t=1 \text { yr } \\
i & =\text { total number of cores that have been removed at time }(t) .
\end{aligned}
$$

With the exception of cobalt 60 , the nuclide contribution from previous cores becomes insignificant within two years after the core responsible for the nuclides has been removed. Because of this phenomenon, the individual nuclide contribution curve.will appear as a series of cycles over an extended period of time (cf. Fig。1).

The total activity in the system at any time would be due to the activity from the core and the activity from the fixed section of the reactor vessel $\dot{i}_{0} e_{0}$, the reflectors, core supports (non-movable areas exposed to a neutron fluxi).

The activity contribution from the immovable areas is found from equation(11) while that from the core is found from equation (12). Therefore the total activity $\left(\mathrm{N}_{\mathrm{T}}\right)$ in the system at any time $(\mathrm{t})$ would be

$$
\mathrm{N}_{\mathrm{T}} \quad=\mathrm{N}_{1}+\mathrm{N}_{2}+\mathrm{N}_{4}
$$

The term $\sum \sigma \phi$ which first appears in equation (1) will require further elucidation. The expression can be written as:

$$
\begin{gathered}
\sigma_{\mathrm{th}}\left[\frac{\mathrm{A}_{1}}{\mathrm{~A}_{\mathrm{c}}} \phi_{\mathrm{th}_{1}}+\frac{\mathrm{A}_{2}}{\mathrm{~A}_{\mathrm{c}}} \phi_{\mathrm{th}_{2}}+\cdots\right. \\
\vdots \\
\sigma_{\mathrm{fe}}\left[\frac{A_{1}}{\mathrm{~A}_{\mathrm{c}}} \phi_{\mathrm{fe}_{1}}+\frac{\mathrm{A}_{2}}{\mathrm{~A}_{\mathrm{c}}} \phi_{\mathrm{fe}_{2}}+\cdots\right.
\end{gathered}
$$


where

$$
\begin{aligned}
\phi_{\mathrm{th}} & =\text { thermal flux } \\
\sigma_{\mathrm{th}} & =\text { thermal cross section } \\
\phi_{\mathrm{fe}} & =\text { effective fast flux } \\
\sigma_{\mathrm{fe}} & =\text { cross section for effective fast flux } \\
& \cdots \text { (resonance integral) }
\end{aligned}
$$

$A_{1,2}, 3 \ldots n=$ various areas in the reactor vessel subjected to the thermal and fast flux.

$\mathbf{A}_{\mathbf{c}}$ $=$ total area subjected to the thermal and fast flux

$$
\left(A_{c}=A_{1}+A_{2}+\ldots .+A_{n}\right)
$$

This expression will be valid for all of the $n-\gamma$ reactions under consideration. Two of the nuclides being investigated ( $\mathrm{Co}^{58}$ and $\mathrm{Mn}^{54}$ ) are formed by an $\mathrm{n}-\mathrm{p}$ reaction on $\mathrm{Ni}^{58}$ and $\mathrm{Fe}^{54}$ respectively. For these nuclides, the thermal cross section $\left(\sigma_{\text {th }}\right)$ is assumed to be zero. The fast flux is the actual fast flux rather than the effective fast flux. The cross section $\left(\sigma_{f}\right)$ for these $n-p$ reactions is based on the fast flux ${ }^{5}$.

There are ample data recorded in the literature for the values of the thermal cross section for the $n-\gamma$ reactions under consideration. These values must be corrected for Maxwell-Bóltzmann distribution and temperature.

The values used for the reasonance integrals were also taken from the literature. 6 . The effective fast flux $\left(\sigma_{\mathrm{fe}}\right)$ that is used with these cross sections is evaluated as follows:

It is assumed that the $n-\gamma$ reactions with the fast flux occur in the $1 / \mathrm{E}$ region tor

$$
\phi_{\mathrm{I}}(\mathrm{E}) \sim \frac{1}{\mathrm{E}}
$$


where

$$
\phi_{f}=\text { The fast flux. }
$$

Therefore,

$$
\phi_{\mathrm{f}}|\mathrm{E}|=\frac{\alpha}{\mathrm{E}}
$$

where

$$
\alpha=\text { constant of proportionality }
$$

The production of active nuclides from the fast flux can be expressed as:

Production of active nuclides $=N^{i} \sigma_{f}^{i}|E| \phi_{f}(E)$ but from equation (16)

Therefore,

$$
\left.\phi_{\mathrm{f}} \mid \mathrm{E}\right)=\frac{\alpha}{\mathrm{E}}
$$

$$
=N^{i} \sigma_{f}(E) \frac{\alpha}{E}
$$

The fast flux is assumed to be between the limits of $0.4 \mathrm{ev}$ to $2 \times 10^{6} \mathrm{ev}$. Evaluating over these limits

$$
=N^{i} \alpha \int_{0.4}^{\frac{\sigma \times 10^{6}}{E}} \frac{\sigma l_{d E}}{E}
$$

The expression $\int_{E_{1}}^{E_{2}} \frac{\sigma(E) d E}{E} \quad \because$ is defined as the resonance

integral and has been determined experimentally ${ }^{6}$.

As stated previously, the fast flux is assumed to have a $1 / E$ behavior. The limits are identical to that of the cross section. 
Therefore,

$$
2 \times 10^{6}
$$

$$
\phi_{\mathrm{f}}=\int_{0,4} \phi_{\mathrm{f}}(E) \mathrm{d} E
$$

Combining equation (16) with equation (20)

$$
\phi_{\mathrm{f}}=\alpha \int_{0.4}^{2 \times 10^{6}} \frac{\mathrm{dE}}{\mathrm{E}}
$$

integrating,

$$
\phi_{\mathrm{f}} \quad \vdots=15.4 \alpha
$$

The value of $\alpha$ is determined from the known ratio of the fast to the thermal flux.

$$
\begin{aligned}
\frac{\phi_{\mathrm{f}}}{\Phi_{\mathrm{th}}} & =\mathbf{R}=\frac{15,4}{\phi_{\mathrm{th}}} \alpha \\
\alpha & =\frac{\mathbf{R} \phi_{\mathrm{th}}}{15.4}
\end{aligned}
$$

At any area of the $S M-2$ reactor vessel the ratio $\mathbf{R}$ as well as the value, of $\phi_{\text {th }}$ is known ${ }^{8}$. The value of $\alpha$ can therefore be determined. This value of $\alpha$ is now defined as the effective fast flux.

$$
\alpha=\phi_{\text {fe }}
$$

The expression $\sum \sigma_{\mathrm{a}} \phi$ which represents the further activation of the var lous nuclides is evaluated by the same argument. There are very little data available on further activation and in most instances this term is zero. The values used to solve the equations derived in this section are tabulated in Appendixes A and B. 


\subsection{Dose Rate Equations}

The equations for determining the SM-2 dose rate at the tube sheet due to the buildup of corrosion product activity were derived from geometrical considerations and experimental data. The equations include the contribution from three.sources: the tubes, the tube sheet, and the water box surfaces. The contribution of the baffle plate has been neglected.

Consider an ionization chamber placed against the tube sheet and encompassing one tube and a section of the tube sheet surrounding the tube. The radiation from other tubes is assumed to be negligible. Ther efore, when taking a reading with this chamber, only the radiation from one tube and its surrounding tube sheet is recorded.

The equation for the dose rate from the tube and tube sheet is derived as follows:

$\mathrm{dD}=$ differential dose rate at the chamber $\mathbf{P}$

$\mathrm{dA}=$ differential area of inner wall of the tube $\left(\mathrm{cm}^{2}\right)$

$P=$ distance from $P$ to $d A$

$\mathbf{R}=$ radius of tube

$\mathrm{h}=$ distance from end of tube to $\mathrm{dA}$

$S_{a}=$ source strength of plane source $\left(\mathrm{mev} / \mathrm{cm}^{2}-\mathrm{sec}\right)$

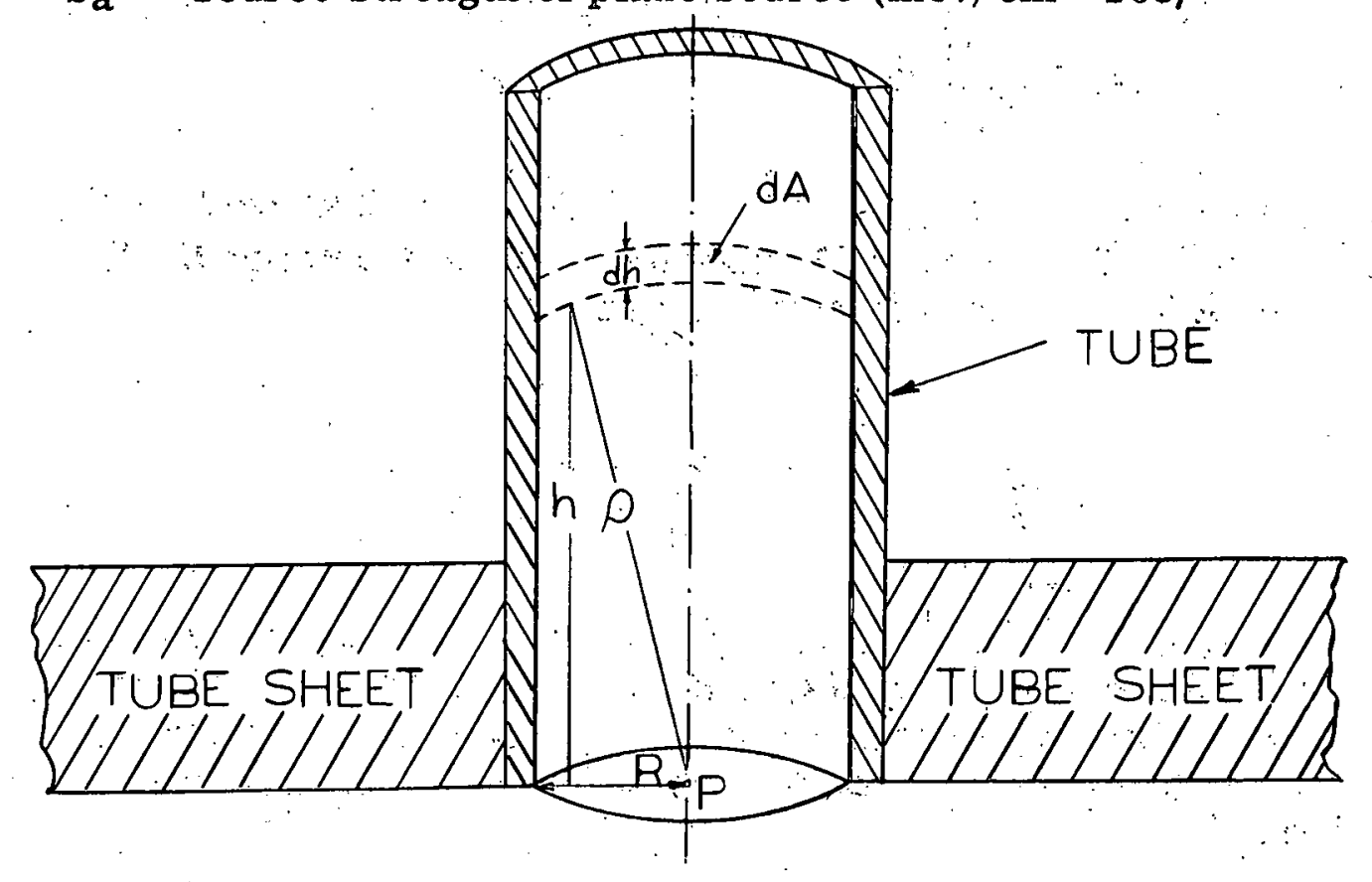




$$
\mathrm{dD}=\frac{\mathrm{dA} \mathrm{S}}{4 \pi \mathrm{D}^{2}}
$$

but

$$
\mathrm{dA}=2 \pi \mathbf{R} \mathrm{d} h
$$

and

$$
\rho^{2}=h^{2}+R^{2}
$$

therefore

$$
\mathrm{D}=\int_{0}^{\mathrm{h}} \frac{2 \pi \mathrm{R} d \mathrm{~h} \mathrm{~s}_{\mathrm{a}}}{4 \pi\left(\mathrm{h}^{2}+\mathrm{R}^{2}\right)}
$$

integrating

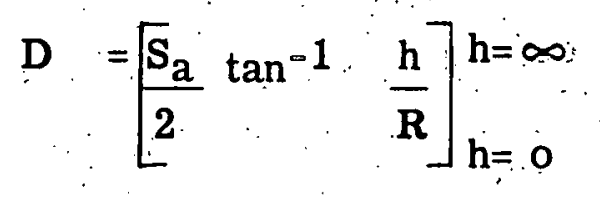

evaluating between the limits

$$
\text { when } \begin{aligned}
h & =0 \quad D=0 \\
h & =\infty \\
D & =\frac{s_{2} \pi}{4}
\end{aligned}
$$

Equation (4) is the dose rate due to the tube only.

By treating the tube sheet surrounding the tube as an infinite slab, the equation for the dose rate from the tube sheet 9 is

$$
D=\frac{S_{\mathrm{a}}}{2}
$$

Therefore, the total dose rate at any tube in the water box due only to that tube and its surrounding tube sheet area is

$$
D=\frac{s_{a} \pi}{4}+\frac{s_{a}}{2}
$$


In the present design of the SM-2 steam generator, the water box is in the form of a hemisphere with the tube sheet as the flat surface. The contribution of the activity deposited on the spherical surfaces of the water box to the total dose rate at point $P$ on the tube sheet is evaluated as follows:

The point $\mathbf{P}$ (ionization chamber) is considered to be at the geometrical center of the tube sheet. This is valid since equation (6), the dose rate due to a tube, would be valid at any point on the tube sheet. The dose rate contribution from the baffle plate has been neglected in this derivation.

$$
\begin{aligned}
& \mathrm{dD}=\text { differential dose rate at } P \text { (due to hemisphere surface) } \\
& \mathrm{dA}=\text { differential area of inner surface of hemisphere } \\
& \mathbf{R}=\text { distance from } P \text { to } \mathrm{dA} \text { (radius of sphere) } \\
& \mathrm{d} \theta=\text { differential angle of two radii from } P \text { to } \mathrm{dA} \\
& S_{\mathrm{a}}=\text { source strength of plane source }\left(\mathrm{mev} / \mathrm{cm}^{2}-\mathrm{sec}\right. \text { ) }
\end{aligned}
$$

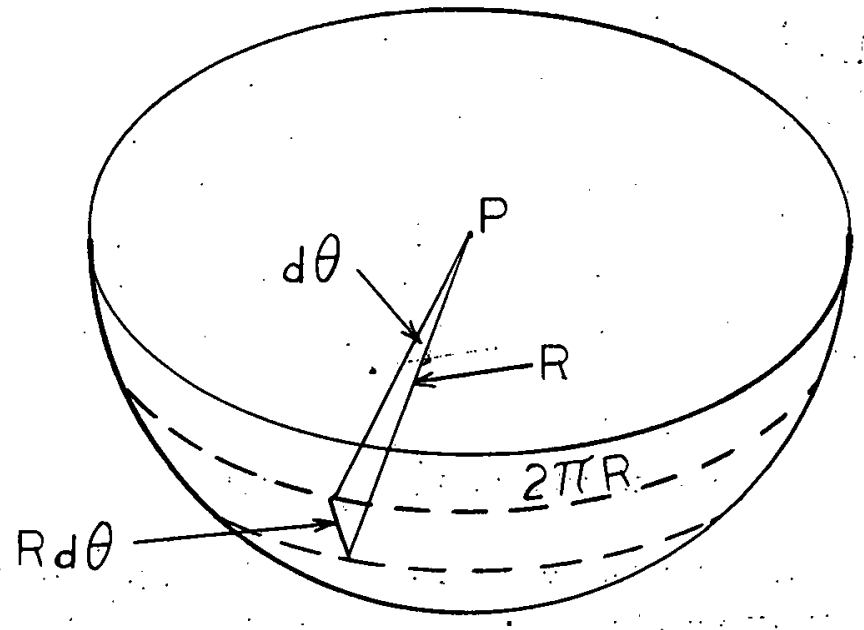

$$
\mathrm{dD}=\frac{\mathrm{dA} \mathrm{S}}{4 \pi \mathrm{R}^{2}}
$$

but $d A=2 \pi R^{2} d \theta$

Therefore,

$$
D=\int_{0}^{\frac{\pi}{2}} \frac{2 \pi R^{2} d \theta: S_{a}}{4 \pi R^{2}}
$$




$$
D=S_{a} \int_{0}^{\frac{\pi}{2}} \frac{d \theta}{2}
$$

integrating

$$
\mathrm{D}=\left[\frac{\mathrm{s}_{\mathrm{a}}}{2}\right]_{\theta=0}^{\theta=\pi / 2}
$$

when

$$
\theta=0
$$$$
\text { D }=0
$$

when

$$
\theta \quad=\pi / 2
$$

$$
\ddot{\mathrm{D}}=\frac{\mathrm{S}_{\mathrm{a}} \pi}{4}
$$

Equation (11) represents the dose rate contribution from the sherical surface of the water box to point $P$. The total dose rate at point $P$ would 'then be the sum of equations (4), (5), and (11) or

$$
D=\frac{s_{a} \pi}{4 C}+\frac{s_{a}}{2 C}+\frac{s_{a} \pi}{4 C}=\frac{2.07 . s_{a}}{C}
$$

where $C$ is a conversion factor for converting $\mathrm{mev} / \mathrm{cm}^{2}-\mathrm{sec}$ to $\mathrm{R} / \mathrm{hr}$ (5.4 $410^{5} \mathrm{mev} / \mathrm{cm}^{2}-\mathrm{sec}$. per $\mathrm{R} / \mathrm{hr}$ for $1 \mathrm{mev}$ gammas).

A similar equation was derived to calculate the SM-1 steam generator dose rate 1. While the SM-1 and SM-2 steam generators differ in size, they are similar in geometric configuration except for the water box design. The SM-1 water box with the baffle plate and head removed resembles an open cylinder. The SM-2 water box with the baffle plate removed resembles a hemisphere. The dose rate equations for the tube and tube sheet contributions were the same in both steam generators. The additional contribution from the SM-1 water box was $1.15 \frac{\mathrm{S}_{\mathrm{a}} \text { : }}{\mathrm{C}}$ The SM- 2 water box contribution was $0.785 \frac{\mathrm{Sa}}{\mathrm{C}}$. The resulting difference between the total dose rate expressions is 15 percent. The unshielded gamma dose rates in the SM-1 steam generator were measured after 17 calendar months of reactor operation. With the 
detector against the tube sheet, the observed dose rates were 4.75 to 5.25 times greater than calculated unshielded results 1 . The value 4.75 was observed on the outlet side of the water box and 5.25 was observed on the inlet side. Consequently, a buildup factor of 5 has been used in the SM-2 calculation. The final expression for converting $\mathrm{mev} / \mathrm{cm}^{2}-\mathrm{sec}$ to Roentgens per hour is therefore:

$$
\text { Dose } \text { Rate (D) Roentgens per hour }=\frac{2.07 \mathrm{~S}_{\mathrm{a}}|5|}{\mathrm{C}}
$$

\section{3 Estimated Radiation Levels in the: SM-2 Steam Generator Water Box}

The equations derived in Sections 3.1 and 3.2 were used to determine the dose rates from deposited activity in the $S M=2$ steam generator over a twenty year period.: The contribution to the dose rate from fission product activity was assumed to be negligible. However, a major cladding defect could result in a significant increase in the dose rate. The 41 -inch stainless steel reactor vessel configuration was used as a reference design together with the radial flux distribution pattern shown in APAE Memo No. 173, Fig. 1-16. The buildup equations were programmed on the IBM-650 for a reference cladding impurity concentration of 0.01 percent cobalt, 0.01 per cent tantalum and a reference reflector impurity concentration of 0.1 percent cobalt, 0.1 percent tantalum.10 "From these results, it was possible to calculate dose rates for various impurity levels of cobalt and tantalum.

The calculated radiation levels in the SM-2 steam generator water box due to $\mathrm{Co} 60, \cdots 58, \mathrm{Ta} 182, \mathrm{Mn} 54$, and $\mathrm{Fe} 59$, are tabulated in Table 1. The radiation levels are plotted in terms of mev per $\mathrm{cm}^{2}$-sec in Fig. 1 and in Roentgens per hour in Fig. 2. The term mev per $\mathrm{cm}^{2}-\mathrm{sec}$ is a more accurate term for radiation since any value of Roentgens per hour is limited by the accuracy of the assumptions regarding the type of source and the configuration in the steam generator. The contributions to the radiation level from the various nuclides have been included in Fig. 1 , while the contributions due only to cobalt-60 and tantalum-182 in the core cladding and the reflectors are included in Fig. 2. The cyclic pattern observed in the case of $\mathrm{Fe}^{59}$, $\mathrm{Co}^{58}, \mathrm{Ta}^{182}$, and $\mathrm{Mn}^{54}$ is due to the effect of the varying corrosion rate and the activation and decay of the successive cores. The results indicate that for a fuel element cladding impurity concentration of 0.01 percent cobalt and 0.01 percent tantalum, together with 0.1 percent cobalt and tantalum in the reflectors, cobalt-58 and iron-59 are the major contributors to the dose rate for approximately seven core lives. During this period the contributions of cobalt-60 and tantalum-182 from the core increase: from 7 to 21 percent and decrease from 4 to 3 percent respectively $y^{\prime}$ (See Table 1). After one year, 84 percent of the reflector contribution is due to tantalum-182. This is a 


\section{TABLE 1}

Relative Contributions to SM-2 Steam Generator Radiation Level over 20-Year Period for 41-Inch Reactor Vessel Cobalt ( 0.01 percent), Tantalum $(0.01$ percent), in Core; Nominal Cobalt (0.1 percent) Tantalum (0.1 percent) in Reflector.

\section{PERCENT CONTRIBUTION}

\begin{tabular}{|c|c|c|c|c|c|c|c|c|}
\hline \multirow{2}{*}{$\begin{array}{l}\text { Time } \\
\text { (Years) }\end{array}$} & \multicolumn{3}{|c|}{ Core and Reflectors } & \multicolumn{2}{|c|}{ Core } & \multicolumn{2}{|c|}{ Reflector $\underline{\text { Total }}$} & \multirow[b]{2}{*}{$\mathrm{R} / \mathrm{hr}$} \\
\hline & $\mathrm{Fe}^{59}$ & $\mathrm{Co}^{58}$ & $\mathrm{Mn}^{54}$ & $\mathrm{Ta}^{18}$ & $\mathrm{Co}^{60}$ & $\mathrm{Co}^{60}-\mathrm{Ta}^{182}$ & $\underset{\mathrm{sec}}{\mathrm{mev} / \mathrm{cm}^{2}}$ & \\
\hline 1 & 33.9 & 31.6 & 13.9 & $3.9 ?$ & 7.2 & $9.5(16)$ & $1.27 \times 10^{5}$ & 2.5 \\
\hline 2 & 28.8 & 28.1 & 15.9 & 3.6 & 11.4 & 12.2 & $1.50 \times 10^{5}$ & 2.9 \\
\hline 3 & 26.0 & 25.2 & 17.5 & 3.3 & 14.3 & 13.7 & $1.65 \times 10^{5}$ & 3.2 \\
\hline 4 & 24.0 & 23.5 & 16.9 & 3.1 & 16.4 & 16.1 & $1.78 \times 10^{5}$ & 3.4 \\
\hline 5 & 22.2 & 21.8 & 15.9 & 2.9 & 18.3 & $18.8(63)$ & $1.95 \times 10^{5}$ & 3.8 \\
\hline 6 & 20.3 & 19.6 & 15.2 & 2.8 & 20.9 & 20.9 & $2.07 \times 10^{5}$ & 4.0 \\
\hline 7 & 19.6 & 19.2 & 14.6 & 2.7 & 20.6 & 23.3 & $2.19 \times 10^{5}$ & 4.2 \\
\hline 8 & 18.7 & 18.2 & 13.9 & 2.6 & 20.9 & 25.7 & $2.30 \times 10^{5}$ & 4.4 \\
\hline 9 & 17.9 & 17.5 & 13.4 & 2.5 & 21,2 & 27.5 & $2.40 \times 10^{5}$ & 4.6 \\
\hline 10 & 17.1 & 16.7 & 12.7 & 2.4 & 21.4 & $29.6(81)$ & $2.51 \times 10^{5}$ & 4.8 \\
\hline 11 & 16.5 & 16.2 & 12.3 & 2.3 & 21.6 & 31.1 & $2.60 \times 10^{5}$ & 5.0 \\
\hline 12 & 16.0 & 15.6 & 11.9 & 2.2 & 21.6 & 32.7 & $2.69 \times 10^{5}$ & 5.1 \\
\hline 13 & 15.5 & 15.1 & 11.5 & 2.2 & 21.9 & 33.8 & $2.78 \times 10^{5}$ & 5.3 \\
\hline 14 & 15.2 & 14.8 & 11.3 & 2.1 & 21.5 & 35.1 & $2.84 \times 10^{5}$ & 5.4 \\
\hline 15 & 14.7 & 14.4 & 11.0 & 2.0 & 21.6 & 36.3 & $2.92 \times 10^{5}$ & 5.6 \\
\hline 16 & 14.3 & 14.0 & 10.7 & 2.0 & 21.7 & 37.3 & $3.00 \times 10^{5}$ & 5.7 \\
\hline 17 & 14.1 & 13.8 & 10.5 & 2.0 & 21.4 & 38.2 & $3.05 \times 10^{5}$ & 5.9 \\
\hline 18 & 13.8 & 13.5 & 10.3 & 1.9 & 21.5 & 39.0 & $3.11 \times 10^{5}$ & 6.0 \\
\hline 19 & 13.6 & 13.3 & 10.1 & 1.9 & 21.2 & 39.9 & $3.16 \times 10^{5}$ & 6.0 \\
\hline 20 & 13.5 & 13.1 & 9.7 & 1.9 & 21.3 & $40.5(86)$ & $3.20 \times 10^{5}$ & 6.1 \\
\hline & & & & & & & $\begin{array}{r}21 \\
02 \quad 025\end{array}$ & \\
\hline
\end{tabular}


106

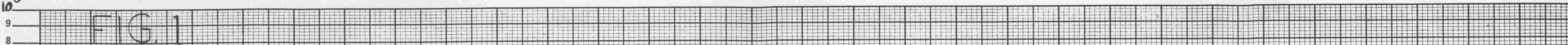

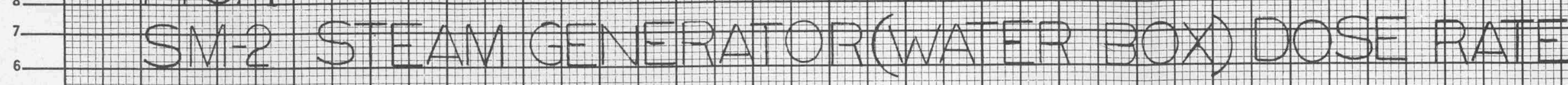

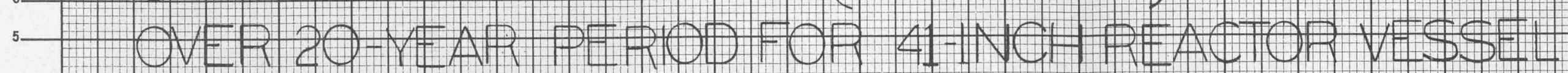

CORE IHETINE-ONE CALENDAR YEAR

$$
3
$$

$\dot{2}^{\sqrt[3]{1+\sqrt{1}}}$

की

$\stackrel{\text { N1 }}{31} 10^{5}$

$\sum 10^{5}$

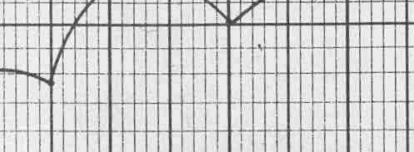

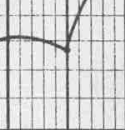

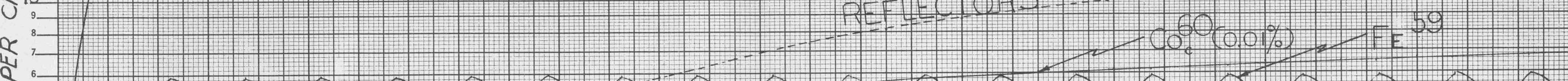

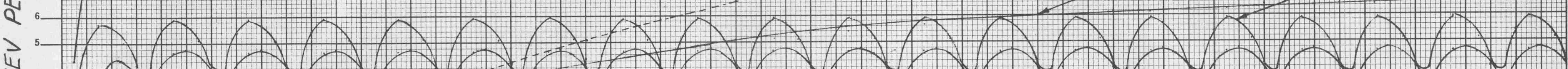

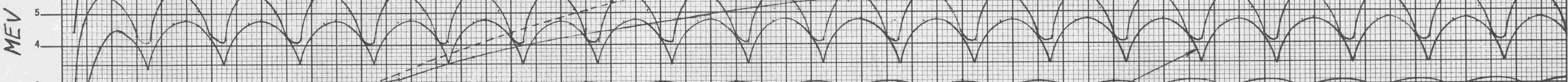

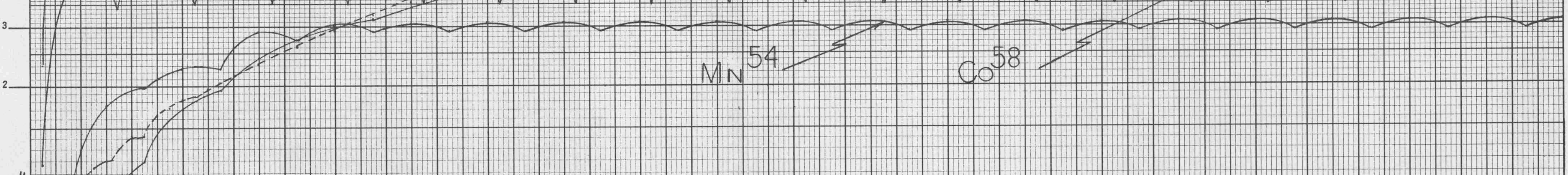
\begin{tabular}{|c|c|c|c|c|}
\hline \\
\hline
\end{tabular} $\begin{array}{lllllllll}1 & 2 & 3 & 4 & 5 & 6 & 7 & 8 & 9 \\ & & & & & & & \text { CORE LIVES - YEARS }\end{array}$ 


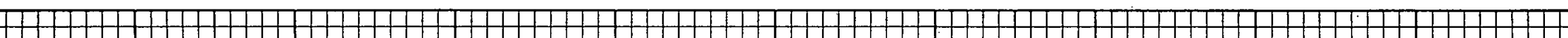

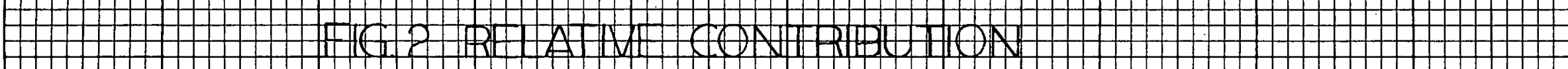

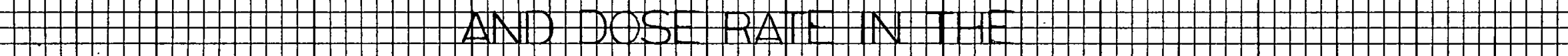

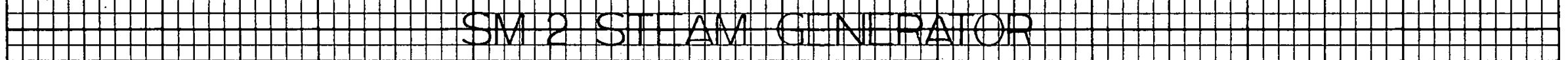

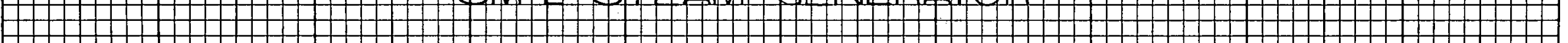

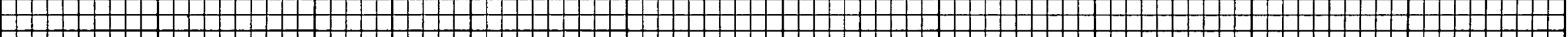

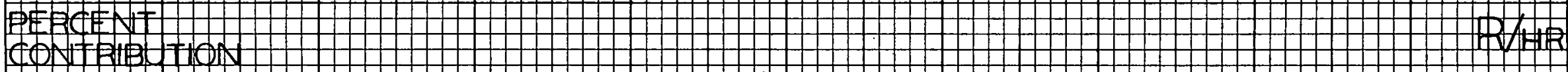

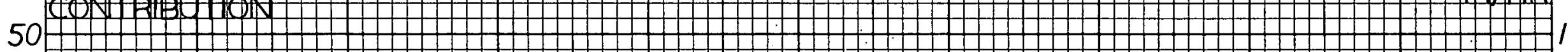

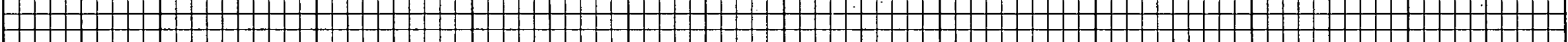

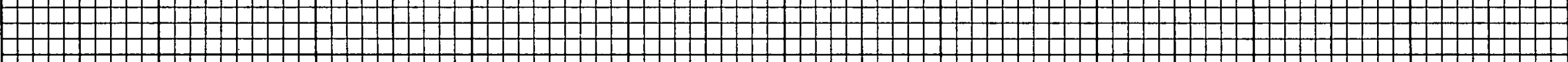

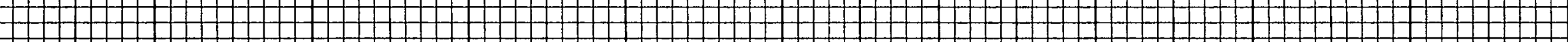
$40 \mathrm{P}$

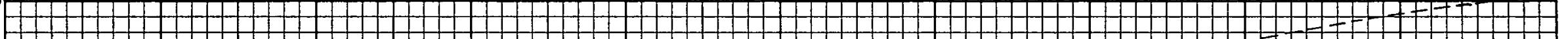

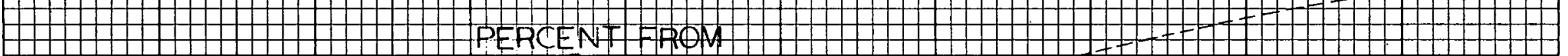

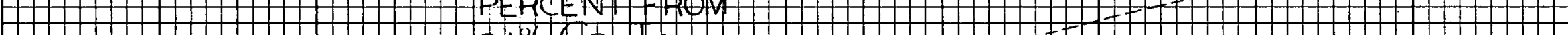

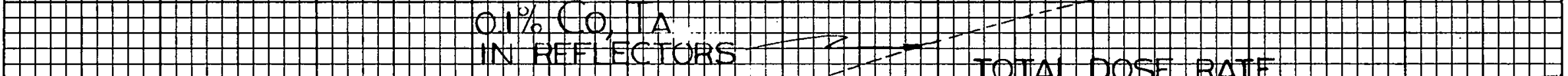

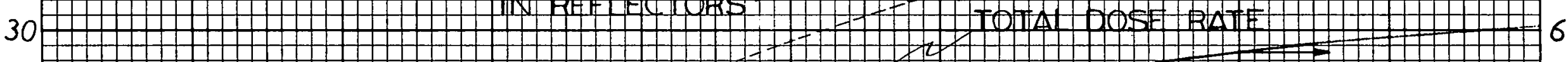

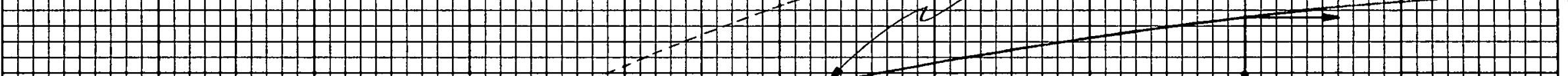
W I

$\rightarrow$

20

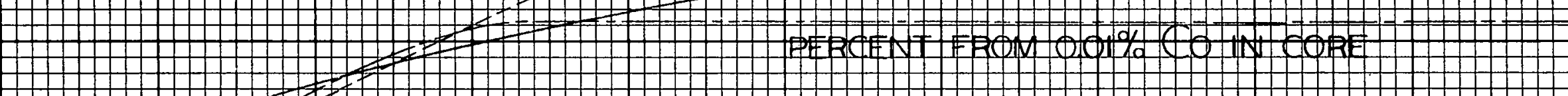
Y)

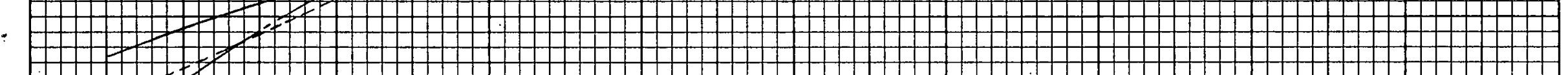
$10 \mathrm{l}$

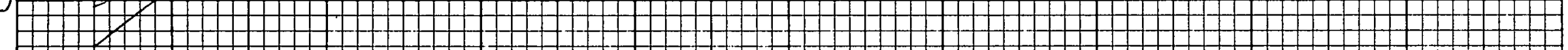

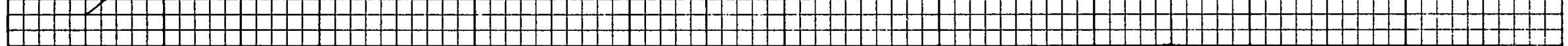

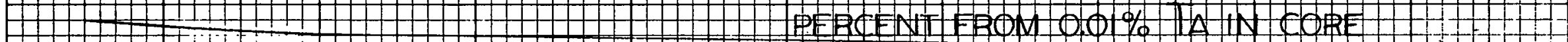

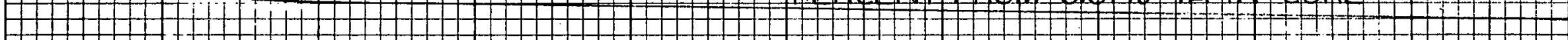


consequence of the half lives and the different fast to thermal flux ratios in the core and reflectors, the reflector ratio favoring the production of tantalum -182 After seven core lives, the contribution from cobalt -60 and tantalum-182 in the reflectors becomes dominant. After 20 years the cobalt60 and tantalum-182 constitute 56 percent and 7.4 percent of the total dose rate respectively.

The data presented in Table 1 were used to calculate the SM-2 steam generator dose rates from various cladding and reflector impurity levels (Fig. 3). These are compared in Table. 2 with SM-1 steam generator dose rates after 18 calendar months of reactor operation.

\section{TABLE 2}

Calculated SM-2 Steam Generator Dose Rates for Various Impurity Levels in the Cladding and Reflector Material (Type 347. Stainless. Steel)

SM-2 Percent Cobalt and Tantalum

Roentgens Per Hour

\begin{tabular}{|c|c|c|c|c|c|c|c|}
\hline Cladding & Reflector & $\underline{1}$ & $1-1 / 2$ & $\underline{5}$ & 10. & 15 & 20 (years) \\
\hline 0.01 & 0.01 & 2.3 & 2.4 & 3.1 & 3.6 & 3.8 & 3.9 \\
\hline 0.01 & 0.1 & 2.5 & 2.8 & 3.8 & 4.8 & 5.6. & 6.1 \\
\hline 0.1 & 0.1 & 5.0 & 6.0 & 10.8 & 15.2 & 17.5 & 18.8 \\
\hline
\end{tabular}

SM-1.Percent Cobalt
0.20 Percent
6. 3 (inlet tube sheet)
2.9 (outlet tube sheet)
0.065 Percent (minus
3. 7* (inlet tube sheet)
Haynes-25 flux
1. 7* (outlet tube sheet) suppressors)
* estimated. 


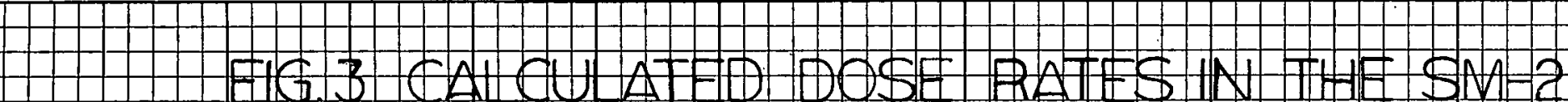

$+\rightarrow$ Mo. Y STE AM GENERATOR FOR VARIOUS

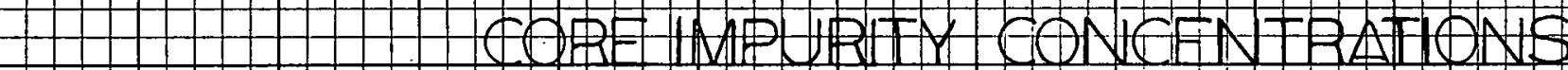

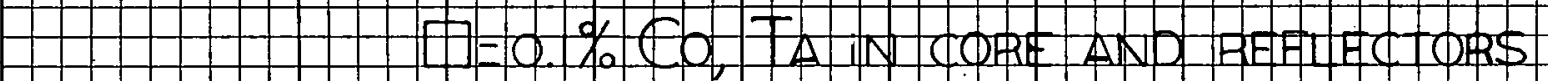

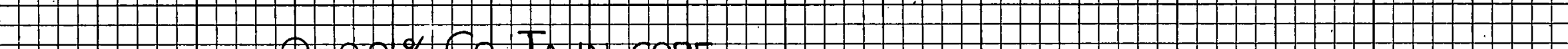
$0=00 \%$ CO, TA N CORE

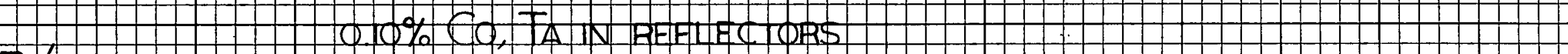

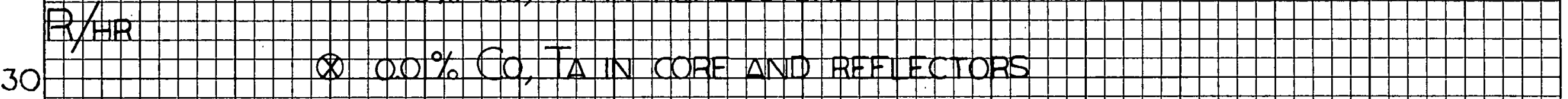

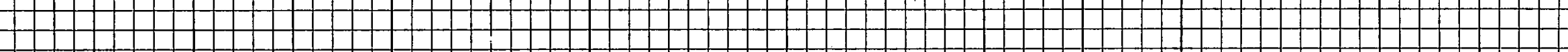

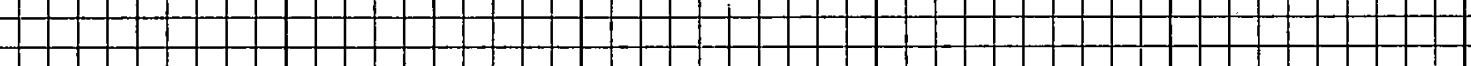

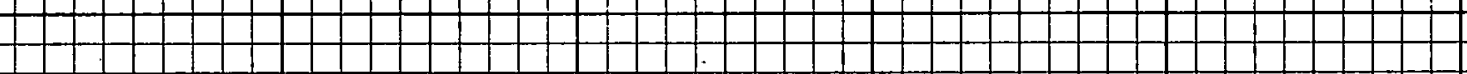

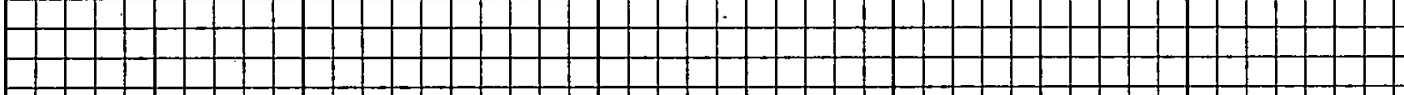

20

3

-

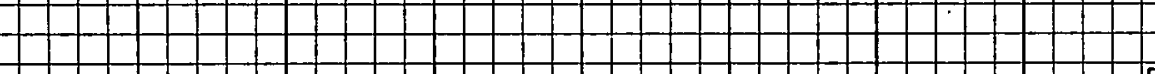

10 \begin{tabular}{ll}
\hline+ \\
\hline
\end{tabular}

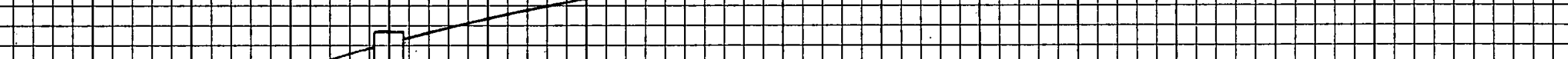

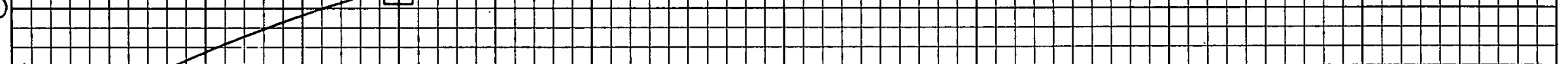

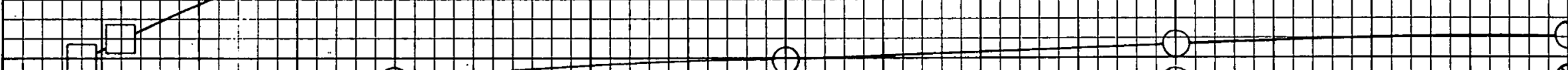

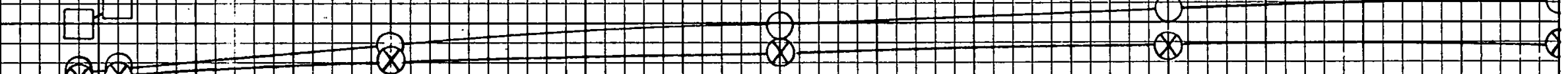

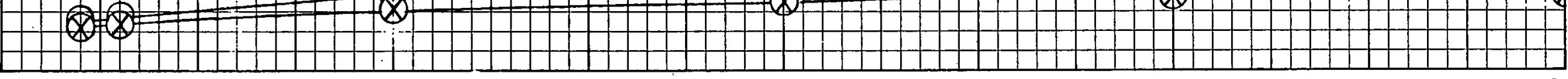
O

5

10

15 
For equal cladding impurity levels (i.e., 0.01 percent cobalt and 0.01 percent tantalum), an increase in the reflector impurity level from 0.01 to 0. 1 percent cobalt and tantalum will increase the total gamma dose rate 9 percent after one year and 56 percent after twenty years. The use of nominal impurity concentrations ( 0.1 percent) in the cladding and reflector will increase the dose rate by approximately 117 percent after one year and 380 percent after twenty years. The large increase is due primarily to the cladding. The tantalum-182 core contribution is relatively small and may permit the use of nominal tantalum impurity concentration in the cladding material. This is shown by the following sample calculations (cf. Table 1):

The tantalum-182 dose rate contribution from a core cladding impurity concentration of 0.01 percent after one year is $2.5 \times 0.039=0.10 \mathrm{R} / \mathrm{hr}$. An increase in the impurity concentration to 0.1 percent would result in a contribution of $1.0 \mathrm{R} / \mathrm{hr}$ or a total dose of $3.4 \mathrm{R} / \mathrm{hr}(2.5-0.10+1.0)$. This is an increase of 36 percent. After twenty years the increase would be 17 percent $(6.1-0,12+112)_{i}$.

The dose rates in the SM-1 steam generator were measured after 17 calendar months of reactor operation. The value $3.7 \mathrm{R} / \mathrm{hr}$ at the inlet tube sheet is based on the assumption that all activity originates in the core and that cobalt-60 accounts for 61 percent of the total dose rate. The latter assumption is based on experimental data. An exact comparison of the two reactor designs cannot be made because of the different parameters involved. Cons equently, the values should only be examined in the light of present SM-1 maintenance requirements. 


\section{0 DISCUSSION OF RESULTS}

The consideration of low impurity core materials is a consequence of the buildup of long-lived radioactive nuclides on primary system surfaces and the resultant maintenance hazard. This buildup however, is not only a material impurity problem. Factors such as purification, $\mathrm{pH}$, and flow rate of the primary coolant, the ratio of "in-flux" to "out-of flux" areas may all affect the deposition of activated corrosion products 3 . For example, a high temperature and pressure filter in conjunction with low temperature ion exchange purification methods can be used to maintain extremely low concentrations of corrosion products in the primary coolant. Experience at KAPL and WAPD with systems employing Zircaloy clad fuel elements indicates that operation at high $(9.5$ to 10.5$) \mathrm{pH}$ reduces the release of corrosion products into the primary coolant 3 . It has also been shown that corrosion products tend to accumulate in areas of stagnant or reduced flow. These "crud traps" can be eliminated by proper design considerations. The relative importance of out-of-flux areas to the buildup of radioactive corrosion products appears to depend upon the type of cladding employed: For systems employing Zircaloy clad fuel elements, the contribution to the activity which originates from out-of-flux areas may be significant. Experience at SM-1 (stainless steel clad fuel elements) indicates that the buildup of activity can be explained on the basis of the activation and subsequent (corrosion) release into the coolant of only in-flux materials of construction 1 . This approach has been used in the present analysis of SM-2 activity buildup.

It is not possible to evaluate the extent of dose rate reduction from these factors because of insufficient data from systems employing stainless steel clad fuel elements. Consequently, with impurity concentration of the core material as the sole basis for controlling dose rates in the SM-2, an evaluation will be made from the standpoint of (1) material economics and (2) component accessibility:

\subsection{Economic Considerations of Low Impurity Core Mațerials}

The cost per pound for various cobalt impurity levels in AlsI Type 347 stainless steel is given below:

Cobalt Range (\%)
$0.20-0.05$
$0.05-0.02$
$0.02-0.005$
$0.005-0.002$
0.002 Max.

$\$$ Cost per. Pound (sheet)

0.80

0.85

2.70

3.53

4.42 
Eighty cents was taken as the base price for commercial AISI Type 347 stainless steel. The cobalt level of such material (based upon mill analyses) usually averages 0.10 percent cobalt and 0.10 percent tantalum 12 . A number of steel companies have indicated their desire to supply special heats of low impurity (low cobalt, tantalum) AISI Type 347 stainless steel. One mill will guarantee limits of 0.01 percent maximum cobalt and 0.01 percent maximum tantalum at $\$ 3.00$ per $\mathrm{lb}$. Two mills will guarantee the same limit of cobalt but with a tantalum limit of 0.02 percent maximum for $\$ 3.00$ per $\mathrm{lb}$. Approximately $5000 \mathrm{lbs}$ of stainless steel would be required to fabricate the fuel elements in the $\mathrm{SM-2}$. It is estimated that $5000 \mathrm{lbs}$. would be required to fabricate the reflectors for the 41 -inch reactor vessel configuration. Since the reflectors would not be replaced during the lifetime of the plant, a reduction in the reflector impurity level might be justified more readily than in the core; which would be replaced twenty times during the plant lifetime. For cost comparison purposes, the maximum of each cobalt range, has been used.

\subsubsection{Low Impurity Reflector Material}

The small contribution of tantalum-182 from the reflector to the steam generator dose rate after twenty years does not warrant the reduction in the reflector tantalum impurity level (Table 1). However, the buildup due to cobalt in the reflector may be significant and warrant a reduction. For a nominal impurity concentration of cobalt and tantalum in the core and reflectors, the calculated steam generator dose rate after twenty years would be $18.8 \mathrm{R}$ per hour. (Table 2 ). Of this, approximately $2.1 \mathrm{R}$ per hour or 11 percent is due to cobalt from the reflector. This dose rate can be reduced to $0.4 \mathrm{R}$ per hour through the use of 0.02 percent cobalt in the reflector material at a premium cost of approximately $\$ 9,500$. The total dose rate would be reduced approximately 9 percent to $17.1 \mathrm{R}$ per hour. With the use of 0.005 percent cobalt in the reflector material, the total dose rate would be reduced 11 percent to $16.8 \mathrm{R}$ per hour but at a premium of approximately $\$ 13,650$. Therefore, the additional 2 percent reduction in dose rate would cost approximately $\$ 4,150$.

For a low impurity core $(0.01$ percent cobalt and 0.01 percent tantalum) and a nominal impurity reflector, the calculated steam generator dose rate after twenty years would be 6.1.R per hour. With the use of 0.02 percent cobalt in the reflector material, the dose rate can be reduced 28 percent to $4.4 \mathrm{R}$ per hour at a premium cost of $\$ 9,500$. With the use of 0.005 percent cobalt, the total dose rate can be reduced 33 percent to $4.1 \mathrm{R}$ per hour at a premium of $\$ 13,650$. The additional 5 percent reduction in dose rate can therefore be achieved at a cost of $\$ 4,150$. 
It would appear more feasible to reduce the cobalt level in the reflector when it is coupled: with a reduced impurity level in the core cladding material. There appears little advantage to reducing the cobalt concentration. in the SM-2 reflectors below 0.02 percent. Recent information indicates that it may be possible to obtain 0.025 percent maximum cobalt in AISI Type $347^{\circ}$ stainless steel at a premium of only $\$ 1$ per $1 \mathrm{lb} 13$.

\subsubsection{Low Impurity Core Material}

The use of low impurity rather than nominal impurity AISI Type 347 stainless steel in the SM-2 core cladding would involve a substantial increase in material costs when compared to reduced impurity levels in the reflector material. This is due to the 1-year core lifetime which will result in 20 core changes over the lifetime of the plant.

The change in steam generator dose rate for various cobalt impurity concentrations in the AISI Type 347 stainless steel core cladding is shown in -Fig. 4. Curves are presented for tantalum core impurity concentrations of 0.1 and 0.01 percent. A reflector impurity concentration of 0.02 percent cobalt and 0.10 percent tantalum is assumed.

The data in Fig. 4 indicate: that initially there is a rapid decrease in the SM-2 steam generator dose rate with decreasing cobalt impurity level. However, as the impurity level decreases below 0.01 percent, the dose rate from other nuclides (cobalt-58, iron-59, and manganese-54) becomes more dominant and the overall dose rate decreases only slightly. The curves of 0.1 percent and 0.01 percent tantalum appear to approach limiting values of approximately 75 and 80 percent reduction in dose rate, respectively $y_{0}$ This corresponds to a cobalt impurity level of 0.001 percent. Present metallurgical techniques do not permit reduction of the cobalt impurity concentration below 0.002 percent. The region of optimum efficiency in dose rate reduction is a cobalt concentration of $0.015-0.025$ percent for 0.01 percent tantalum and 0.01-0.02 percent for 0.1 percent tantalum. This corresponds to a dose rate reduction of approximately $60-70$ percent.

The premium cost over a 20 -year period (20 cores) for procuring low impurity AISI Type 347 stainless steel for various reductions in steam generator dose rate is shown in graphical form in Fig. 5. The percent increase in material cost for various reductions in steam generator dose rate is shown in Fig. 6. The maximum reduction in dose rate ( $75-80$ percent) would involve a cost increase of approximately 510 percent over that for the procurement of nominal impurity core cladding material. The region of optimum reduction efficiency appears to center around 65 percent At this point the curves for 0.1 and 0.01 percent tantalum cross, indicating that 
STEAM GENERATOR DOSE RATE $(R /$ HR $)$ AFTER 20 YEARS

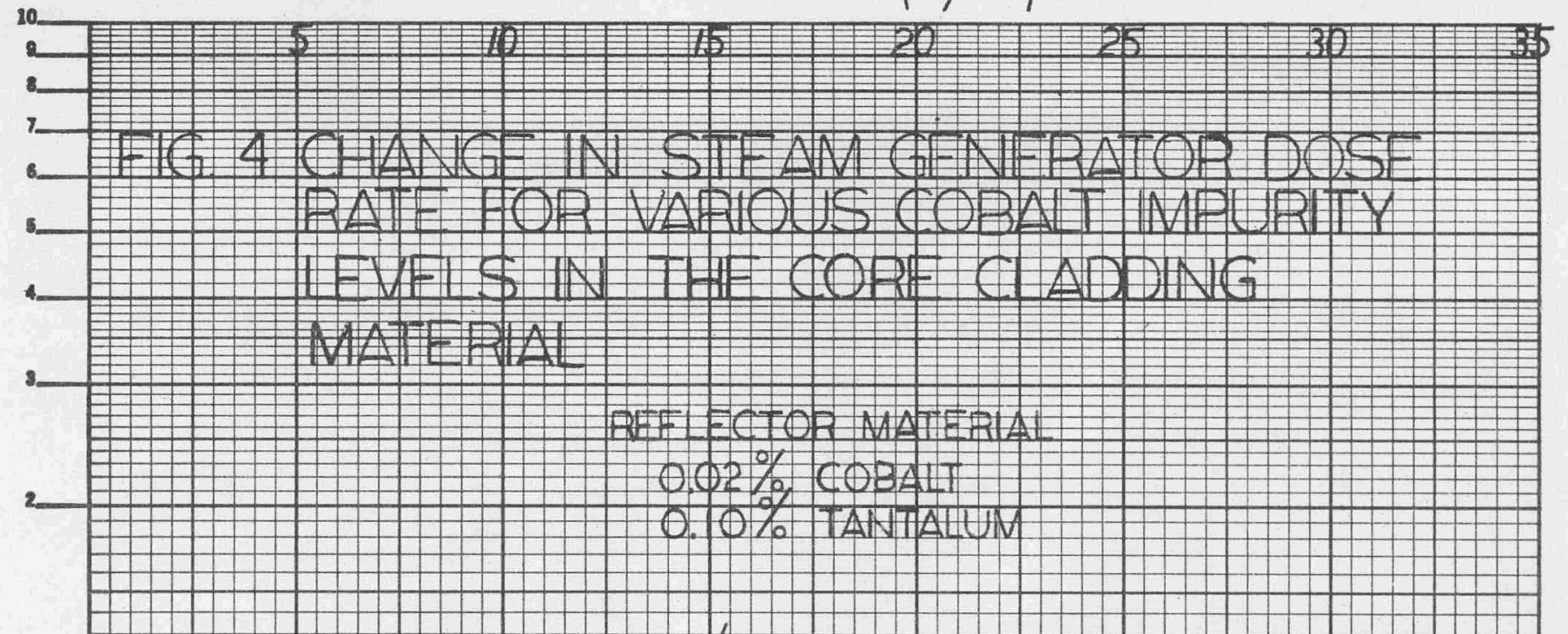

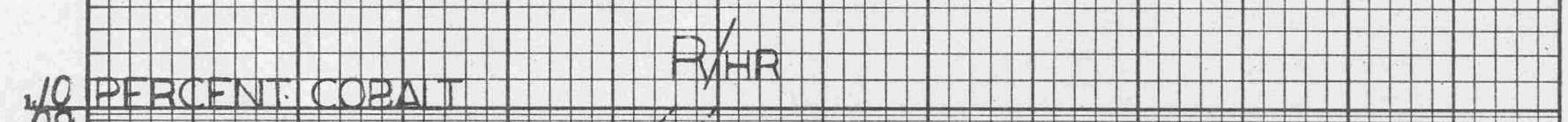

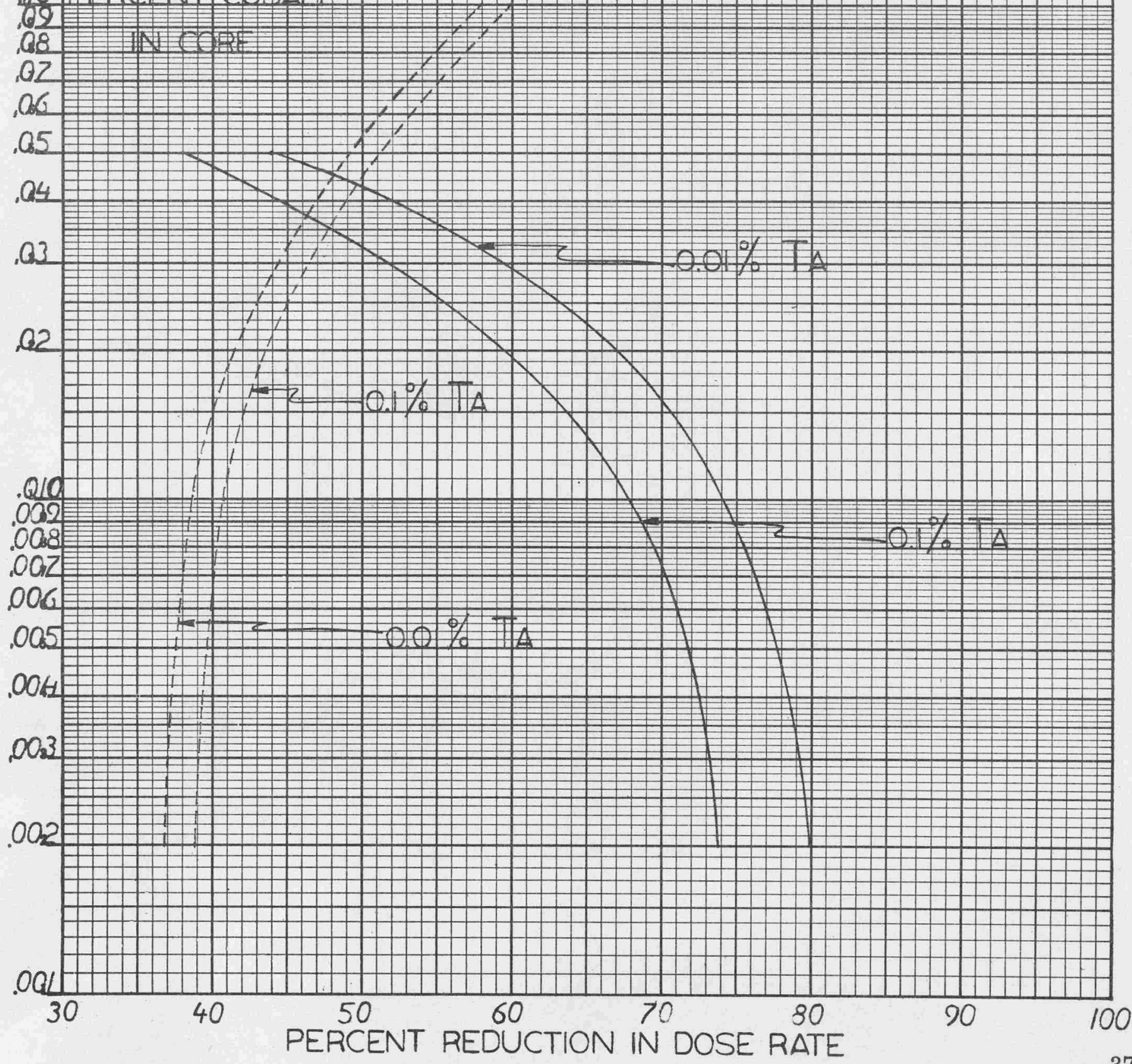




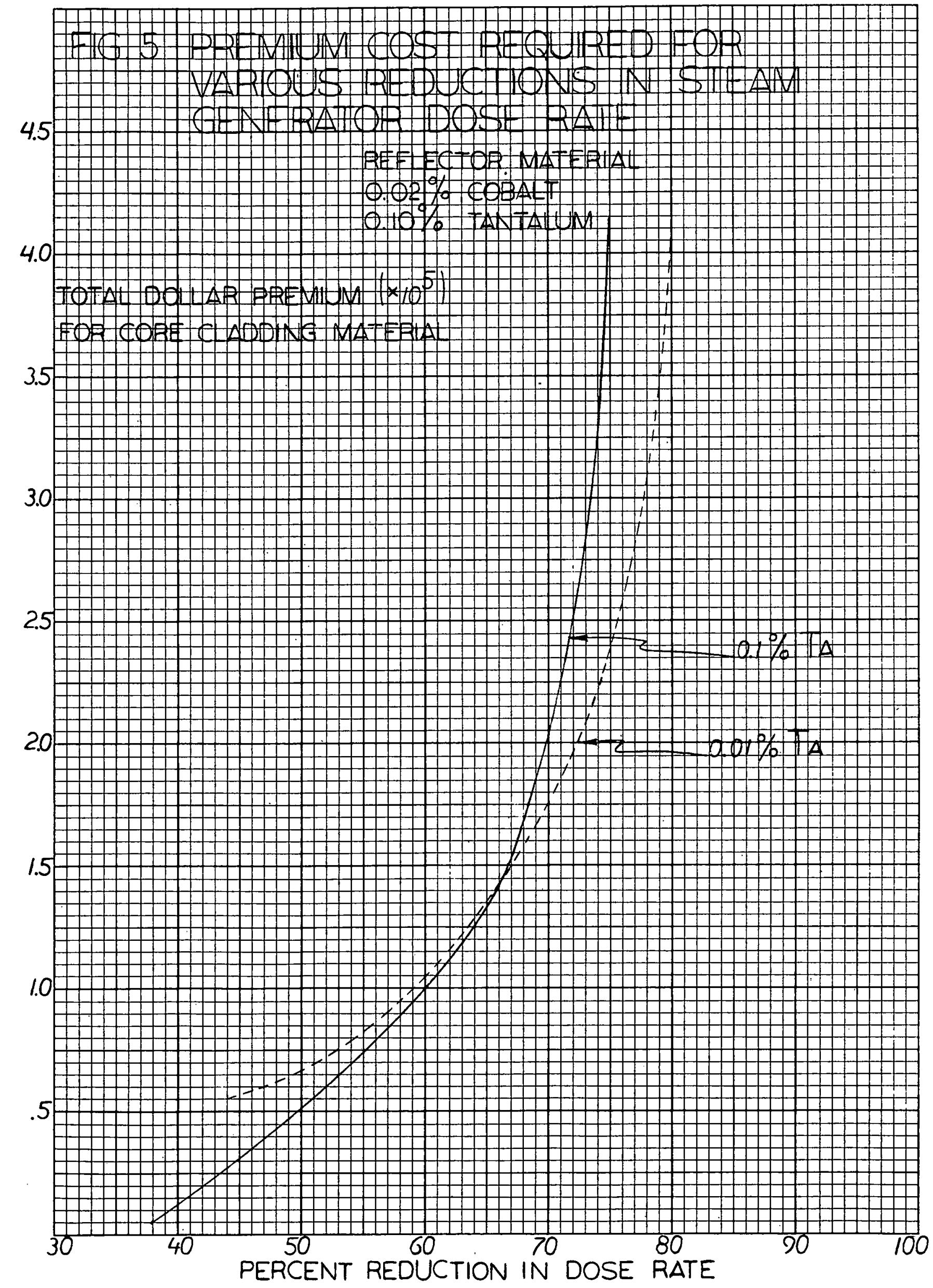

?.2\% :35 
\#lG.

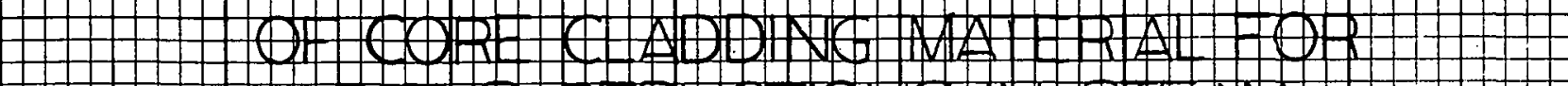

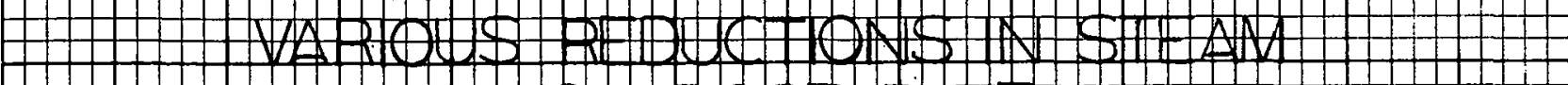

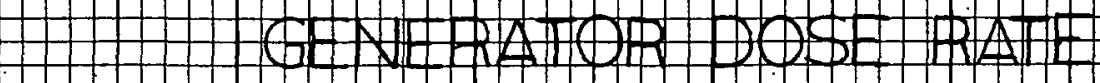
7 II
O.02

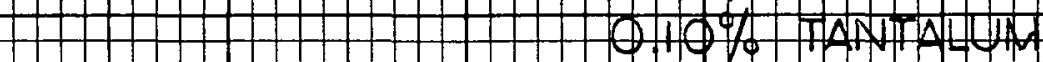

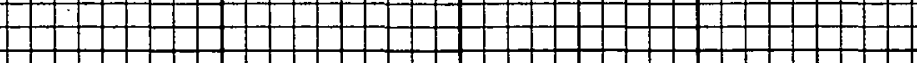

$4-10$

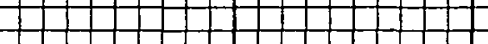

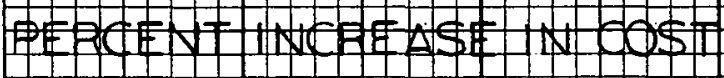

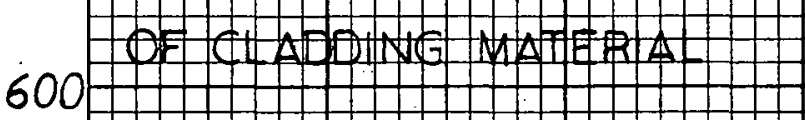

500

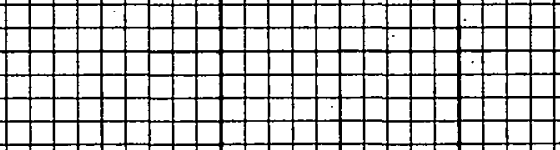
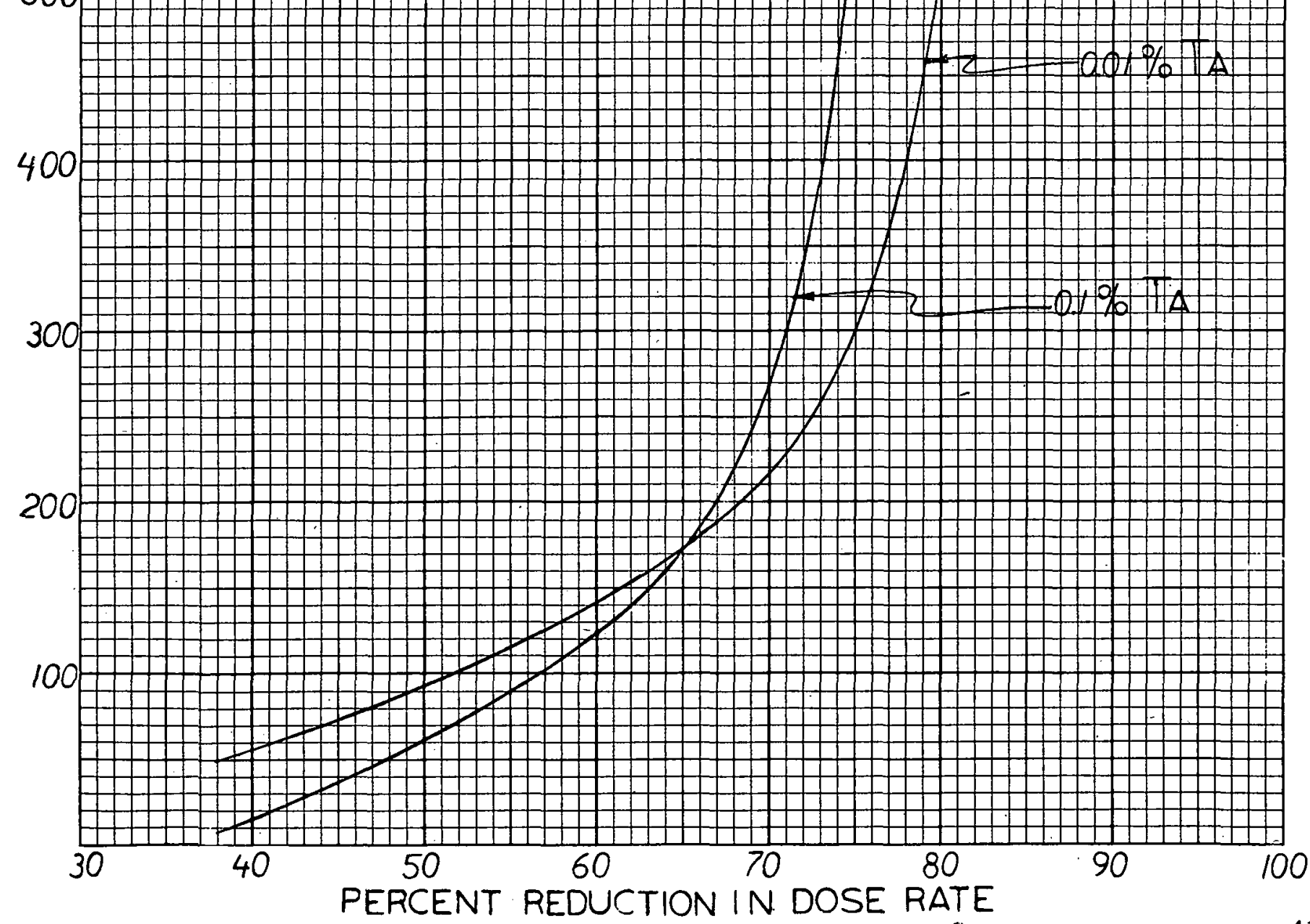

Q22 036 
either level will involve the same material premium, $i_{\circ} e_{\circ}, 175$ percent increase in cost over normal AISI Type 347 stainless steel. While not a problem from a radiation aspect, the parasitic capture of neutrons by tantalum in the core cladding might have an adverse effect on reactivity. In this case, the lower tantalum impurity level would be desired. Therefore, with the tantalum impurity level fixed at 0.01 percent, the cobalt level at a 65 percent reduction in dose rate would be 0.0225 percent. $A$ suitable range would be $0.020-0.025$ percent cobalt. As stated in the previous section, it may be possible to secure 0.025 maximum cobalt at a premium of only $\$ 1$ per $1 \mathrm{~b}$. The tantalum impurity level would depend upon the extent of the reactivity problem involved.

On the basis of material economics, a reduction in the cobalt and tantalum concentration of AISI Type 347 stainless steel for core cladding material appears justified. For SM-2 core cladding material, a practical cobalt range appears to be $0.020 \div 0.025$ percent. Any reduction below this range would result in minimal reductions in dose rate with substantial increases in material cost. Thejanticipated SM-2 steam generator dase rates for a 20-year period using optimum impurity levels in the core cladding and reflector material,are shown in Fig. 7.

In the next section, the feasibility of impurity reduction will be reviewed from the aspect of the maintenance problem involved.

\subsection{Maintenance Aspects of Reduced Impurity Levels}

Ease of maintenance is particularly important in small power plants where staffs are small and excessive dose rates could seriously restrict operation 14. From the standpoint of radiation hazard involved, maintenance of the steam generator tube and tube sheet can be a difficult operation. The SM-2 steam generator surface area constitutes approximately 75 percent of the primary system surface area. The present design of the SM-2 steam generator does not permit ready access to the water box 15 . It is estimated that approximately seven minutes would be required for one man to enter, position himself for work, and leave the water box.

Present AEC tolerance limits allow a man to receive a maximum of $900 \mathrm{mrem}$ at any one time. After this exposure, he may not be exposed at any radiation for thirteen weeks d $_{\text {On }}$ On the basis of the dose rate results presented in Section 3.3, it is possible to determine the "productive labor exposure time" per man for any operation. The productive labor exposure time per man is defined as the time a man will have to perform any work .while in a radiation field. It is exclusive of the time necessary to enter and leave the radiation area. These times are tabulated for various impurity 


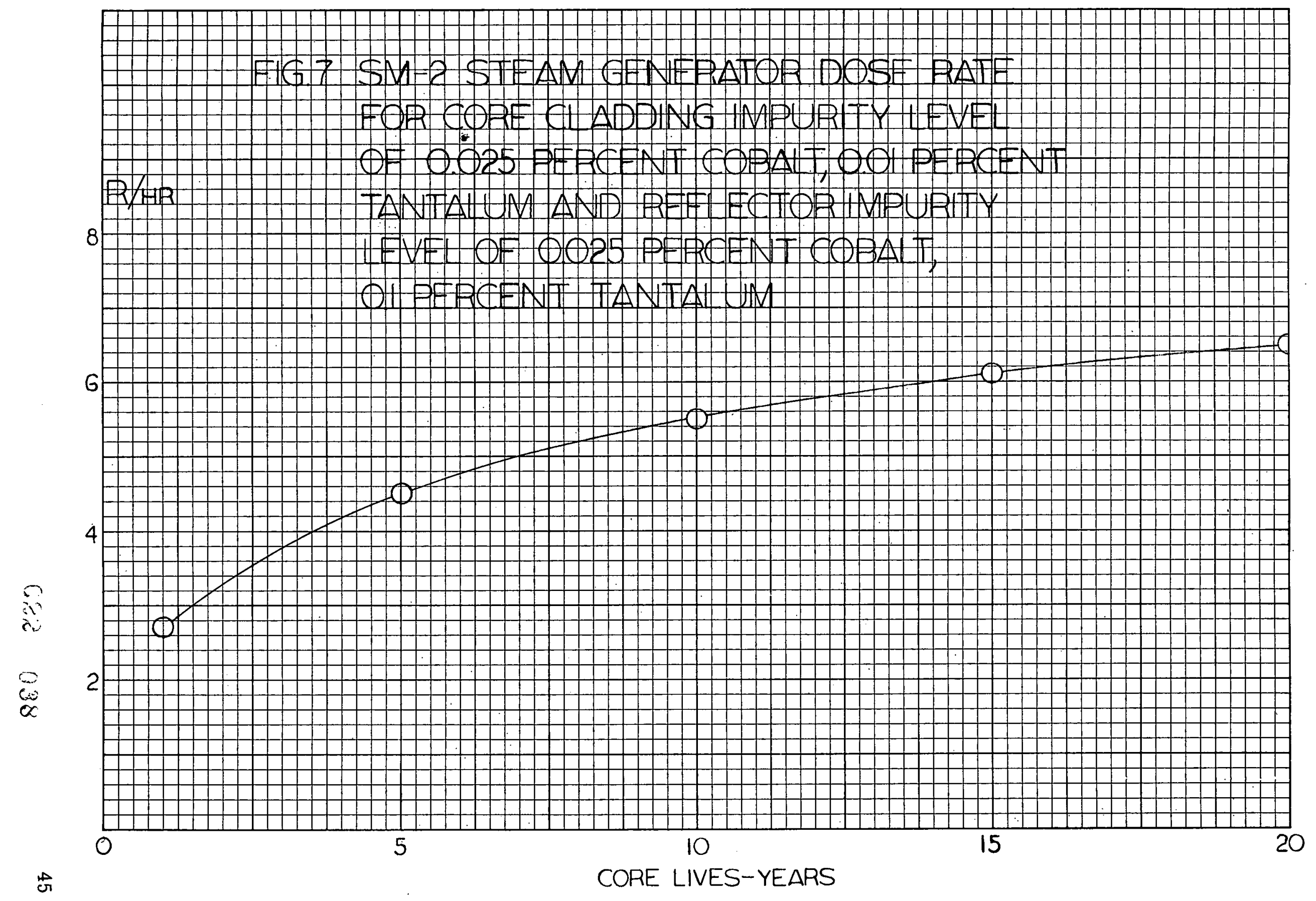


levels during the steam generator lifetime in Table 3.

\section{TABLE 3}

"Productive Labor Exposure Time" in the SM-2 Steam

Generator for Various Core. Impurity Levels,...

(Reflector Impurity:Level $0.02 \% \mathrm{Co}, 0.1 \% \mathrm{Ta}$ )

Core Cladding

Impurity. Level

\begin{tabular}{llllll}
$\begin{array}{l}\text { Percent } \\
\text { Cobalt }\end{array}$ & $\begin{array}{l}\text { Percent } \\
\text { Tantalum }\end{array}$ & $\underline{1 \mathrm{yr}}$ & $\underline{5 \mathrm{yrs}}$ & $\underline{10 \mathrm{yrs}}$ & $\underline{20 \mathrm{yrs}}$ \\
\cline { 2 - 3 } & 0.1 & $4 \mathrm{~min}$ & $0 \mathrm{~min}$ & $0 \mathrm{~min}$ & $0 \mathrm{~min}$ \\
0.05 & 0.1 & $7 \mathrm{~min}$ & $0 \mathrm{~min}$ & $0 \mathrm{~min}$ & $0 \mathrm{~min}$ \\
0.02 & 0.1 & $8 \mathrm{~min}$ & $4 \mathrm{~min}$ & $2 \mathrm{~min}$ & $0 \mathrm{~min}$ \\
0.01 & 0.1 & $9 \mathrm{~min}$ & $5 \mathrm{~min}$ & $4 \mathrm{~min}$ & $3 \mathrm{~min}$ \\
0.005 & 0.1 & $10 \mathrm{~min}$ & $7 \mathrm{~min}$ & $5 \mathrm{~min}$ & $4 \mathrm{~min}$ \\
0.002 & 0.1 & $10 \mathrm{~min}$ & $7 \mathrm{~min}$ & $6 \mathrm{~min}$ & $5 \mathrm{~min}$ \\
0.05 & 0.01 & $10 \mathrm{~min}$ & $2 \mathrm{~min}$ & $0 \mathrm{~min}$ & $0 \mathrm{~min}$ \\
0.02 & 0.01 & $14 \mathrm{~min}$ & $6 \mathrm{~min}$ & $4 \mathrm{~min}$ & $2 \mathrm{~min}$ \\
0.01 & 0.01 & $15 \mathrm{~min}$ & $9 \mathrm{~min}$ & $7 \mathrm{~min}$ & $5 \mathrm{~min}$ \\
0.005 & 0.01 & $16 \mathrm{~min}$ & $9 \mathrm{~min}$ & $9 \mathrm{~min}$ & $7 \mathrm{~min}$ \\
0.002 & 0.01 & $17 \mathrm{~min}$ & $12 \mathrm{~min}$ & $10 \mathrm{~min}$ & $9 \mathrm{~min}$
\end{tabular}

After one year of reactor operation with impurity levels of 0.1 percent and 0.01 percent tantalum, decreasing the cobalt impurity level from 0.02 percent to 0.002 percent results in an increase in available time of 2 and 3 minutes, respectively. This is an increase in time of approximately 18 per cent with a corresponding cost increase of 40 percent. Beyond one year of operation the time gained by lowering the cobalt impurity below 0.02 percent is greater but the productive labor exposure time per man becomes quite short. The expense involved in obtaining this added time by reducing impurity level cannot be justified.

The time required to perform any type of maintenance on the tube sheet is difficult to predict. There are many indeterminable factors which must be taken into account. These include experience of maintenance personnel, 
location and type of repair, and the number of personnel available. It is believed that the productive labor exposure times tabulated in Table 3 are not sufficient to permit maintenance of the steam generator. Consequently, for the SM-2, any reduction in impurity level from the standpoint of maintenance does not appear justified.

As mentioned, in Section 4.0, other methods of preventing activity buildup such as improved purification systems, coolant chemistry, etc., should be considered along with any reduction in impurity level. At the present time there are insufficient data available to fully evaluate these aspects. Therefore, one is faced with the problem of either performing maintenance in a radiation field or removing the deposited activity.

Maintenance can be performed in a radiation field with the use of special tools which can be handled remotely.

The major disadvantage of iremote maintenance is that a specific tool must be designed for each type of repair . If a failure develops for which no tool has been provided, an extended period of shutdown time (non-operating time) may be expended while a suitable tool is designed and fabricated.

The deposited activity may be removed by decontamination. Two possible systems for decontamination which can be considered are as follows:

1. A permanent decontamination system incorporated into the original design of the plant.

2. A temporary decontamination system which vould be installed at the time when decontamination was necessary; this system is presently being considered as a means of decontamination for the SM-1 steam generator 16 .

A nuclear power plant provided with a permanent decontamination facility could permit much higher radiation levels than a plant without such a provision. The system would be decontaminated only when maintenance was necessary and when radiation. levels prevented accessibility.

A temporary decontamination system would require "breaking" into the primary system for purposes of installation. For example, one entry point in the proposed SM-1 decontamination system is the primary coolant pump. The location of the entry point would determine the practical impurity level. An excessive dose rate at the entry point could prevent necessary modification of the system for purposes of decontamination. Therefore, it would be necessary to perform periodic decontamination to maintain low activity levels. A reduction in the impurity level would decrease the frequency of such periodic decontamination. 
$8, \cdots$

APPENDIXES 
APPENDIX A

Nuclide Data

$\underline{\mathrm{Cr}-51} \because \underline{\mathrm{Mn}-54} \underline{\mathrm{Co}-58} \quad \underline{\mathrm{Fe}} \mathrm{\underline {CO } - 6 0}: \quad \underline{\mathrm{Ta}-182}$

$\begin{array}{lccccccc}P / \mathrm{S} * & 2.53 \times 10^{-4} & 4.03 \times 10^{-2} & 4.33 \times 10^{-2} & 2.14 \times 10^{-3} & * & * \\ \lambda \quad\left(\mathrm{sec}^{-1}\right) & 2.88 \times 10^{-7} & 2.55 \times 10^{-8} & 1.13 \times 10^{-7} & 1.74 \times 10^{-7} & 4.17 \times 10^{-9} & 7.2 \times 10^{-8} \\ \sigma_{\mathrm{th}}\left(\mathrm{cm}^{2}\right) & 10.4 \times 10^{-24} & 0 & 0 & 0.46 \times 10^{-24} & 24.0 \times 10^{-24} \\ \sigma_{\mathrm{f}}\left(\mathrm{cm}^{2}\right) & \mathrm{NA} & 0.01 \times 10^{-24} & 0.04 \times 10^{-24} & \mathrm{NA} & \mathrm{NA} & \mathrm{NA} \\ \sigma_{\mathrm{fe}}\left(\mathrm{cm}^{2}\right) & \mathrm{ND} & \mathrm{NA} & \mathrm{NA} & 13 . & \times 10^{-24} & 49 \times 10^{-24} & 590 \times 10^{-24} \\ \sigma_{\mathrm{th}}\left(\mathrm{cm}^{2}\right) & \mathrm{NA} & \mathrm{NA} & \mathrm{ND} & \mathrm{NA} & 3.9 \times 10^{-24} & 3 \times 10^{-20} \\ \Psi & 4.63 \times 10^{10} & 4.3 \times 10^{10} & 4.0 \times 10^{10} & 4.0 \times 10^{10} & 3.9 \times 10^{10} & 1.3 \times 10^{10} \\ \mathrm{mev} / \mathrm{dis} & 0.32 & 0.84 & 0.81 & 1.18 & 2.5 & 1.2\end{array}$

Abundance of parent nuclides in the crud

Variable concentrations

Cross section for activation of the daughter nuclide

Not applicable

No data available 


\section{APPENDIX B}

Physical Data 1,8

\begin{tabular}{|c|c|c|c|}
\hline$\alpha$ & 5.32 & $\times 10^{-5}$ & $1 / \mathrm{sec}$ \\
\hline D & 1.815 & $\times 10^{-10}$ & $1 / \mathrm{cm}^{2}-\mathrm{sec}$ \\
\hline$\beta$ & 3.66 & $\times 10^{-8}$ & $1 / \mathrm{sec}$ \\
\hline $\mathbf{K}$ & 3.95 & & $\mathrm{mg} / \mathrm{dm}^{2}-\mathrm{mo}$ \\
\hline C & 1.24 & & $\mathrm{mg} / \mathrm{dm}^{2}-\mathrm{mo}$ \\
\hline$A_{c}$ & 7.71 & $\times 10^{5}$ & $\mathrm{~cm}^{2}$ \\
\hline$A_{t}$ & 7.9 & $\times 10^{6}$ & $\mathrm{~cm}^{2}$ \\
\hline$V_{t}$ & 5.93 & $\times 10^{6}$ & $\mathrm{~cm}^{3}$ \\
\hline
\end{tabular}




\section{APPENDIX C \\ Definition of Conversion Factor $\Psi$.}

The units of equation (2), Section 3.1 are derived from the following symbols appearing in that equation:

$$
\begin{aligned}
& \frac{\Psi \mathbf{A}_{\mathbf{c}} \sum \sigma \phi, \mathrm{K} \mathrm{P}}{\left(\lambda+\sum \sigma \phi\right) \mathrm{s}} \\
& \frac{\Psi \mathrm{cm}^{2} \mathrm{~cm}^{2} \frac{1}{\mathrm{~cm}^{2}-\mathrm{sec}} \frac{\mathrm{mg}}{\mathrm{dm}^{2}-\text { month }}}{\frac{1}{\mathrm{sec}}}
\end{aligned}
$$

The units of $\frac{\mathrm{d} \cdot \mathrm{N}^{\prime}}{\mathrm{d} \mathrm{t}} \quad[$ equation (2).]are atoms/sec

therefore the units of $\Psi$ are

$$
\Psi=\frac{\mathrm{dm}^{2}}{\mathrm{~cm}^{2}} \quad \frac{\text { atoms }}{\text { moles }} \frac{\text { moles }}{\text { gm }} \quad \frac{\text { months }}{\mathrm{sec}} \frac{\mathrm{gm}}{\mathrm{mg}}
$$

combining equations (2) and (3)

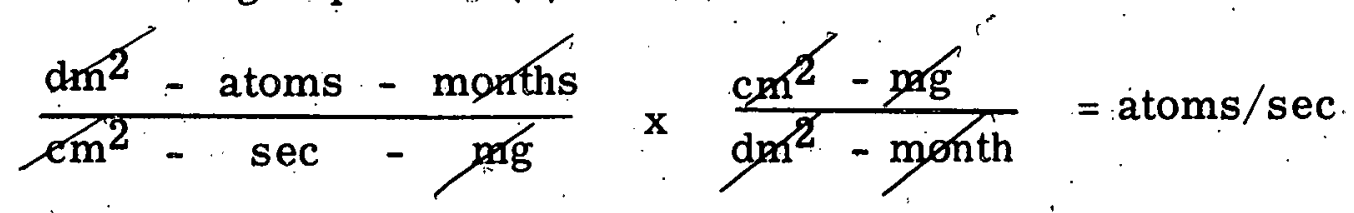




\section{BIBLIOGRAPHY}

1. W. S. Brown, et al, SM-1 Research and Development Program, Final Report on Activity Buildup, Task:I, APAE No. 51, August 10, 1959.

2. J. L.: Meem, "Cobalt Activity Buildup in the Nuclear Merchant Ship Reactor," Babcock and Wilcox Report No. 1130, October 1, 1958.

3. A. L. Medin, et al, "Literature Survey for Activity Buildup on Reactor Primary System Components," APAE No.25, January 15, 1958.

4. W. S. Brown, et al'. "SM-1 (APPR-1) Research and Development Program, Activity Buildup Program Task.I, Status Report February to November 1958," APAE Memo No.180, March 1, 1959.

5. R. S. Rochlin, "Fission-Neutron Cross Sections for Threshold Reactions," Nucleonics, Vol。17, No。 1 (January, 1959), p. 54, 55.

6. $\quad R_{0}$. L. Macklin and $H_{0}$. S. Pomerance, "Resonance Capture Integrals," International Conference on the Peaceful Uses of Atomic Energy, Vol. 5, p. 833, (1955).

7. E. E. Gross, "Estimate of the Ratio of Ta 182 to Co 60 Activity Expected in the APPR-1.Core," ORNL, CF-58-2-32, February 10, 1958 .

8. $\mathrm{J}_{0}$ : G. Gallagher, et al, SM-2 (formerly APPR-1B) Reactor Core and Vessel Review Report, December 5, 1958 to February 13, 1959, APAE Memo No. 173, February 20, 1959.

9. T.. Rockwell UI, "Reactor Shielding Design Manual, ". D. Van Nostrand and Co. , 1956.

10. ALCO Products, Inc., Program No. 309;

11. J. G. Gallagher, et al, "SM-2 Reactor Core and Vessel Review Report, February 14, 1959 to May 27, 1959," APAE Memo 197, June 5, 1959.

12. R. Kelleman, ALCO Products, Inc., personal communication, April 21, 1959 .

13. Ibid., July 15, 1959. 


\section{BIBLIOGRAPHY}

14. G. J. Vodapivc, et al, "APPR-1 Inspection-Steam Generator Water Box, ". APAE Memo No. 153, December 19, 1958.

15. Drawing No. AES $312-$ Steam Generator, SM-2:

16. G. P. Pancer, J. L. Zegger, APPR-1 Research and Development Program Decontamination Program Task II, Vol." III, "Recommended Procedure for Decontamination of a Stainless Steel Steam Generator,". APAE No. 43 , February 13, 1959. 
314681

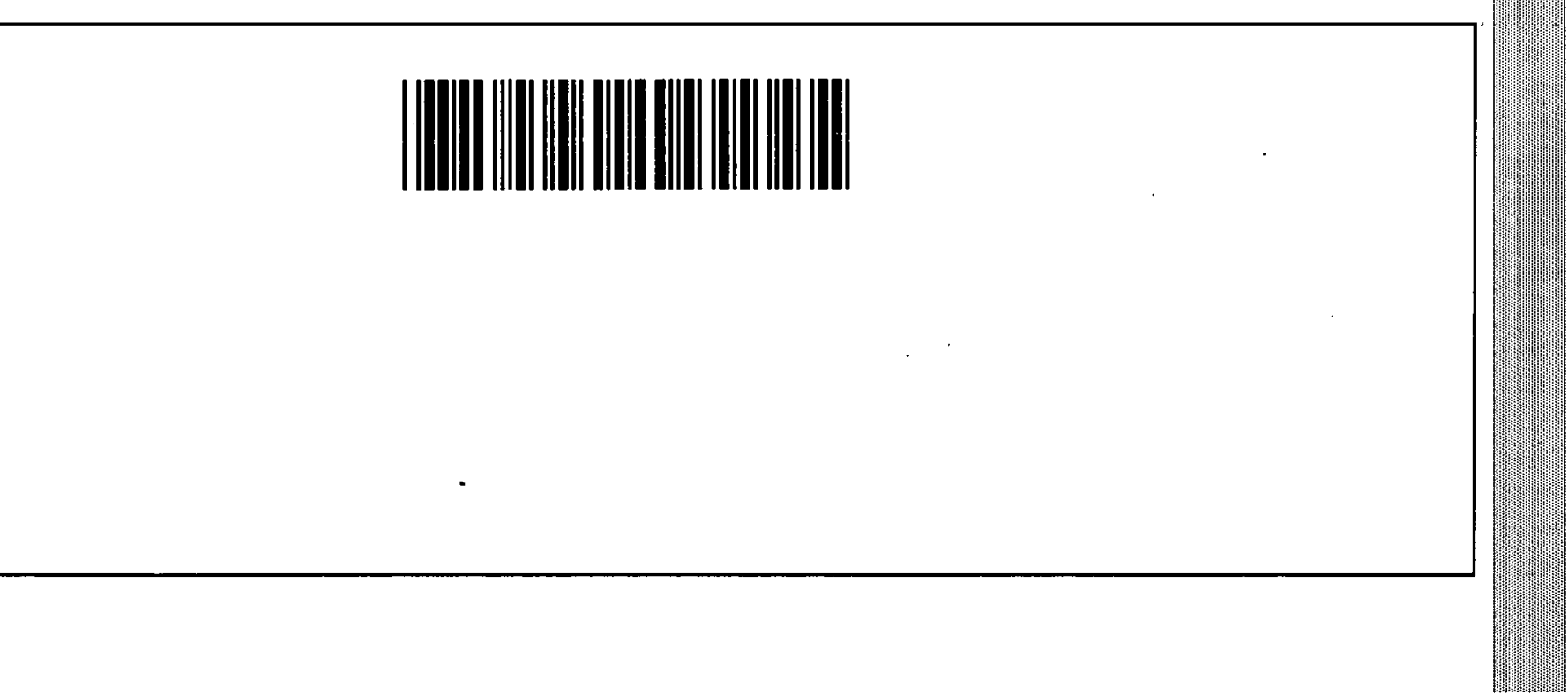


APAE MEMO No. 215

$\mathrm{SM}-2$

\section{REACTOR CORE AND VESSEL MONTHLY REPORT}

May 28, 1959 to July 9, 1959

CONTRACT NO. AT $(30-3)-326$

ISSUED JULY 17, 1959

J. G. Gallagher - Project Engineer

\section{NOTICE}

This report contains patentable, preliminary, unverified, or erroneous information. For one or more of these reasons the author or issuing installation and responsible office have limited its distribution to Governmental agencies and their contractors as authorized by AEC Manual Chapter 3202-062. A formal report will be published at a later date when the data is complete enough to warrant publication.

ALCO PRODUCTS, INC. POST OFFICE BOX 414 SCH ENECTADY, N. Y 


\section{ERRATA}

The last sentence on Page ix, INTRODUCTION of APAE MEMO 215 reads The next formal review is scheduled for September 15, 1959.? The date should be September 14, 1959 . 
COPIES

\section{DISTRIBUTION}

$1-2$

New York Operations Office

$U_{0}$ S. Atomic Energy Commission

376 Hudson Street

New York 14, New York

Attention: Chief; Army Reactors Branch, NYOO

$3-5$

U. S. Atomic Energy Commission

Army Reactors Branch

Division of Reactor Development

Washington 25, D. C.

Attention: Chief, Water Systems Project Branch

Office, Ass' t. Director: (Army Reactors)

6

U. S. Atomic Energy Commission

Chief, Patents Branch.

Washington 25, D. C.

Attention: Roland A. Anderson

7

U: S. Atomic Energy Commission

Chief, New York Patent Group

Brookhaven National Laboratory

Upton, New York

Attention: Harman Potter

8

U. S. Atomic Energy Commission

Idaho Operations Office

Phillips Petroleum Company, NRTS

Technical Library.

P. O. Box 1250

Idaho Falls, Idaho

Attention: Technical Liaison Officer, Army Reactors

$9-11$

Nuclear Power Field Office

USERDL

Fort Belvoir, Virginia

Attention: : Chief, Nuclear Power Field Office 
COPIES

\section{DISTRIBUTION}

$12-13$

Union Carbide Nuclear Corporation

Oak Ridge National Laboratory

U-12 Building 9704-1

P. O. Box "Y"

Oak Ridge, Tennessee

Attention: J., Cunningham and A. L. Boch

$14-17$

The Martin Company

P. O. Box 5042

Middle River, Maryland

Attention: AEC Contract Document Custodian

18 Combustion Engineering, Inc.

P. O. Box 2558

Idaho Falls, Idaho

Attention: Mr. W. B. Allred, Project Manager SL-1

19

U. S. Atomic Energy Commission

Reference Branch

Technical Information Services Extension

P. O. Box 62

Oak Ridge, Tennessee

Alco Products, Inc.

P. O. Box 145

Fort Belvoir, Virginia

Attention: H. L. Weinberg

21-22

Battelle Memorial Institute

505 King Avenue

Columbus, Ohio

Attention: S. Paprocki

23 Dr。 R. L. Murray

North Carolina State College

P. O. Box 5596

State College Station

Releigh, North Carolina

iv 


\section{COPIES}

\section{DISTRIBUTION}

24

25

26

27

28

29

30

31

32

33

34-35

36-37

38-39

$40-41$

42

43-44

45

46-47

48-49

50

51

52-59
W. D. Leggett

G。 R. Griffith

K. Kasschau

H. Kreikle

G. A. Young

G. A. LeClair

J. F. Haines

J. G. Gallagher

D. D. Foley

J. P. Tully

P. E. Bobe

I. Beretsky

T. F. Connolly

R. D. Robertson

R. A. Shaw

W. M. S. Richards

R. J. Clark

J. W. Noaks

G. W. Knighton

R. E. Williams

G. M. Van de Mark File 


\section{CONTENTS}

INTRODUCTION $\cdots \cdots+\cdots, \ldots$ PROGRESS SUMMARY - - -
A. Core Nuclear Design - Task 8. 0 $\ldots \ldots$
B. Core Thermal Design - Task 2.0 $\ldots \ldots$
C. Reactor Vessel Design - Task 3. 0.-...-
D. Core Metallurgical Development Program - Task 4. 0 - - - 15
E. Welded Fuel Element Assembly Development - Task 5. 0 - - 27
F. Hydraulic Analysis and Test - Task 6. 0
G. Flexible Critical Experiment - Task 7.0
H. Rod Drive Development - Task 11.0 _........ 37 


\section{INTRODUCTION}

This report contains the significant progress during the period May 28, 1959 to July 9, 1959. A formal review was made of the SM-2 Reactor Core and Vessel Program at Schenectady, N. Y., on June 10, 1959. The next formal review is scheduled for September 1. 1959. 
PROGRESS SUMMARY

1. A revised power distribution has been established. A check calculation of the fully poisoned experiment indicated an error of $-3.8 \%$ in reactivity. Calculations indicate that the overall power distribution can be improved by operation with the center rod fully inserted (Task 8. 0$)$.

2. Calculations indicate that the presence of a water gap between the end of the fuel plate and side plate does not affect the temperature pattern within the plate (Task 2.0).

3. A drawing of the reference reactor vessel has been completed. A cross-section thru the core has been completed. Another study layout of the full scale closure test was made (Task 3.0).

4. The evaluation of the effect of impurity level on activity buildup in the steam generator has been completed. Specimens and capsule parts for the MTR test have been completed. The first ETR capsule has been sealed (Task 4,0).

5. Arc starting difficulties have been overcome on the TIG welded assemblies. An element with $0.040^{\prime \prime}$ side plates was successfully assembled. A static corrosion test was completed on both TIG and resistance welded assemblies. (Task 5,0).

6. The static pressure drop across the reference control rod has been evaluated for both operating and room temperature and found to be 22.3 and $28 \mathrm{ft}$., respectively. Two more elements have undergone static deflection tests (Task 6.0).

7. The parameter. study has been completed using the reordered boron impregnated mylar tape. The preliminary SM-2 midlife mockup was completed. In this core the flow divider costs $-\$ 1.28$ in reactivity and the reference laminated steel reflector adds $\$ 0.50$ (Task 7.0).

8. The seal assembly drawings are complete and material requisition has been started. The detailing of the clutch assembly is complete. (Task 11.0). 


\section{PREVIOUS PROGRESS REPORTS IN THIS SERIES}

APAE Memo 150

APAE Memo 160

APAE Memo 166

APAE Memo 170

APAE Memo 1.73

APAE Memo 185

APAE Memo 192

APAE Memo 197
APPR-1B Reactor Core and Vessel Progress Report, September 16, 1958 to October 25, 1958.

APPR-1B Reactor Cpre and Vessel Progress Report, October 26, 1958 to December 4, 1958.

APPR-1B Reactor. Core and Vessel Progress Report, December 5, 1958 to December 31, 1958.

APPR-1B Reactor Core and Vessel Progress Report, January 1, 1959 to January 23, 1959 .

SM-2 (Formerly APPR-1B) Reactor Core and Vessel Review Report, December 5, 1958 to February 13,1959 .

SM-2 (Formerly APPR-1B) Reactor. Core and Vessel Progress Report, February 14, 1959 to March 24, 1959.

SM-2 (Formerly APPR-1B) Reactor Core and Vessel Progress Report, March 25, 1959 to April 24, 1959.

SM-2 Reactor Core and Vessel Review Report, February 14, 1959 to May 27, 1959. 


\section{A. CORE NUCLEAR DESIGN}

1. Progress (Task 8.0)*-P.. E. Bobe

Detailed thermal and fast flux and power distributions were calculated for the reference core and vessel at $510^{\circ} \mathrm{F}$. Heating rates were calculated based upon these flux and power distributions. New power peaking factors were calculated based upon the results of the SM-2 flexible critical experiment.

The suppression of the axial power peaking at the bottom of the core has been investigated. One possible method which was studied was the incorporation of B-10 in the bottom of the picture frame matrix. It was found that about $0.03 \mathrm{w} / \mathrm{o}$ B-10 in stainless steel was adequate to suppress the bottom peak below the maximum within the core. This value does not include allowance for burnup.

The nuclear parameters of the flexible critical experiment fuel elements were calculated as a function of $B-10$ content per plate. The parameters for both fixed and control rod elements at $68^{\circ} \mathrm{F}$ and atmospheric pressure were calcuiated. Reactivity of the core. as a function of boron loading was calculated and compared to experiments.

A comparison of the radial power distributions for a fixed element core, and a fixed element core with a centerline absorber fully inserted, was made at $510^{\circ} \mathrm{F}, 2000 \mathrm{psia}$, at start-up. with no xenon. Operation of the reactor with the central rod fully inserted results in a more uniform power distribution.

2. Analysis of Critical Experiments (Task 8.1) - P.E. McElligott; P. E. Bobe

\section{a. Suppression of Power Spike}

As reported in APAE Memo 19.7, both experimental measurements and theoretical calculations confirm that a power spike exists at the bottom of the core. Two approaches are being studied to suppress this spike. The first approach is the effect of a flux suppressor incorporated in the bottom of the picture frame. Boron was assumed to be placed in the lower $1 / 2$ inch of the picture frame and to displace none of the steel: B-10 concentration is given in terms of weight percent of B-10 in steel. Two-group, multiregion

*: Task 8.0 replaces Task 1.0 in FY-60 
flux calculations were made to obtain the peaking effect as a function of boron content. The results of these calculations are shown in Figure 8-1. The concentration of B-10 necessary to diminish the spike below the maximum power in the core is seen to be about $0.03 \mathrm{w} / \mathrm{o}$. This value is for reactor startup and does not include the effect of boron burnup during core lifetime.

Another approach is the effect of fuel tapering at the bottom of the fuel plate. The decrease in fuel concentration within this region will decrease the spike since the relative peaking between two regions is proportional to the relative absorption. This effect.will be investigated during the next progress period.

\section{b. Surface vs. Volume Distribution of Boron}

The boron used in the flexible critical experiments is added in the form of boron-impregnated mylar tape which is glued to the fuel plates. This results in a loss of reactivity compared to a volume distribution of boron within the fuel matrix. Using theory developed by R. L. Murray*, the reactivity loss as a function of boron addition was calculated for fixed fuel elements containing 18 fuel plates. The results of these calculations are shown in Figure 8-2. It is seen that the maximum calculated reactivity loss for the SM-2 flexible critical experiment fuel elements is about $0.75 \%$

c. Nuclear Parameters of Fuel Elements

The nuclear parameters of the flexible critical experiment fuel elements were calculated as a function of B-10 content per plate. The parameters were obtained at $68^{\circ} \mathrm{F}$ and atmospheric pressure through use of the following IBM-650 codes: Program 53**, Program 54***, MUFT III $f$

*. Murray, R. L., "Comparison of Surface and Volume Distributions of Burnable Poison in Heterogeneous Cells", AP Note 149, April 28, 1959.

* Bobe, P. E. , and P. V. Oby, "Medusa, Preparation Routine for MUFT III and $P_{3}$ Calculations on the IBM-650", AP Note 158, May 29, 1959.

*** Bobe, P. E. , and P. V. Oby, "Program 54, P3 Calculation of Thermal Parameters of APPR Type Control Fuel Elements on the IBM-650", to be issued.

f Hellens, R. L., "Multigroup-Fourier Transformation Calculation-Description of MUFT III Code", WAP.D-TM-4, July 1956. 
and Plate Type $\mathrm{P}_{3}$ Calculations $f f$ : Boron loadings considered were 0 ; $1 / 2,1,3 / 2$ and 2 times the reference B-10 loadings per plate as given in APAE Memo 160. The results of these calculations for fixed and control fuel elements containing 18 and 16 fuél plates, respectively, will be issued as an AP Note.

\section{d. Reactivity as a Function of Boron}

The reactivity of the core as a function of B-10 content was calculated by the use of VALPROD*, a two-group, multiregion IBM-650 code and compared to experimental results as presented in Figure 7.1 of APAE Memo 197. The core considered was water reflected containing 18 and 16 fuel plates in the fixed and control fuel elements respectively. The effect of boron introduced as a surface distribution (boron-imprègnated mylar type) instead of the usual volume distribution within the fuel matrix was included. "The results of these calculations are shown in Figure 8-3. It is seen that for a clean core, containing no boron, the calculated reactivity is greater than the measured value, while for a fully poisoned core, the calculated value is lower than the measured value. The reasons for this behavior are not apparent at this time but are being investigated.

3. Core Analysis (Task 8.2) - J.R. Tomonto, E. F: Clancy, P. E。 Mc Elligott

\section{a. Radial Flux and Power Distributions}

The radial flux and power distributions for the reference $\mathrm{SM}-2$ core and vessel configuration (APAE Memo 197, Drawing No. AEL-450) were calculated by use of VALPROD, a two-group, multiregion IBM-650 code. The distributions were calculated both at startup and end of life for the core operating at $510^{\circ} \mathrm{F}$ and 2000 psia. The core contains a 93 mil flow divider and is reflected by a thick laminated steel reflector. The radial

At. Byrne, B.J., and R。 L。 Caton, "Two Dimensional $P_{3}$ Calculation for APPR - Type Fixed Fuel Elements", AP Note 96, February 14; 1958

* Oby, P. V., . "Modified Two-Group Multiregion Calculation Using the VALPROD Code for the IBM-650", AP Note 24 (Revised), August 14, 1957. 
fast and thermal flux distributions are shown in Figures 8-4 and 8-5 for startup and end of life, respectively. The relative radial power distribution is shown in Figure 8-6.

\section{b. Radial Heat Generation}

Utilizing the flux distribintions shown in Figure $8-5$, the radial heat generation rate distribution was obtained by use of the ROC shielding codes* which calculate heating in the thermal shields and pressure vessel from direct core gammas and secondary (capture) gammas. Radial heat generation rate as a function of distance from the core centerline is shown in Figure $8-7$.

The axial heating rate and the heat generation within the core and vessel components are also being calculated and will be completed during the next progress period. The results of these calculations will be issued as an AP Note.

\section{c. Power Peaking Factors}

An estimate of the power peaking has been obtained for the SM-2 as a function of fuel burmup. The axial power distribution as a function of burnup was based on a non-uniform axial burnup using the Windowshade code

The core considered in the non-burnup calculations was reflected by a laminated steel reflector operating at $440^{\circ} \mathrm{F}$ and $1200 \mathrm{psia}$. The most recent SM-2 reference core, operating at $510^{\circ} \mathrm{F}$ and $2000 \mathrm{psia}$, will cause some slight change in the axial power distribution but will not be radically different from that at $440^{\circ} \mathrm{F}$. Both the experimental data, reported under Task 7 of APAE Memo 19:7, and the Windowshade calculations indicate that the axial power peak occurs at the bottom of the core. This power spike reaches a maximum at approximately $18 \%$ of fuel burnup. Table $8-1$ gives the axial peaking factors (spike to average and core maximum to average) as a function of fuel burnup.

* Rosen, S. S。, P.V。Oby, and R。L.Caton, "Primary Shielding Calculations on the IBM 650 (ROC Codes)", APAE Memo 142, October 15, 1958.

* McElligott, P. E. "Burnout Calculations for the SM-2 Reference Core", AP Note 138, April 3, 1959. 
Table 8-1

\section{SM-2 Axial Peaking Factors $f$}

\% Burnup

0

5

12

18

20

.25

30

35
Spike to Average Power

2. 49

2. 72

2. 99

3.05

3. 04

2. 90

2. 62

1.86
Core Max. to Avg. Power

1. 56

1. 64

1. 74

1. 78

1. 78

1.74

1.66

1.45

+ Based on $440^{\circ} \mathrm{F}$ and 2000 psia.

The gross radial power distribution was obtained from a VALPROD calculation conduct ed on the reference core at $510^{\circ} \mathrm{F}, 2000 \mathrm{psi}$, and is shown in Figure 8-6. These calculations include the effect of the flow-dividex and of a laminated steel reflector.

A local hot spot factor at $510^{\circ} \mathrm{F}$ due to side plate peaking was calculated from $\mathrm{P}_{3}$ thermal flux distributions and corrected to agree with experimental data at $68^{\circ} \mathbf{F}$. Since the power peaking calculated from these distributions was considerably smaller than that measured in the SM-2 flexible eritical experiments and reported under Task 7 of APAE Memo 197, the theoretical distributions were corrected by assuming that the shape of the calculated power distribution was correct but the magnitude of the peaks was too small. The local peaking factors as a function of lifetime were obtained, assuming nonuniform burnout within the cell.

There are several combinations of geometrical configurations within the SM-2 core which result in appreciable local power peaking. In order of importance these are:

1. Peaking at the edge of a fixed fuel element adjacent to a control rod element with both sets of fuel plates perpendiculär to the common interface.

2. Peaking at the edge of a fixed fuel element separated from a control rod element by the flow divider. with the fuel plates perpendicular to the interface. This case results in approximately the same calculated power peaking as in the previous configuration. 
3. Peaking at the edge of a fixed fuel element adjacent to another fixed fuel element with both sets of fuel plates perpendicular to the interface.

Experimental data is available for cases 1 and 3. Since the calculated local power peaking factors are equivalent for cases 1 and 2, an experimental correction has been applied to case.2, also.

With the new values of axial and radial power peaking factors, the values of $Q(\Delta T)$ and $Q(\Delta \theta)$, * as reported in APAE Memo 160 , were revised. Calculations indicate that the most adverse hot spot factor reaches a maximum at $12 \%$ fuel burnup. Table $8-2$ gives the values of $Q(\Delta T)$ and $Q$ $(\Delta \theta)$ for $0 \%$ and $12 \%$ fuel burnup. The nuclear uncertainty factors $F_{N}(\Delta T)$ and $F_{N}(\Delta \theta)$ and the heat release factors $\psi(\Delta T)$ and $\psi(\Delta \theta)$ are also given in Table $8-2$.

Table 8-2

SM-2 Radial Power Distribution

Element No.

0\% Burnup

12\%. Burnup

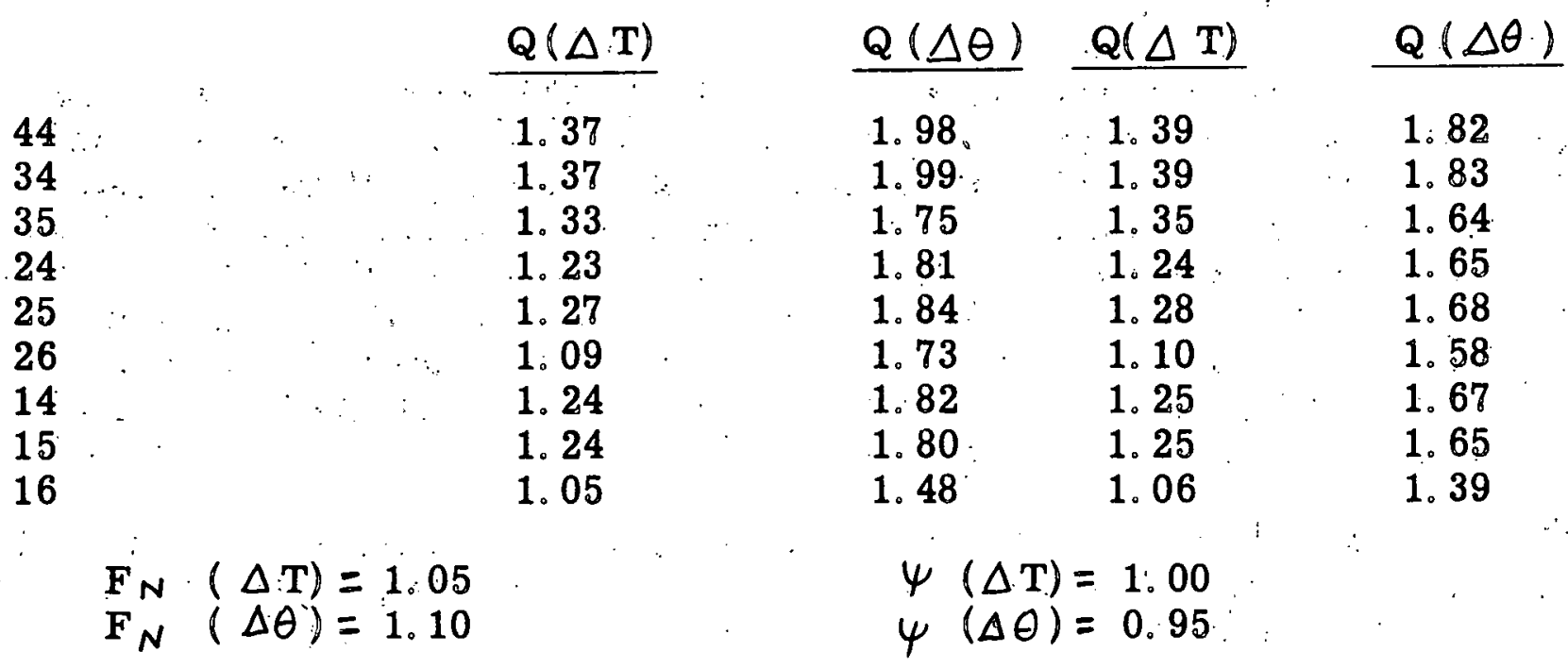

d. . Power Distribution for a Fully Inserted Central Control Rod

A comparison of the radial power distributions for a fixed element core, and a fixed element core with the central control rod fully inserted,

* : Byrne, B. . Power Distribution for APPR Type Cores, AP Memo 195 (to be published). 
was made for a laminated steel reflected core at $510^{\circ} \mathrm{F}, 2000$ psia, $0 \%$ burnup, and no xenon. The power was calculated by VALPROD, a twogroup multiregion calculation on the IBM-650. The absorber section was approximated by the following configuration: a water region surrounded by a Eu-SS region, which in turn was surrounded by a water-SS region. The flow divider was omitted. The results of these calculations are shown in Figure 8-8. It is seen from this figure that operation of the core with the central rod fully inserted results in a more uniform radial power distribution. In addition, the required coolant flow rate could be decreased due to the reduction in the gross peak to average value of the radial power distribution. This effect will be investigated further during the next progress period. 


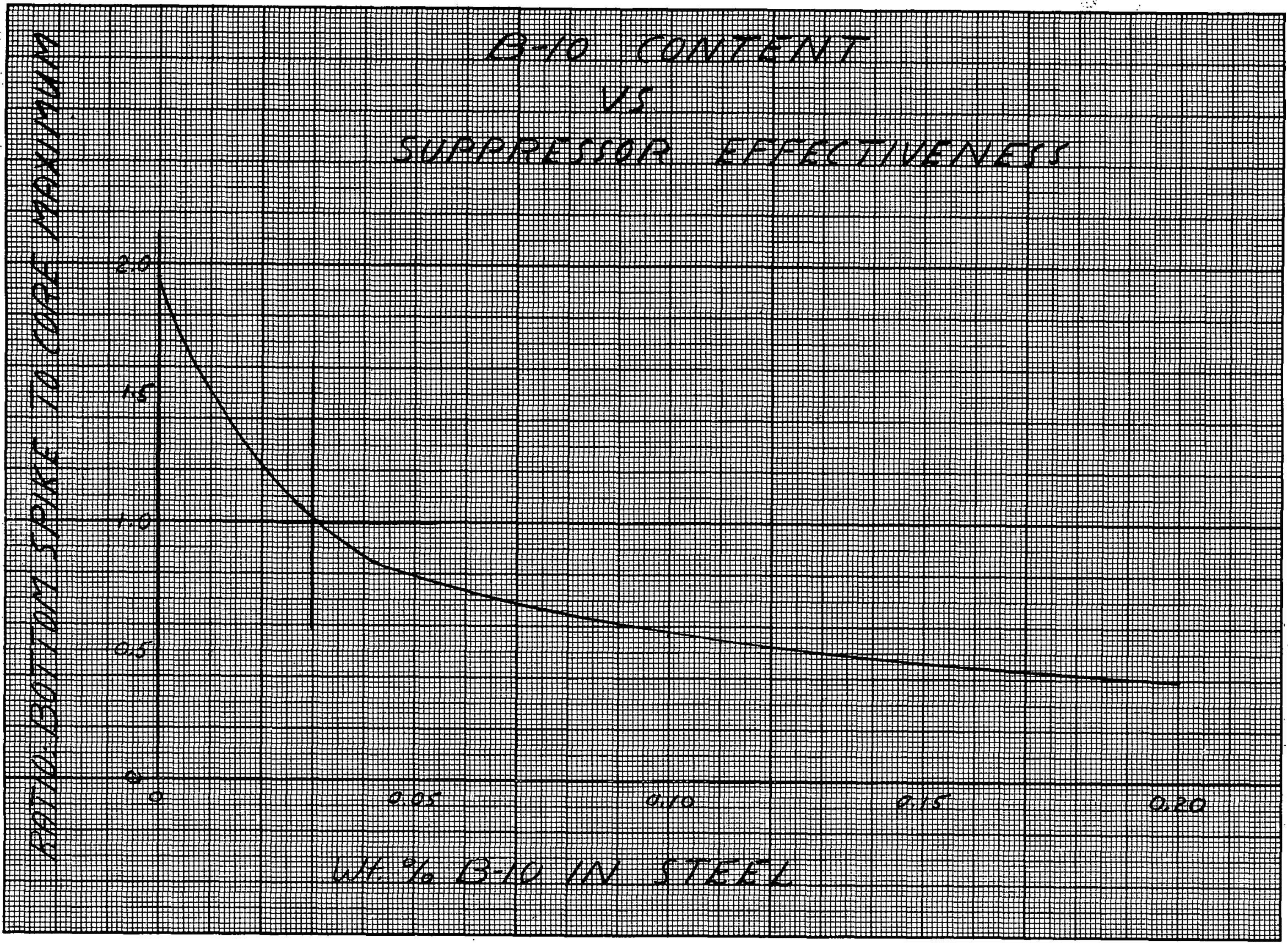

FIG, 8-I 


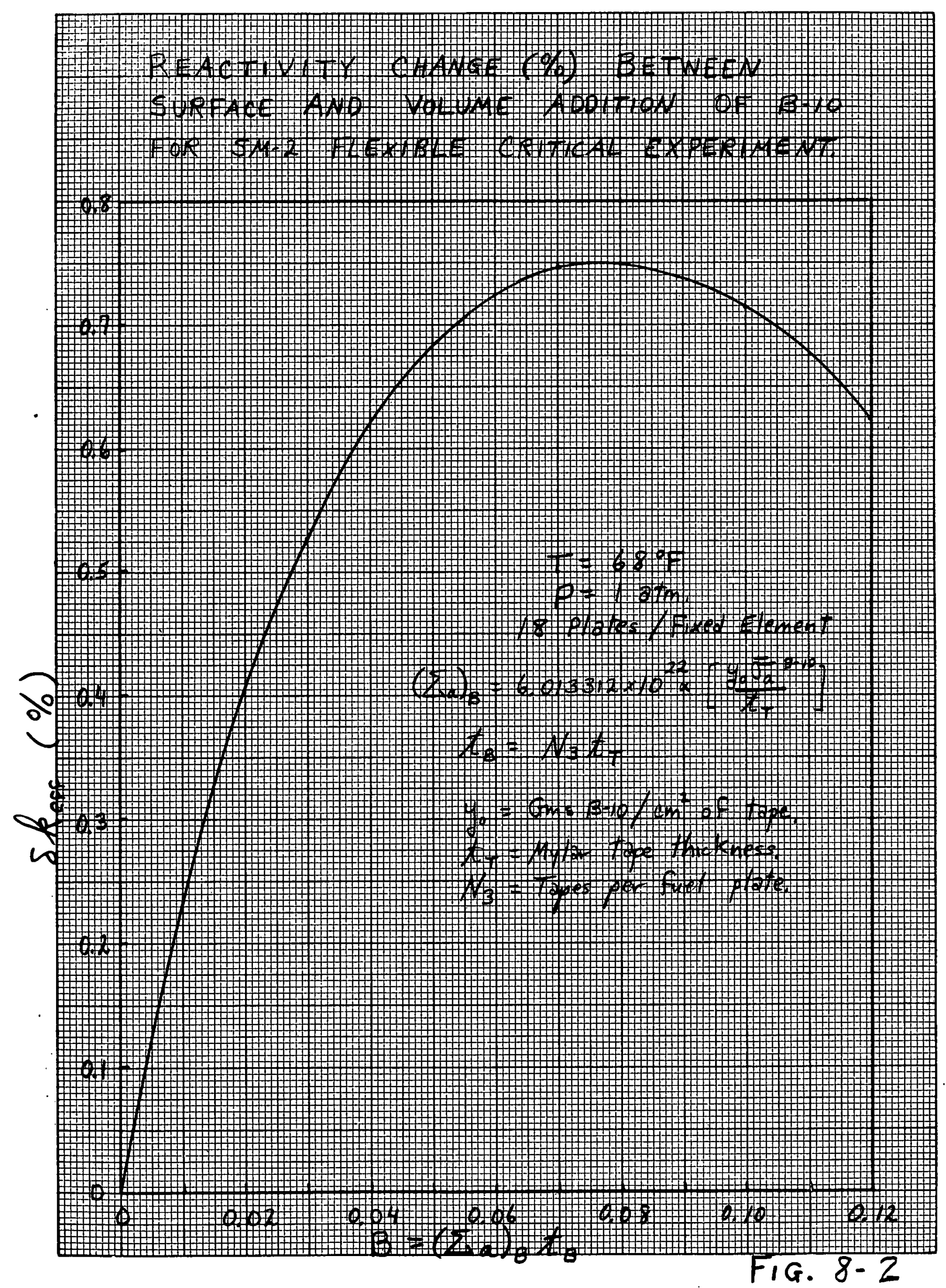

$068 \quad 015$ 


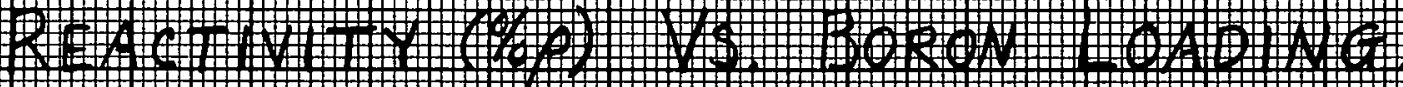
I

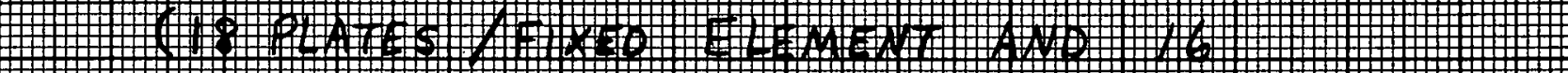

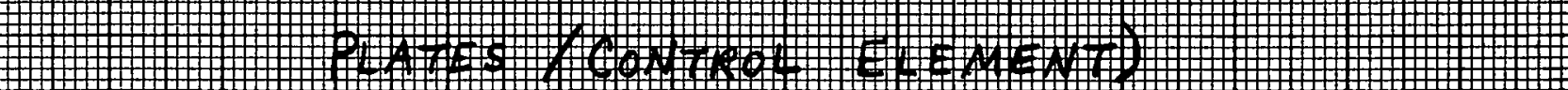
' (

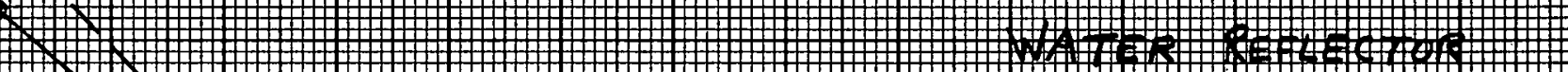

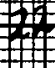
鹿 (

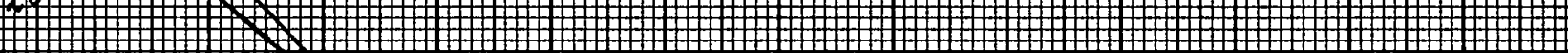
将

$$
\text { }
$$

ש

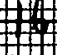

(1)

$\underbrace{2}$

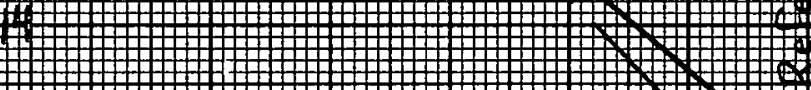

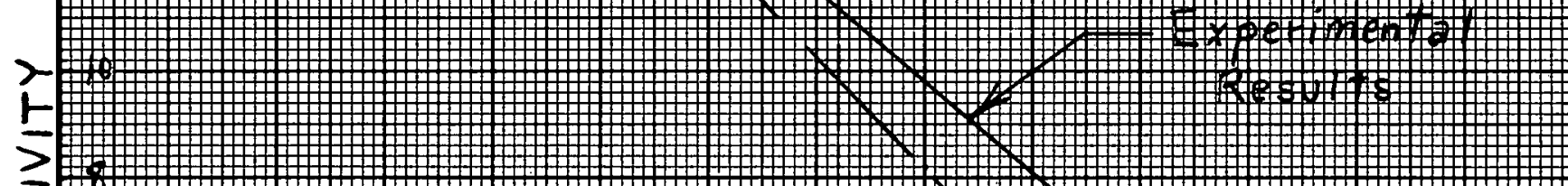

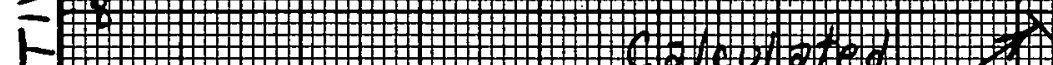

'

囬

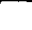

\#軽

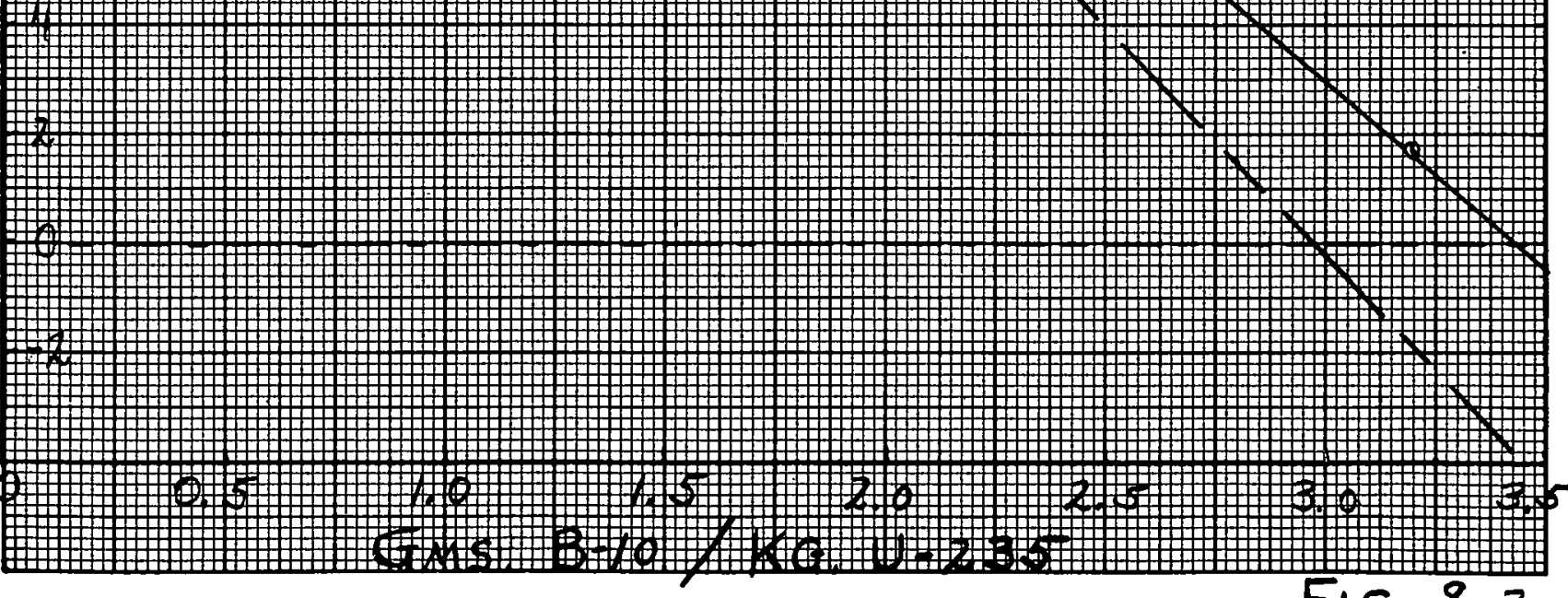

$$
068016
$$


$m$

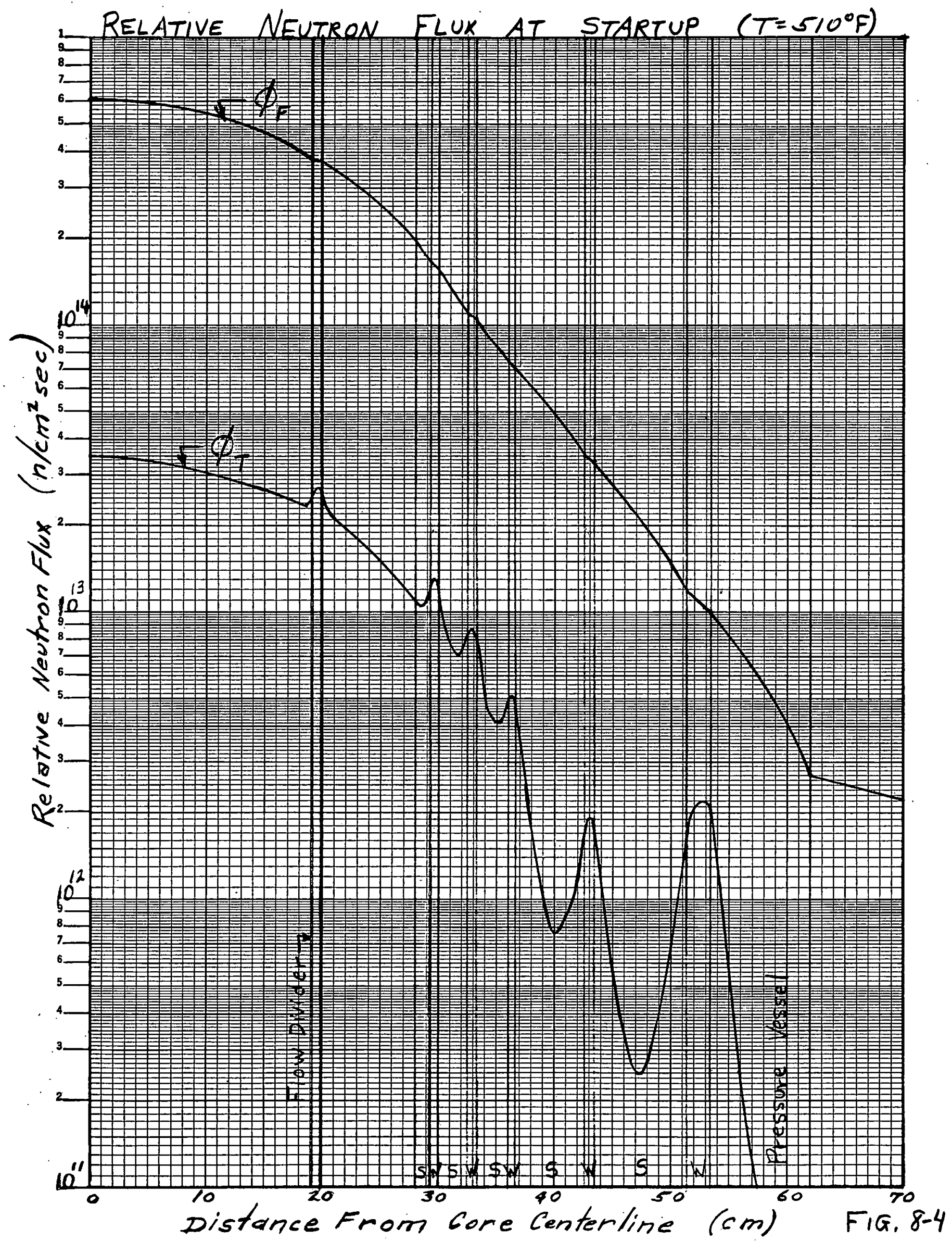

$068 \quad 017$ 


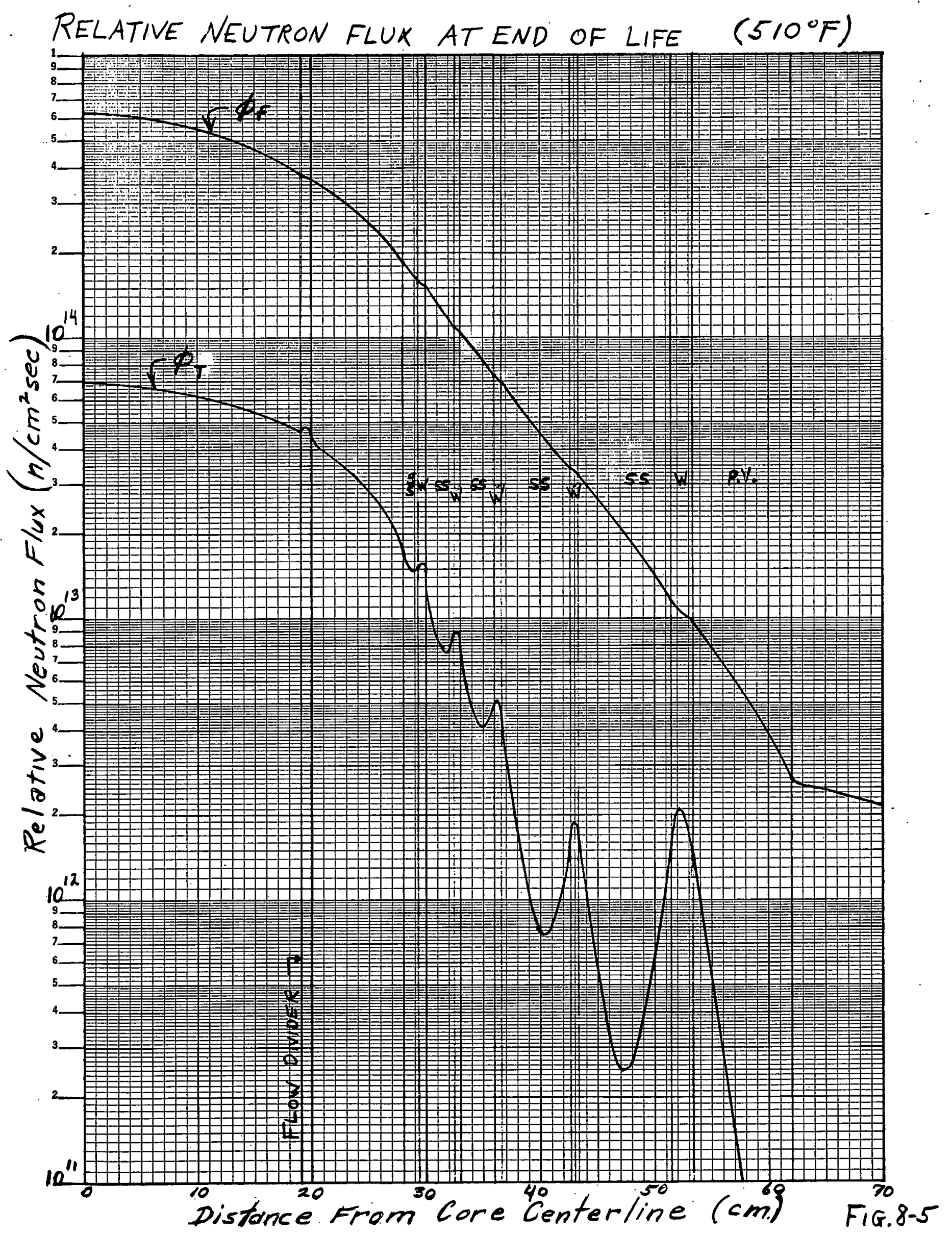

$068 \quad 018$ 
FIG. 8-6

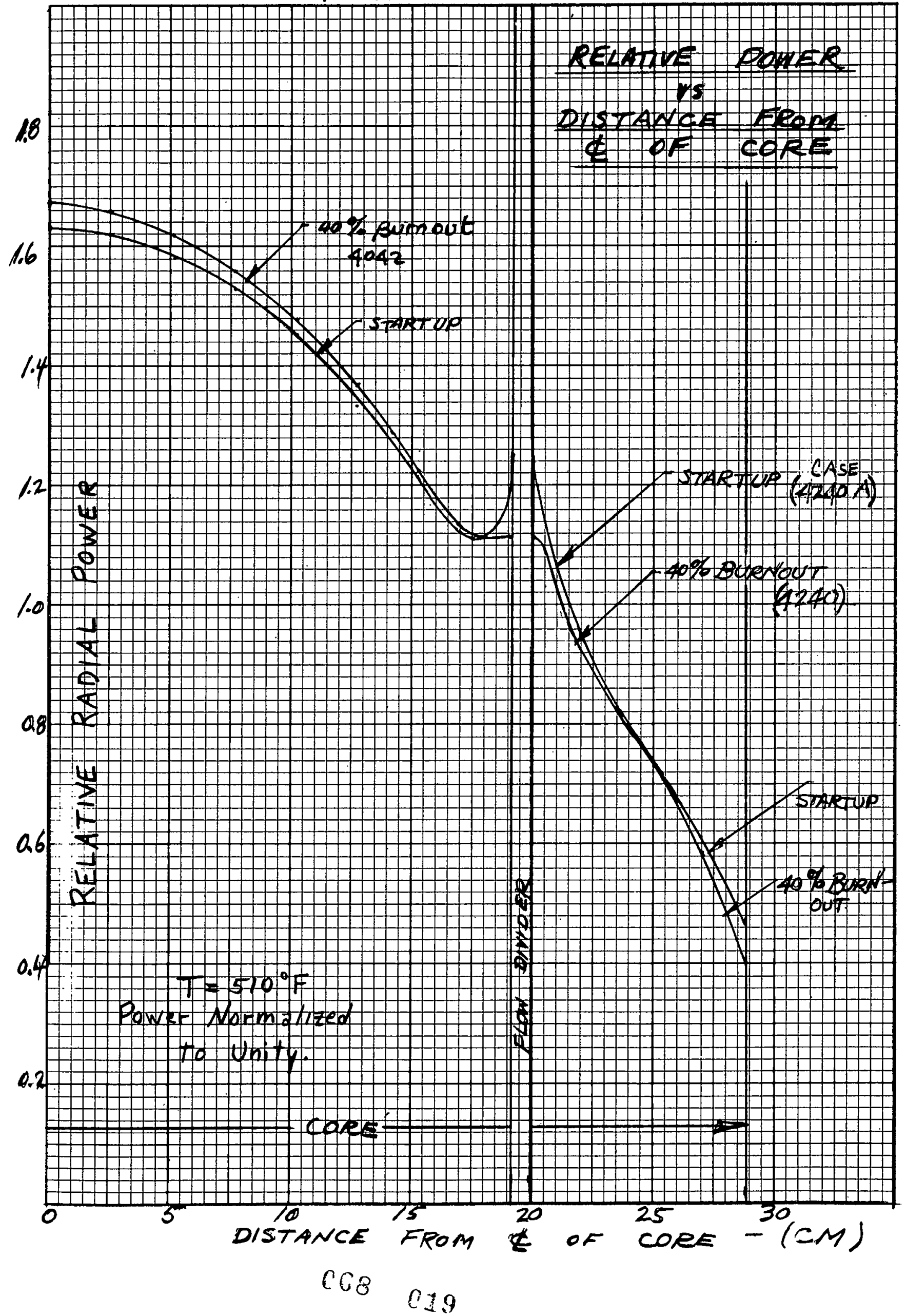




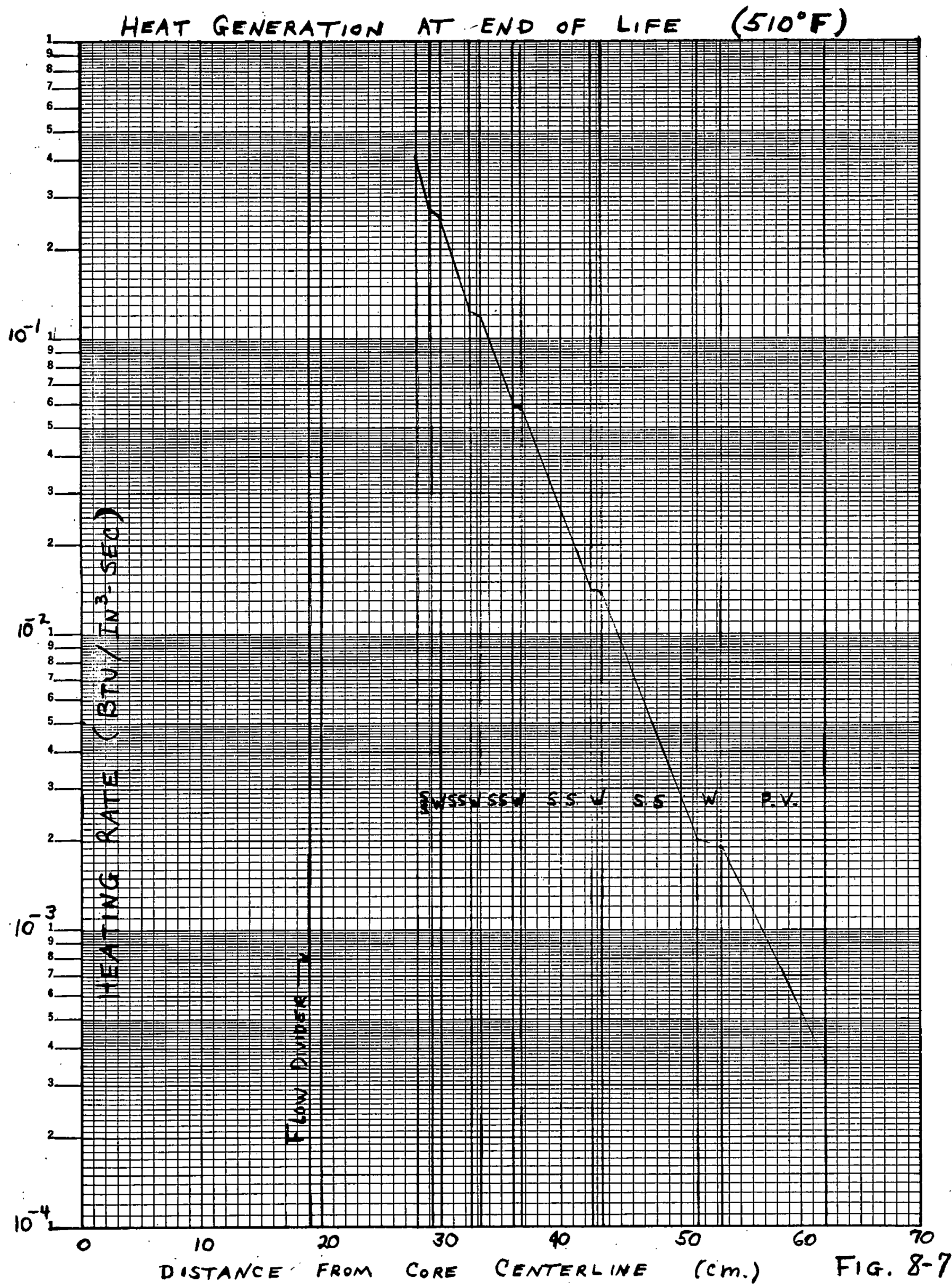




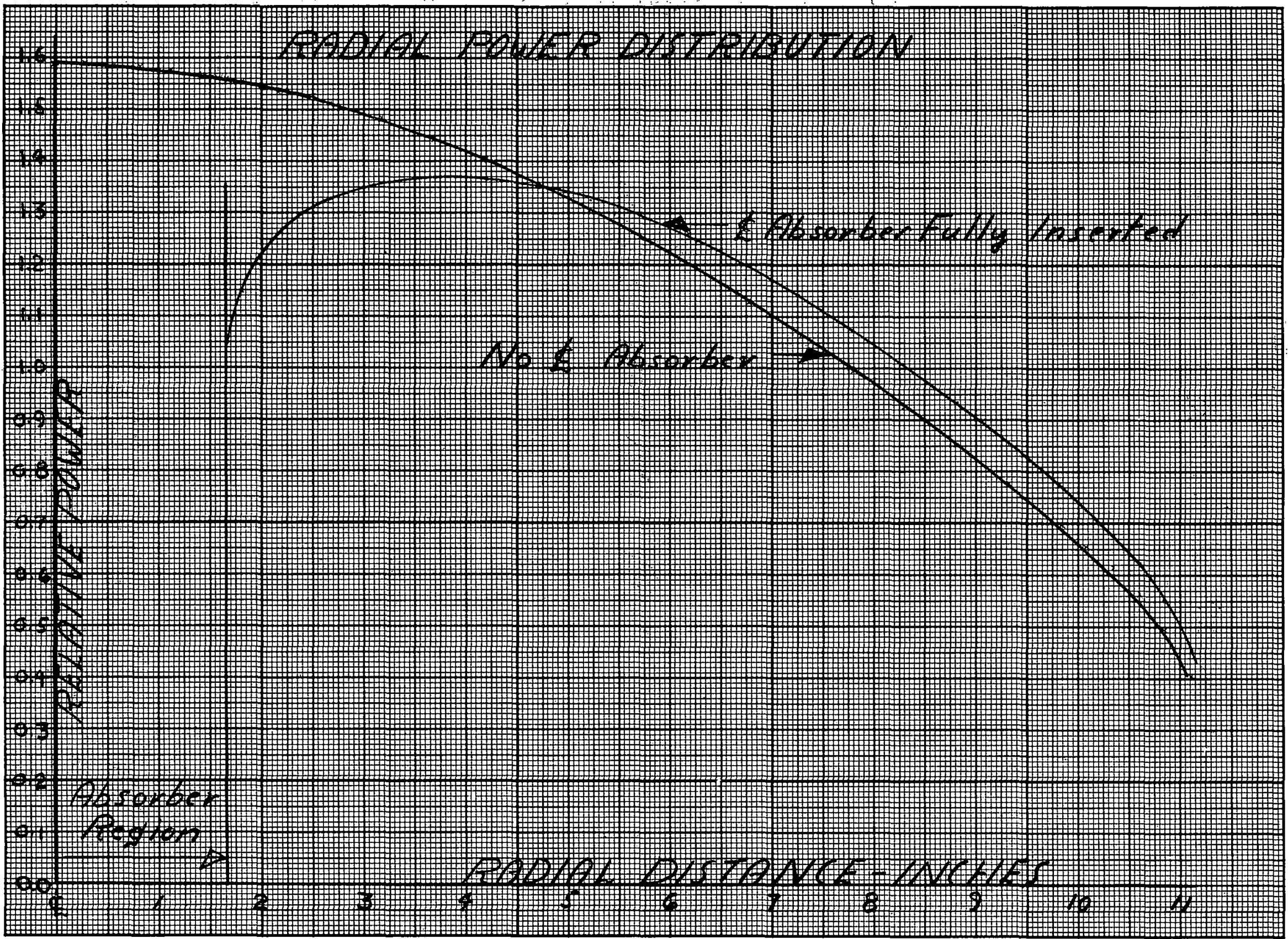

FIG. $8-8$ 


\section{B. CORE THERMAL DESIGN}

1. Progress (Task 2.0) - I. Beretsky

The steady-state boiling code, $A B W A C$, is being used to investigate reference as well as off-design performance. Data is being analyzed, and will be presented in the next progress report.

SM-2 fuel ellement temperature distribution has been deter mined for the transverse section as presented in AP Memo 197, without having the water gap present. The temperature distribution was found to be roughly the same as that reported in AP Memo 19.7.:

Axial temperature distributions (two-dimensional) were calculated using the IBM-704 in order to determine whether any fin effect was present which could reduce the surface temperature at the spike. The data has not yet been completely analyzed; however; there seems to be negligible fin effect.

A one-dimensional axial conduction code pertaining to fins with uniform heat generation has been written. This code calculates the temperature distribution along the fin. The output of this code is used in another code which calculates the thermal stress from the output of the first code. These codes will be published as AP Memos.

2. Effect of Variables on Burnout (Task 2.7) - J.o. D. Love

This study of off-design conditions of the SM-2 reactor is nearing completion. No immediate conclusions are presented herein. Final results will be forthcoming in the next month or so.

3. Final Flow Requirements (Task 2.8) - J. D. Love

New power distributions have been prepared by Task 8.0 and will be used in calculating new flow requirements and temperature distributions.

4. Fin Effect of SM-2 Fuel Elements (Task 2.10) - I. Beretsky, L。 Hecht

Two-dimensional temperature distributions of the SM-2 final element along its axial length have been calculated using the IBM-704. The data is

* I. Beretsky has replaced J。D. Love as task engineer on Task .2.0 Mrs. Love will remain active on Task 2.0. 
presently being prepared for final presentation. It appears, however, that the picture frame at the bottom of the fuel plate has a negligible effect in reducing the temperature of the spike.

5. Thermal Stress of Fuel Elements (Task 2.10) - I. Beretsky

In the two-dimensional picture of the fuel elem ent presented in AP Memo 197, a water gap was present between the end of the fuel plate and side plate. The same configuration was rerun on the $\mathbb{B B M}-704$ to determine what effect the water gap had on the temperature distribution. The results

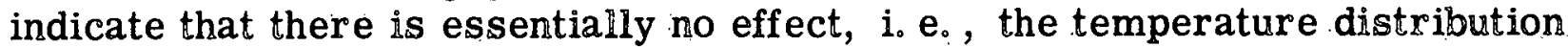
is almost identical to that presented in AP Memo 197. This data will be presented in a forthcoming $\mathrm{m}$ emo.

6. One-Bimensional Heat Transfer Code (Task 2.10) - I. Beretsky

A one-dimensional analysis of a plate having internal heat generation and a dead edge portion surrounded by a connecting medium was performed. In Figure 2-1, a sketch of such a fin is shown. The solution of the temperature distribution was obtained and can be shown to be:

$\mathrm{U}(\mathrm{x})=\mathrm{T}(\mathrm{x})-\mathrm{To}=\frac{\mathrm{G}}{\mathrm{kN}^{2}}+(\operatorname{Cosh} \mathrm{Nx}) \frac{\mathrm{G}}{\mathrm{kN}^{2}}:\left\{\operatorname{Sinh} \mathrm{Nm}\left[\begin{array}{c}\operatorname{Cosh} \mathrm{Np} \frac{-\mathrm{h} 1}{\mathrm{kN}} \operatorname{Sinh} \mathrm{Np} \\ \operatorname{Sinh} \mathrm{Np}-\frac{\mathrm{h} 1}{\mathrm{kN}} \operatorname{Cosh} \mathrm{Np}\end{array}\right]-\operatorname{Cosh} \mathrm{Nm}\right\}$

for $0 \leq \mathrm{x} \leq \mathrm{m}$

and

$V(X)=T \cdot(X):-T o=\frac{G \operatorname{Sinh} N m}{k^{2}}\left\{\operatorname{CoshNx}\left[\frac{\operatorname{Cosh} N p-\frac{h \cdot 1}{h N} \operatorname{Sinh} N p}{\operatorname{Sinh~Np}-\frac{h 1}{k N} \operatorname{Cosh~Np}}\right]-\operatorname{Sinh~Nx}\right\}$

for $\mathrm{m} \leq \mathrm{x} \leq \mathrm{p}$

where $\mathrm{N}-\sqrt{\frac{2 \mathrm{H}}{\mathrm{k} \ell}}$ in the units of Length $^{-1}$ 
These equations have been programmed for the IBM-650. The output of this code is then used as imput to a second code which calculates the thermal stress. These two codes will be presented in AP Memos:

In looking at Equations (1) and (2), if the arguments i。e., Np or Nm, are large, the cosh and sinh functions are approximately equal. That is, if Np or $\mathrm{Nm} \geq 7, \cosh \mathrm{Np} \approx \sinh \mathrm{Np}$.

Then, equation (1) reduces to $U(x) \cong \frac{G}{\mathrm{kN}^{2}}$ and equation (2) to $V(x) \cong 0$

It can be shown that with a given geometry, film coefficient, and thickness of plate, all of which determine the parameter $\mathrm{N}$, that the temperature distribution will be approximately the same, regardless of the values of $\mathrm{N}$, so long as $\mathrm{N}$ is large. 


\section{REACTOR VESSEL DESIGN}

1. Progress (Task 3.0) - T. Fo Connolly

Control rod assembly (AEL $445^{\circ}$ AP Memo 197) has been selected as reference and the details released so that the test models can be fabricated.

Another study layout of the full scale closure test was made and is shown on Drawing AEL-469. This vessel employs 12 studs and 12 thru bolts in alternating positions around the bolt circle. The height-to-width ratio of the gasket has been changed to get a self-sealing effect at the contemplated pressures.

A drawing of the cross section thru the core (AES 341) has been completed and, except for two possible minor changes, is selected as reference. It may not be necessary to turn all the fuel elements in the outer row to keep the plates perpendicular to the skirt. Also, it may be desirable to reduce the first water gap in the laminated reflector from $1 / 4^{\prime \prime}$ to $1 / 8^{\prime \prime}$.

Drawing AEL-460 is a complete drawing of the reactor vessel, and has been selected as reference except:for the vessel height, which may change slightly with the final core configuration. A cost estimate of this vessel and the carbon steel vessel is being prepared.

The upper flow divider has been simplified and an additional shield $x$ ing has been added above the flow divider to reduce radiation heating in the vessel wall. The lower ends of the outer steel reflector rings have been modified to permit flow thru the support plate and to ease the mounting problems. These changes are shown on AEL-460.

Tentative materials for the vessel bolt and nut have been selected, buit have not been ordered due to a pending decision on FY60 estimates. 
AMBIENT TEMPERATURE: $=T_{0}$

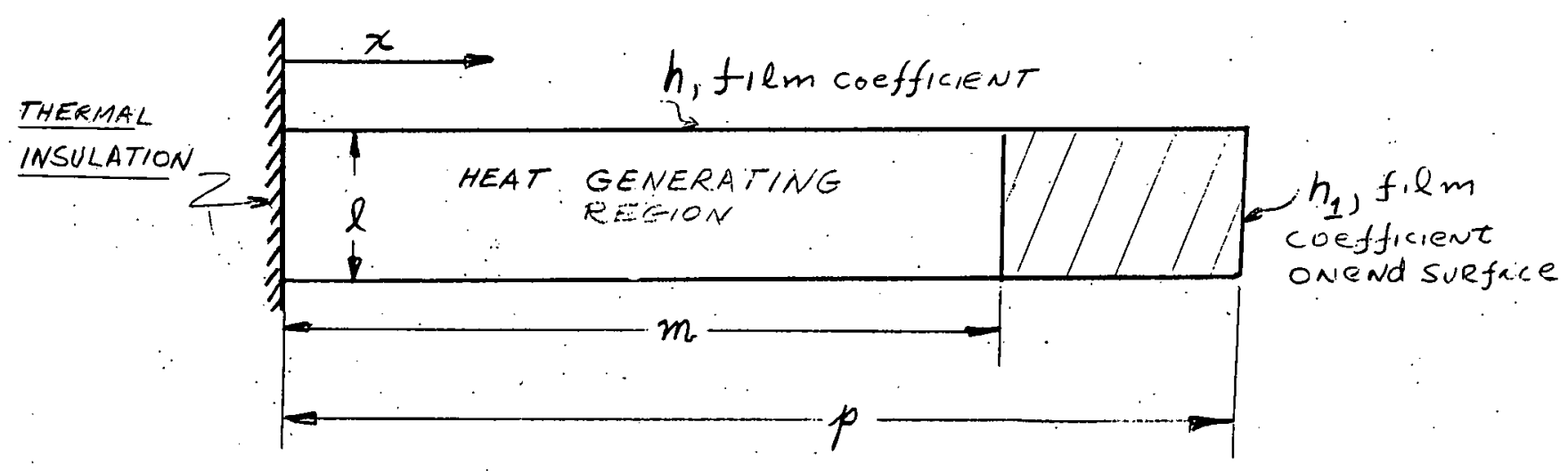

$G=$ Heat Generation rate, BTU/hr-m $\mathrm{m}^{3}$

$k=$ Thermal Conductuity of fin material, BTU/hr-gt-oi

$T(x)=$ Temperature, ${ }^{\circ} F$

$\ell=$ thucteness of plate, in:

$m=$ length 1 hecitginareting section

$p=$ total length of fin, in

FIG $2-1$

$068 \quad 226$ 


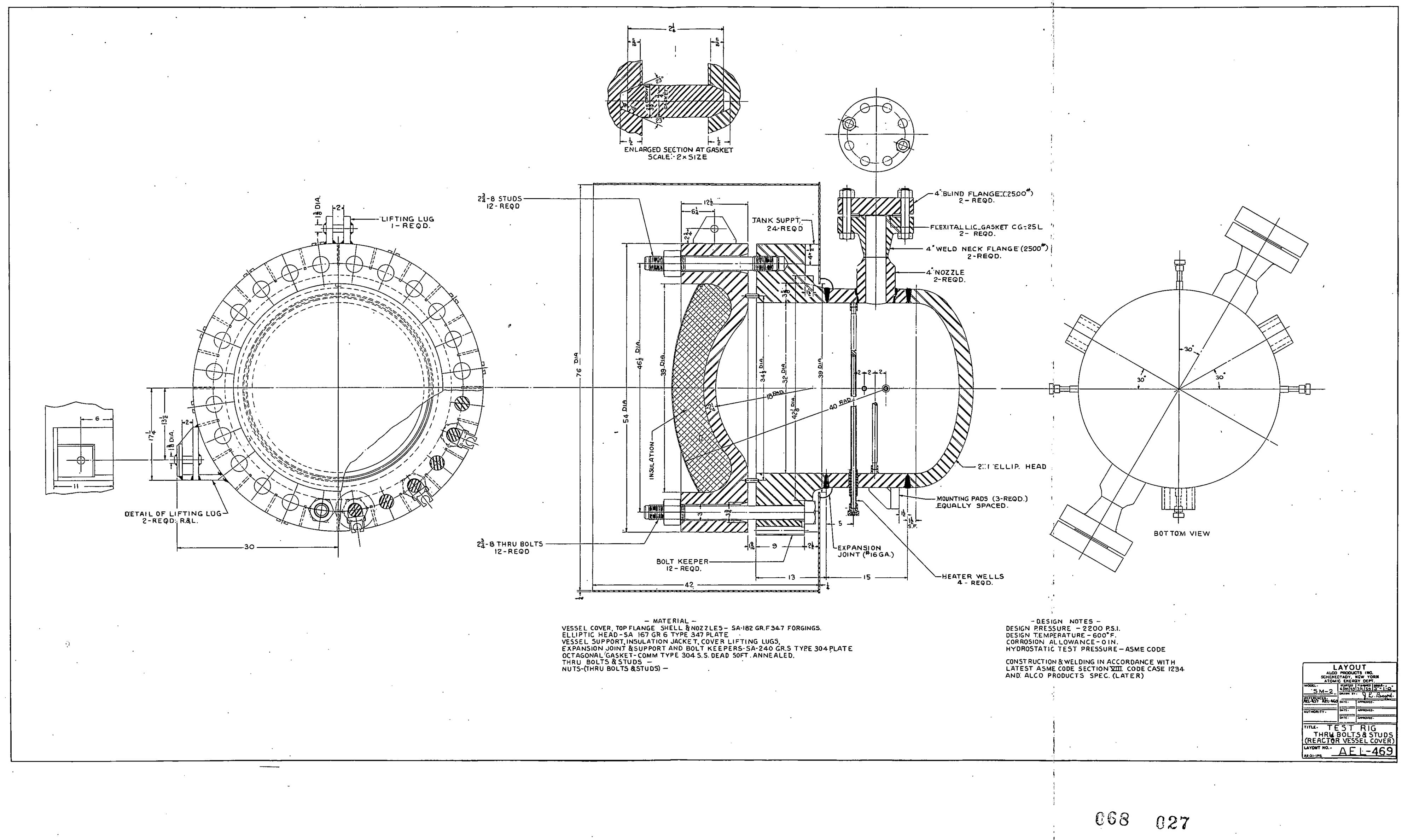




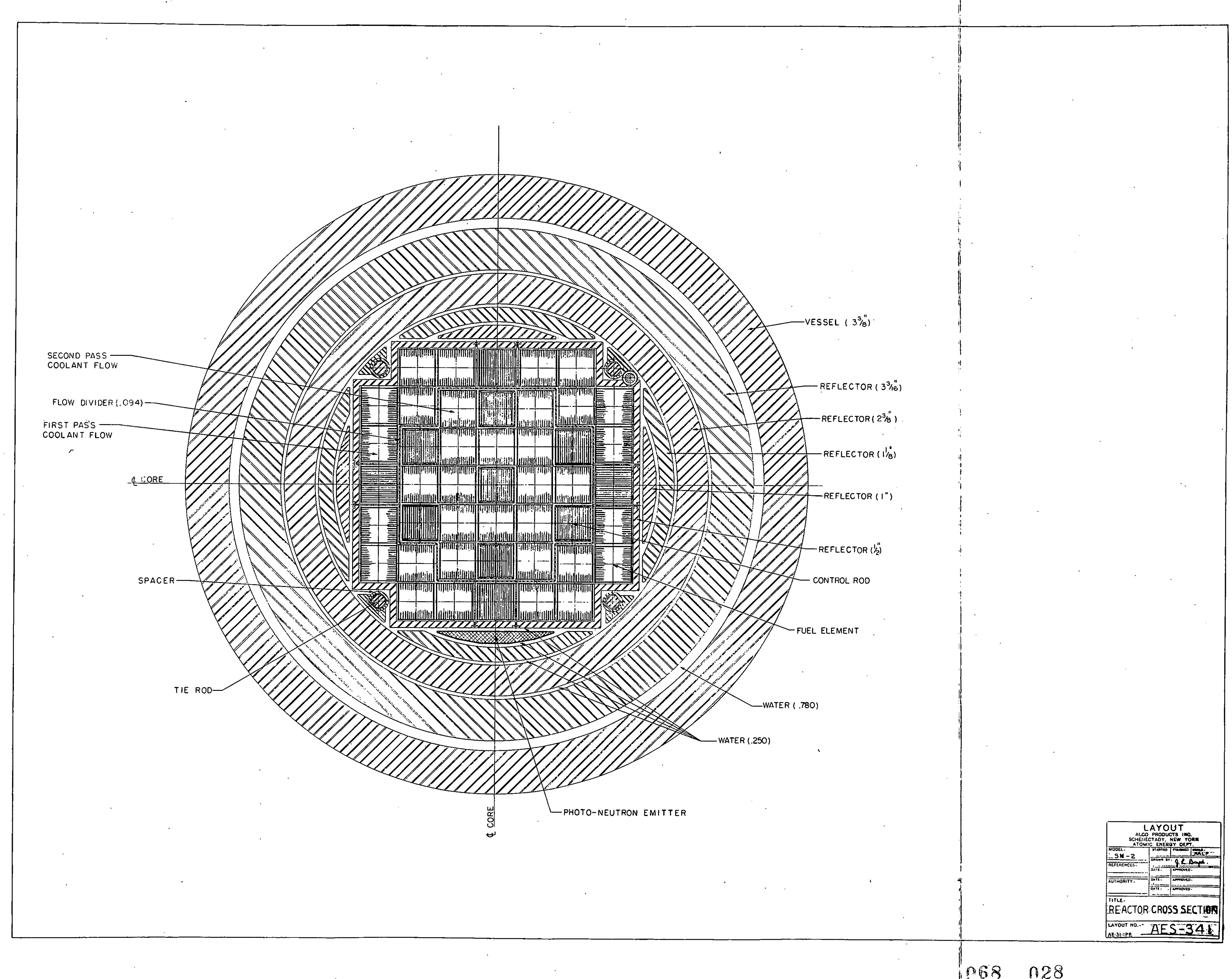




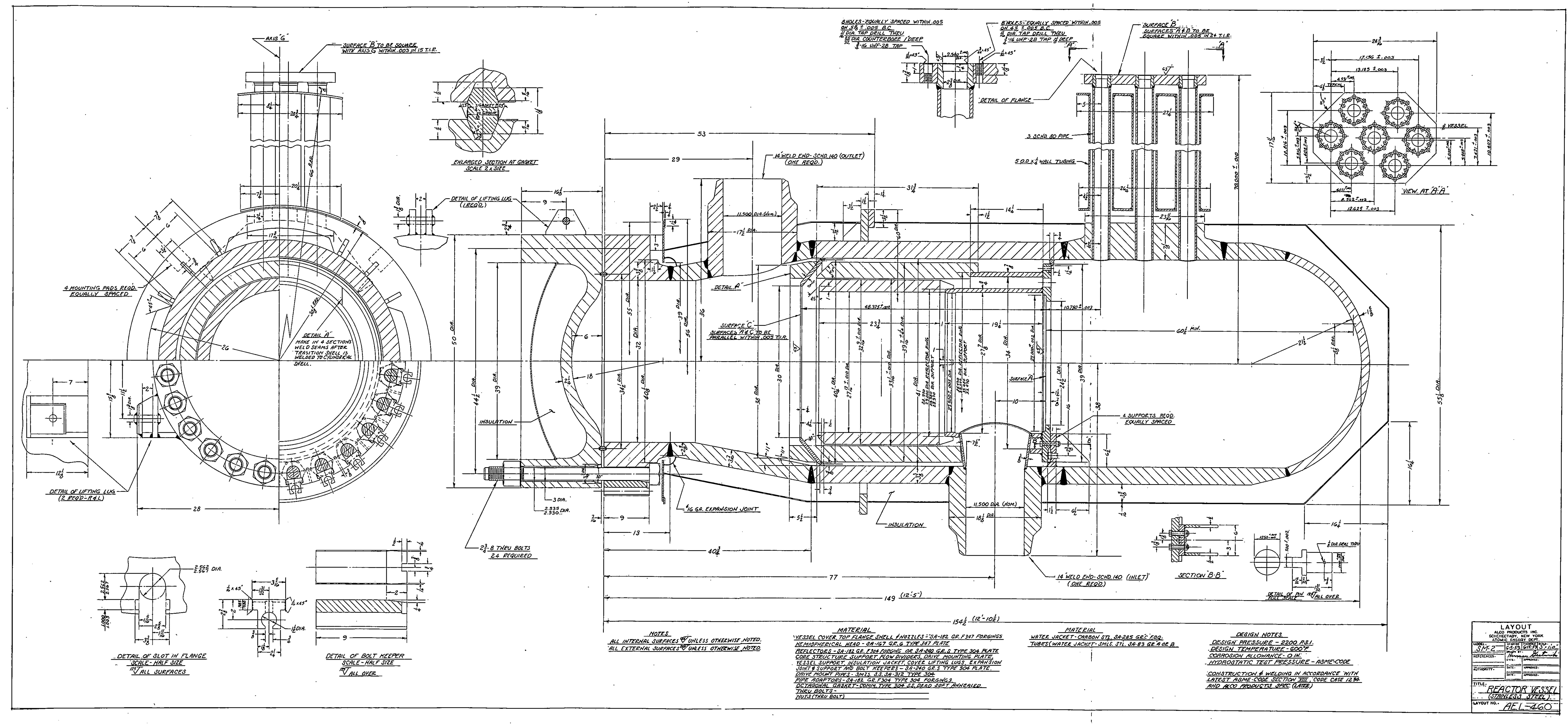




\section{METALLURGICAL DEVELOPMENT PROGRAM}

1. Progress $($ Task 4。0)-R。D。 Robertson

The evaluation of AISI Type 347 stainless steel with reduced cobait and tantalum impurity concentrations for use as a core cladding or struc-: tural material in the SM-2 was completed.

Final arrangements were made for the procurement of the irradiated B-10 stainless steel alloy samples from KAPL to be used for corrosion testing. Construction of the corrosion testing facility at Alco is proceeding on schedule, and actual delivery of the irradiated specimens from KAPL to A]co wili take place on July 27, 1959. Corrosion testing is expected to start on or about September 1, 1959 provided approval is granted by the A. E. C. on the FY60 estimates.

The study of irradiation damage to pressure vessel materials was completed. A report covering the effects of irradiation on materials for reactor vessels is being prepared in the form of an APAE Memo.

A survey was made to determine suitable nut and bolting materials for use with a stainless steel reactor vessel.. As a result, A-286 was selected as the reference bolting material and Unitemp 212 as the backup material. A testing program is being outlined to determine the notch sensitivity, susceptibility to oxygen stress corrosion cracking and the general overall corrosion characteristics of these two alloys.

The BMI report follows after section 5 of the report of this program.

\section{Type 347 Stainless Steel Investigation (Task 4.2) - R。W。Kelleman, J. Zegger \& $G_{0}$ Pancer}

An evaluation of the value of reduced cobalt and tantalum impurity concentrations in AISI Type 347 stainless steel in the SM-2 core cladding and structurail material has been made on the basis of material costs involved and present decontamination philosophy. This evaluation will be contained in an A.PAE Memo to be issued shortly. Conclusions drawn as a result of this investigation are as follows:

11) The use of nominal cobalt and tantalum concentrations (0.1 percent) in the cladding and reflector material will result in a gamma dose rate in the Steam Generator Water Box of approximately 8 roentgens per hour after one year, and 31 roentgens per hour 
after twenty years. This dose rate can be reduced to approximately 10 roentgens per hour after twenty years at an added cost of $\$ 220,000$, through the procurement of 0.01 percent cobalt and 0.01 percent tantalum in the core cladding material.

(2) The use of 0.01 percent cobalt and nominal 0.1 percent tantalum in the core cladding at an added cost of $\$ 170,000$ will reduce the dose rate to 12 roentgens per hour after twenty years.

(3) The use of steel with nominal cobalt and tantalum contents in the reflector material will not significantly add to the dose rate.

(4) A nuclear power plant provided with either an automatic decontamination system or provisions for remote maintenance may not require the use of low impurity core materials.

3. Discrete Burnable Poisons (Task 4.3) - R。 W。 Kelleman

Final arrangements have been made for the procurement of the irradiated B-10 stainless steel samples from KAPL。 The samples will be delivered to Alco on July 27.

Construction of the corrosion testing facility at Alco is near completion. The autoclaves and the majority of the associated equipment have been received and installed. It is expected that actual corrosion testing of the irradiated B-10 stainless steel samples will be started on or about September 1, 1959 , provided approval is granted to continue the program in FY 1960 .

4. Pressure Vessel Material Selection (Task 4.4) - R.W. Kelleman

The study of irradiation damage to pressure vessel materials has been completed. A report covering the effects of neutron irradiation on the properties of carbon, low alloy, and stainless steel is being prepared in the form of an AP Memo. It is expected that this report will be issued by August 15,1959 。

5. Nut and Bolt Materials for Stainless Steel Reactor Vessel (Task 4.5) -

A preliminary survey has been made to determine suitable nut and bolting materials for use with a stainless steel reactor vessel. As a result, the following nut and bolt combinations are being considered as likelly possibilities:

Bolting Materials

A-286 (Reference Material) 16
Nut Materials

A-286, Type 304

Unitemp 212, Type 304 
Both A-286 and Unitemp have coefficients of thermal expansion close to that of stainless steel, and also possess the required strength for bolting applications. A-286 has been used primarily in high temperature aircraft applications. Unitemp 212 is a fairly new material which is also gaining popularity where high strength and corrosion resistance are required.

Although these two alloys are used in the aircraft industry as high temperature bolting materials, their ability to withstand operating conditions encountered in pressurized $\mathrm{H}_{2} \mathrm{O}$ reactor systems is not known. The "notch sensitivity", susceptibility to stress corrosion cracking, and the general overall corrosion characteristics of these alloys will have to be determined. Cost of such a program, including materials, is being estimated. 
SM-2 CORE MATERIALS DEVELOPMENT PROGRAM

July 9，1959

Battelle Memorial Institute

505 King Avenue

Columbus 1 , Ohio

$$
i^{60}
$$

$068 \quad 033$ 
Stainless steel- $\mathrm{UO}_{2}$ dispersion-type specimens containing both ORNL hydrother mal $\mathrm{UO}_{2}$ and Mallinckrodt sphericical $\mathrm{UO}_{2}$ have been fabricated for irradiation testing in the ETR and MTR. These specimens embody a burnable poison in the form of $\mathrm{ZrB}_{2}$ or $\mathrm{CbB}_{2}$ compound dispersed in the fuel core. Studies have recently been initiated to develop techniques for the fabrication of full-size fuel elements incorporating these materials.

Capsules have been designed for the ir radiation of SM-2 specimens in both the ETR and MTR. The ETR capsules will be fully instrumented with thermocouples, dosimeters, and auxiliary resistance heaters. The MTR. capsules will be uninstrumented, as they will be irradiated in MTR core positions which do not accommodate instrumentation leads. Capsule mockups are being prepared and will be forwarded to the ETR and MTR for low-power exposure to determine the total capsule perturbation. These data will be utilized to more accurately estimate burnup rates during irradiation of the SM-2 specimens.: The first ETR capsule has been sealed. Leads to the heaters and ther mocouples are being installed. Parts for the three MTR capsules have been completed.

Development of Fuel-Elem ent Systems

Reference and alternate fuel-element materials have been selected, and techniques are being developed for preparing full-size plates. The reference fuel elements contain 0.030-in -thick cores of $26 \mathrm{w} / \mathrm{o} \mathrm{UO}_{2}$ and $1.1 \mathrm{w} / \mathrm{o} \mathrm{ZrB}_{2}$ dispersed in a prealloyed Type 347 stainless matrix and clad with 0.005 -in. -thick Type $347:$ stainless. Alternate plates involve a change in the boron compound and $\mathrm{CbB}_{2}$ and $\mathrm{BN}$ are being investigated as alternate compounds. Fabrication procedures are being evaluated on the basis of metallographic examination, chemical analysis, and physical and mechanical properties. : In addition, a major part of the development program has been directed toward the production of irradiation specimens.

Several full-size fuel plates have been fabricated to approximate dimensions and sufficient data have been collected to design the core compacting die. The die is being machined and will be used for producing fullsize plates for evaluation tests. Other work on the reference plates has 
been primarily concerned with determining the effect of various impurities on the behavior of $\mathrm{ZrB}_{2}$ and the effect of impurities and changes in shape of $\mathrm{UO}_{2}$ particles on the quality of the roll-clad dispersion.

As previously reported, under poor sintering conditions $\mathrm{ZrB}_{2}$ will oxidize, boron will be lost, and, in some cases, a reaction product may be observed in the matrix. However, even under these conditions, the behavior of individual $\mathrm{ZrB}_{2}$ particles varies. Thus, it appears that impurities or secondary phases in the $\mathrm{ZrB}_{2}$ may be detrimental. Therefore, a series of tests are being conducted to deter mine whether impurities such as carbon, silicon, columbium, or oxygen bearing constituents cause reaction when added either to the $\mathrm{ZrB}_{2}$ or to the metal matrix. Samples containing 3 grades of $\mathrm{ZrB}_{2}$ with known impurity contents are being used. In addition, iron matrix specimens containing 1 to $3 \mathrm{w} / \mathrm{o}$ silicon, 0.1 to 1.0 w/o carbon, or 0.5 to $2.0 \mathrm{w} / \mathrm{o}$ columbium are being used to evaluate the effect of impuritities added to the matrix metal. These specimens have been fabricated but have not been examined.

A series of specimens prepared to determine the effect of carbon and silicon on the stability of $\mathrm{ZrB}_{2}$ in a stainless matrix have not yet been fully evaluated. However, examination of specimens consisting of $1 \cdot \mathrm{w} / \mathrm{o} \mathrm{ZrB}_{2}$ dispersed in Type 318 prealloyed powders. with less than 1 and up to 2.5 . w/o silicon indicates that in the low silicon powders, the $\mathrm{ZrB}_{2}$ is completely oxidized but in the high silicon powders, while little or no oxidation occurs, an unidentified precipitate can be detected in the matrix. Chemical analyses for boron have not been completed for these specimens.

Preliminary work with spherical $\mathrm{UO}_{2}$ indicates that fracturing and stringering of $\mathrm{UO}_{2}$ particles are related to the amount of spherical particles present.: Apparently the strength of the particle is closely related to the shape. Additional tests are being planned to establish this relationship.

Results of transverse tensile tests are being used to aid in evaluating fabrication procedures.: The effect of varying the total reduction is being tested on a series of plates containing 28 w/o minus 100 plus 200 mesh spherical $\mathrm{UO}_{2}$ and $1 \mathrm{w} / \mathrm{o}$ minus 200 plus 270 mesh $\cdot \mathrm{ZrB}_{2}$ dispersed in a prealloyed Type 347 matrix. The plates were rolled at $2200 \mathrm{~F}$ using a 40 per cent reduction in thickness on the first pass followed by 20 per cent reductions for remaining passes. All plates were cold. rolled 15 per cent and annealed at $2050 \mathrm{~F}$ before testing. The results of the room temperature tensile test are shown in Table 1. Although there is no marked change in strength over the range of $6: 1$ to $9: 1$ total reduction, there is a trend toward decreasing strength at higher reductions. 
Effect of Total Reduction on Transverse Tensile Strength of $28 \mathrm{w} / \mathrm{o} \mathrm{UO}_{2}-1 \mathrm{w} / \mathrm{o} \mathrm{ZrB}_{2}$ Dispersion Cores

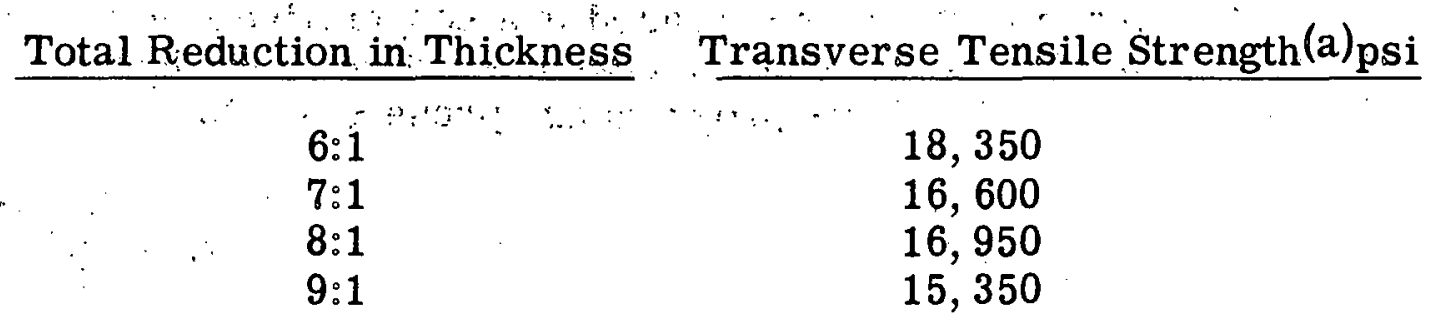

(a) Measured at room temperature - average of two tests.

Work was continued on investigation of alternate poison compounds for the $40 \mathrm{w} / \mathrm{o} \mathrm{UO}_{2}$ specimens.

To re-evaluate the previously reported results concerning $1.94 \mathrm{w} / \mathrm{o}$ $\mathrm{ZrB}_{2}$ and $40 \mathrm{w} / \mathrm{o} \mathrm{UO}_{2}$ in elemental matrices, a specimen of this type fabricated under reference conditions (prefiring, of $\mathrm{ZrB}_{2} 2 \mathrm{hr}, 2300^{\circ} \mathrm{F}$ in vacuum, prefiring iron powder $2 \mathrm{hr}$ in $1400 \mathrm{~F}$ in dry hydrogen, vacuum sintering at $2000^{\circ} \mathrm{F}$, and hot rolling at $2000^{\circ} \mathrm{F}$ ) was annealed in hydrogen for 2 hours at $2300^{\circ} \mathrm{F}$. Maximum variation of specimen temperature was $10^{\circ} \mathrm{F}$ as measured by a thermocouple adjacent to the specimen. Metallographic examination showed distinct $\mathrm{ZrB}_{2}$ particles with a continuous, but slight, oxide layer around the circumference.

Identical specimens have also been prepared with the high loading in a prealloyed matrix. By use of spherical $\mathrm{UO}_{2}$, a discrete dispersion comparable with the elemental matrix was obtained after hot rolling. Evaluation after cold rolling has not been made, but it appears that good dispersions containing 40 w/o $\mathrm{UO}_{2}$ can be made with prealloyed matrices.

In order to determine whether boron could be in the matrix but not visible because of the fabrication procedure, a series of roll-clad specimens was run through two cycles of heating $2 \mathrm{hr}$ at $2300^{\circ} \mathrm{F}$ in hydrogen followed by furnace cooling overnight. Specimens and results indicate that when $\mathrm{ZrB}_{2}$ is used, no new phases are present after heat treating. A slight precipitate was visible in the case of $\mathrm{CbB}_{2}$, but $2300^{\circ} \mathrm{F}$ is considerably higher than the fabrication temperature $\left(2000^{\circ}\right)$. These results can be correlated with previously reported chemical analysis on microdrillings in a specially prepared matrix.

Boron nitride (BN) has also been investigated in both elemental and prealloyed matrices at sintering temperatures of 2000 and $2200^{\circ} \mathrm{F}$ for periods of $3 \mathrm{hr}$, after standard mixing and pressing. Both types of matrix showed reaction 
precipitates after sintering at $2200^{\circ} \mathrm{F}$. After sintering at $2000^{\circ} \mathrm{F}$, the elemental matrix showed slight edge reaction of the BN, while the structure of the sample containing prealloyed powder compares favorably with $\mathrm{CbB}_{2}$ fabricated at $2000^{\circ} \mathrm{F}$.

Pitkin and Battelle are engaged in a cooperative study to resolve discrepancies in results of boron analyses obtained on identical specimens. Preliminary results of this program are presented below.

\section{Sample}

Master Alloy Sheet Stainless Stee 1-Boron Alloy Powder $\mathrm{ZrB}_{2}$ Powder (Batch No. 8)

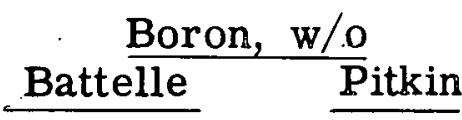
0.46
0.48
0.32
0.37
15.2
16.02

The results are in closer agreement than previous results, especially on the $\mathrm{ZrB}_{2}$ powders; however, better agreement is necessary and must be obtained before a core loading can be prepared. The studies are continuing and additional specimens are being exchanged between the two laboratories.

\section{Status of Irradiation Program}

In the initially formulated irradiation program, it was planned to irradiate ten fully instrumented capsules in the ETR. These capsules were to embody dosimeters, thermocouples, and auxiliary resistance heaters. They were planned for insertion in the beryllium reflector for exposure to an estimated flux of $3 \times 10^{14} \mathrm{nv}$. Since the time this program was formulated, the operating schedule of the ETR has been drastically affected by the installation of several loops. It is currently estimated that the ETR full power operation will be limited to approximately 15 per cent rather than the 70 per cent that is considered normal for this reactor.

In view of this developm ent, a meeting was held between Alco and Battelle representatives to consider the utilization of reactor space other than the ETR. In this review, the prime consideration was high flux positions that would permit burnups within a relatively short period of time. In order to establish material specifications by June 30,1960 , it will be necessary to obtain a burnup above the SM-2 average burnup ( $37 \mathrm{w} / \mathrm{o}$ total) and examine and evaluate the specimens prior to June $30,1960$.

The most promising high flux positions other than in the ETR are available in the central core of the MTR. Three positions with a flux profile of 2 to 
$5 \times 10^{14} \mathrm{nv}$ are available. However, these positions cannot accommodate leads so that these capsules would not contain thermocouples or auxiliary heaters.

After a review of the ETR status and other available reactor space, a recommendation was made by Alco-Battelle to irradiate thr ee noninstrumented capsules in the central core of the MTR and seven instrumented capsules in the ETR. The specimens irradiated in the MTR will be subjected to a postirradiation heat treatment and evaluated to establish initial material specifications by June 30,1960 . The results obtained with these specimens will be correlated with specimens irradiated under controlled conditions in the ETR. It is estimated that the ETR capsules will remain on test beyond June 30, 1960.

Since the ETR is scheduled for very brief low power cycles in the immediate future, a lead instrumented capsule will be inserted to evaluate design and test operation. Ultimately, six additional capsules will be placed on test.

Fabrication of Irradiation Capsules

Design studies involving the three MTR capsules were completed by computational and analog procedures. These capsules are designed on the basis of an unperturbed thermal neutron flux of 5.0 x 10 14 , a Brad-Lewis correlation derived capsule perturbation factor of 0.38 , a gamma heating rate of 10 watts per gram, and a specimen surface temperature of $650^{\circ} \mathrm{F}$. The design formulated is similar to that previously developed for the ETR capsules in that the various elements are selected to dissipate a large quantity of fission heat while maintaining a relatively low specimen temperature. In essence, the specimens are immersed in $\mathrm{NaK}$ with a split copper block insert adjacent to but not touching the specimens. These components are sealed into a nickel water-contacting shell. In the heatered capsules, coils of sheathed resistance wire heaters are wrapped around the copper block assembly.

Also supplementary capsule-perturbation-factor studies were conducted using a P-3 type analysis with an IBM 650 computer. Results now available for the case of capsules in MTR core positions indicate the total capsule perturbation may be roughly twice as great as predicted from the Brad-Lewis analysis. However, since both calculational procedures are based on simplifying assumptions, it appears necessary to conduct actual nuclear mockup experiments to obtain concrete data. An appropriately dosimeter ed capsule mockup is now being constructed, and early in July, this mock up will be shipped to MTR for a low-power exposure. At the 
same time, another mockup will be submitted for an exposure in the ETR beryllium reflector. The immediate use of data derived from these mockups will be in estimating burnup rates as the irradiation of the three MTR and the first ETR capsules progress. If the high perturbations predicted. by the P-3 calculations are verified, it will probably be desirable to modify the design of the later series of six ETR capsules in the direction of a reduced heat dissipation characteristic. 


\section{E. WELDED FUEL ELEMENT DEVELOPMENT}

\section{Progress (Task 5.0) - R. A. Shaw}

Arc starting difficulties have been overcome. Crater cracking difficulties have been practically eliminated. Intergranular and stress-corrosion tests show TIG welds and heat affected areas to be crack-resistant.

An element TIG welded with $0.025^{\prime \prime}$ side plates developed severe side plate buckling. However, an element welded with .040" side plates did not develop buckling and no crater cracking was encountered.

Static corrosion tests and test evaluations have been completed on one TIG welded and one resistance welded dummy fuel element.

\section{Development of Welding Processes (Task 5.1) - R。A. Shaw}

Arc starting difficulties have been overcome. Pilot arc starting and high frequency starting were used and do not produce good starts as consistently as the touch-retract mechanism. Inconsistencies in the touchretract mechanism were attributed to a faulty switch in the automatic welding. head, which has now been corrected.

Crater cracking difficulties have been practically eliminated by extending the current decay time and by improvement of the argon injection system during the current decay period. At this time, crater indications are being found on approximately two per cent of the welds.

TIG welds have been given Strauss test and acid etch test to determine resistance to intergranular corrosion in the as-welded condition. The Strauss test (acidified copper sulphate solution) has no effect on the specimens. The acid etch test $\left(10 \% \mathrm{HNO}_{3}, 3 \% \mathrm{H}_{\mathrm{f}}\right)$ revealed a narrow sensitized area in the heat-affected zone around the weld. TIG welds in the as-welded condition were also stress-corrosion tested in a $60 \%$ solution of magnesium chloride for 40 hours. No cracking was detected by micro-and macro-examination.

A TIG element has been welded using .025" side plates and .040" fuel plates. Severe buckling of the side plate occurred during welding. This buckling condition lifts the side plate off the fuel plates. Without the fuel plates to conduct heat from the weld, the side plate material overheats and a hotshort condition results. A TIG element has been welded using.030" fuel plates, .030" side plates, and spacers between fuel plates. This attempt at controlling distortion by the use of spacers was insuccessful, but this was probably due to the wide tolerance of the spacers used and not to the method employed. 
One TIG element has been welded using . 040" side plates, and .040" fuel plates. This element had no crater cracks.

Future Work:

TIG welded elements -

Elements are scheduled to be welded using various weld spacings. Results of the structural tests on these elements will be correlated with Task 5 welding development. As soon as crater cracking conditions have been completely eliminated, two elements will be fabricated with depleted fuel plates, and test plates will be made with variation in the depth of dead edge.

\section{Resistance welded element -}

Tensile tests will be made on the resistance welded elements to determine strengths of welded joints and to compare with the TIG elements. An acid etch test will be made to check the corrosion resistance. Stress-corrosion samples will also be prepared. Two elements of this type will be fabricated with depleted plates.

3. Corrosion Testing (Task 5.2) - L. E. Phillips

\subsection{Corrosion Testing Progress - Welded Fuel Elements}

Five hundred-hour autoclave tests and test evaluation were completed on one preliminary TIG welded and one preliminary resistance welded dummy fuel element. Both fuel elements were of unsatisfactory quality as received. It could not be established definitely whether or not defects such as crater cracks were propagated by corrosion. No significant attack was noticeable in the main welds or heat affected areas.

\subsection{Corrosion Testing - Europium Oxide Absorber}

Two specimens of unclad europium oxide-stainless steel core material and two clad defective specimens of the same material will be subjected to five hundred-hour autoclave tests upon receipt from BMI. The tentative schedule for these tests is as follows:

Sept. $1-25$

Test of two unclad specimens in deoxygenated, demineralized water at $635^{\circ} \mathrm{F}$ and $2000 \mathrm{psi}$. Weight change will be determined after 20 hours and 500 hours of testing. 
Sept. 28 - Oct. 19

Test of two clad defective specimens in deoxygenated, demineralized water at $635^{\circ} \mathrm{F}$ and 2000 psi. Weight change and depth of penetration will be determined after 500 hours of testing.

The test dates may have to be revised because of autoclave availability, but the periods for testing will be approximately as given. The clad specimens might be tested in August in the same test water with a dummy fuel plate, if the specimens are available at that time. 


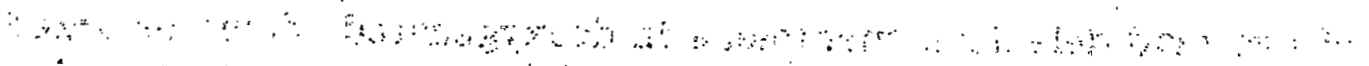

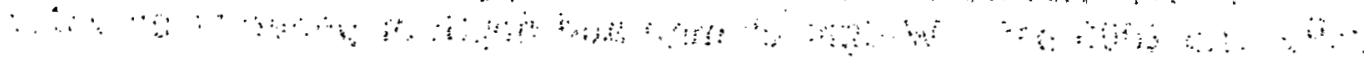

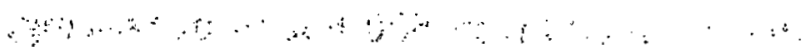

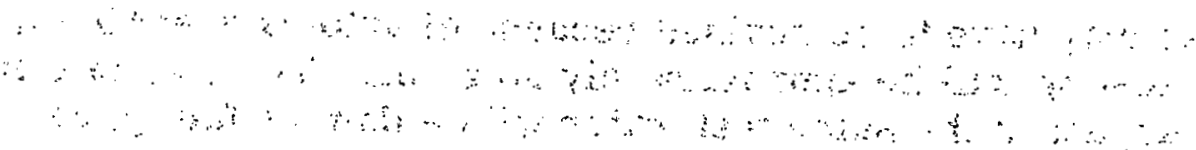




\section{F. HYDRAULIC ANALYIIS AND T星TT}

1. Progress (T2sk $\left.\theta_{8} 0\right)-W_{0}$ M. Bi Riehards

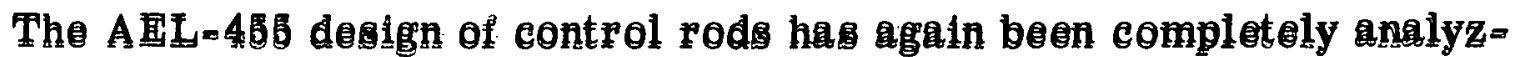
ed for pressure drop, and the possiblo improvements in flow passages evilo uated. The improvements woro not as satisfactory as oxpected, so that it will require a further design modification to achieve positive free fall of the rods agelingt reted flow of the cold water.

Two more welded fuel elements have been tested for statie deflection under uniform loading without end restraint

2. Pregsure Drop Analysis (Tagk 6.1) - F. T. Matthews

Because of the importance of the control rod pressure drop in fixing the inner pass pressure drop, and also in determining the required rod weight which will geram under gravity alone, the latest control rod design ghown on

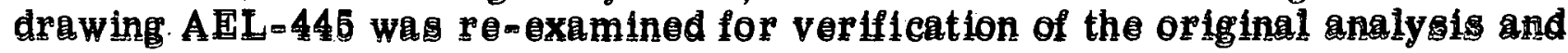
for possible improvements in pressure drop.

Although many of the events the flow experiences while passing thru the rod were analyzed by different approaches this time, the finil overall rod total prossure drop for the hot operating condition was 20.65 ft. as compared to 20 ft, calculated previously.

The hot static pressure loading on the control rod is $22.3 \mathrm{ft}$, if the control rod is to be charged with the pressure 1083 in turning the coolant from the vertical direction at the rod discharge; the rod pressure drop, which is lolso the Inner pass prossure drop, will be 22.3 ft. This is strictly aressure logs accounting procedure and does not incr ease the overall vegsel loss but mer ely redistributes the losses.

Soma detalls of the anglysis are present ed below:

A) Inlet - The inlet was analyzed as two rectangular passages which provide a combined turn and contraction for the fluid. The inlet was andyzed as a square duct corrected for aspect ratio. The two fluid streams are combined inside the rod case. Rounding of all edges of the bottom piston was considered to help locilly with the turn. In addition, the posgible use of a twQdimensional cone was postulated to bo placed over the rack retaining nut to pro= vide an inner wall for turning the fluid. The experimental program will test with and without this feature. 
In order to reduce the inlet loss, slots were considered in the rod case just below the leading edge of the fuel plates. These slots take advantage of the static pressure differ ential existing across the case at that plane. Bleeding flow into the rod here reduces the necessary flow going thru the inlet proper to make up the required total flow.

In addition, the effect of extending the long fuel plates down into the inlet to serve as turning vanes was also looked at.

The above configurations are shown in Figure 6.1

Configuration - As designed: W/Slots W/Vanes

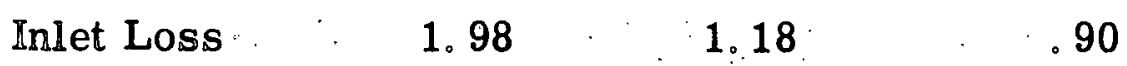

These losses are presented graphically in Figure 6. 2 .

B) Fuel Plate Loss - This loss was obtained by the use of $\mathbb{I B M}$ Code 302 ABWAC-MNC, a boiling water heat code. The curve of fuel plate losses was presented previously in APAE Memo \#185. For the required flow rate of $340 \mathrm{gpm}$, the fuel plate loss is $13.8 \mathrm{ft}$. of water at operating conditions and $18.9 \mathrm{ft}$. cold.

C) Absorber Section - The loss here is predominantly friction loss. The friction factor used was obtained from the Moody Line of friction factor versus Reynold's No. This loss is $0.95 \mathrm{ft}$. hot and $1.3 \mathrm{ft}$. cold.

D) Exit - Two parallel paths are provided for the flow: The pressure losses for the two paths are determined and the flows at equal pressure losses are added to determine the total performance of the exit.

The summation of pressure losses for the internal passage may be written as: contraction from absorber to the inner passage of cap $\phi$ disturbance due to the lock $f$ expansion out of the cap $f$ friction loss $f$ stagnation loss. This summation reduces to -

$$
\begin{aligned}
& \text { 16. } 28 \mathrm{~F}_{\text {in }}^{2} \text { hot } 9.37 \mathrm{ft}_{\text {。 }} \text { at } 340 \mathrm{GPM} \\
& 16.88 \mathrm{~F}_{\mathrm{in}}{ }^{2} \text { cold } 9.72 \mathrm{ft}_{\text {. }}
\end{aligned}
$$

The summation of losses for the external path is as follows Expansion at the absorber cutouts $f$ contraction into the area around the outside of lock $f$ contraction into corners $f$ two $45^{\circ}$ angle turns $f$ stagnation loss. 
This reduces to $529.33 \mathrm{Fext}^{2}$, which at $50 \mathrm{GPM}$ amounts to $6.55 \mathrm{ft}_{\text {. }}$ loss. The individual path losses and the flow addition at equal pressure losses is presented in Figure 6. 3 .. At a total flow of $340 \mathrm{GPM}$, the exit loss is $6.6 \mathrm{ft}^{\text {。 }}$ hot with a flow split of 288 GPM internal and 52 GPM external.

Bleed holes thru the case at the end of the absorber section were also considered. At the static pressure differential existing across the case at that point, only 7 GPM could be bled off.' This, however, is subject to experimental verification, as the assumed effective flow area of these holes is questionable. The contribution of these holes was not considered here.

E) The overall static pressure loading on the control rod cold was calculațed to be $28.1 \mathrm{ft}$.

3. Static Deflection and Thermal Stress Tests (Task 6.2) - J.A. Christenson

Two more welded fuel elements have been tested in the static deflection rig, bringing the total to five. These were Nos. 2-2 and 5R, a standard TIG welded and a standard resistance welded element, respectively。 (neither of these was listed on the original identification Table, No. 6. 1 on page VI-2. of APAE Memo 197, but they represented improved results from Task 5, over the elements that had been tested previously). In both cases the tests showed deflections $20 \%$ to $25 \%$ less than observed with the previous elements, and no significant difference is noted between the two welding methods.

\section{Vibration and Collapse Testing (Task 6.3) - J. A. Christenson}

A high velocity flow test - up to $174 \%$ of design maximum has been run on a stationary element with a rake of pitot-static probes measuring the flow in each of the 17. internal channels. At the expected maximum rated flow for a stationary element of 356 GPM, no collapse was indicated.

Between rated flow and the maximum of this test, several channels showed loss of flow through some of the channels; but the tests are still inconclusive. This is because it is not certain whether clogging of the probes by entrained crud in the loop was the cause of the diminished signal. A testing procedure is being worked out which is expected to permit differentiating between these causes, despite the incurability high level of crud in this loop.

5. Flow Distribution Tests (Task 6.4)

Single Element Tests (Task 6.4a) - Jo A. Christenson

It has been necessary to convert completely to the use of pitot-static instrumentation. This will replace the hot wire anemometry, which has caused the severe delay in this program. 
As design work on core supports progressed, it became evident that the internal components of the Single Element Test rig would not provide adequate simulation of actual core flow conditions, particularly for investigation of flow distribution to the lattice. In the original planning this problem was relegated to the full scale $r$ ig where the interaction of all channels as well as entrances and exits is obtained directly. The importance and urgency of this problem and the scheduling of the full scale test made it necessary to tackle this problem in the single element flow rig. Consequently, a redesign of the rig became necessary. This new design is presented in Figure 6.4 (AES-345). It provides a lattice flow passage along the entire length of the element, and provisions for balancing flow on each side of the entrance to the passage. Thus the flow conditions approaching the test element can be regulated to account for the effect of the adjacent elements or control rod.

The core support design shown in the end view on AES-345 is a duplicate of a portion of the design shown in AES-325, which was included under the Task 3 section of APAE Memo 197. The portion is that which supplies the first element at the left end of the bottom row. A second set of support plates will duplicate the portion supplying the third element from the left of the third row from the bottom. Fabrication of the new components for the redesigned rig is in process at present.

\section{Full Scale Flow Test (Task 6.4b) - D。 E。 England}

The primary effort has been directed towards collecting the finalized segments of the core design as they become available from the different groups. These were then combined into a semi-final core assembly drawing, modified for testing purposes.

Most work has now ceased on the project pending the decision whether SM-2 full scale work will be performed in water or air, because of the revised FY 60 estimate. 
Suggested features to reduce pressure LOSS SHOWN WITH DASHED LINES

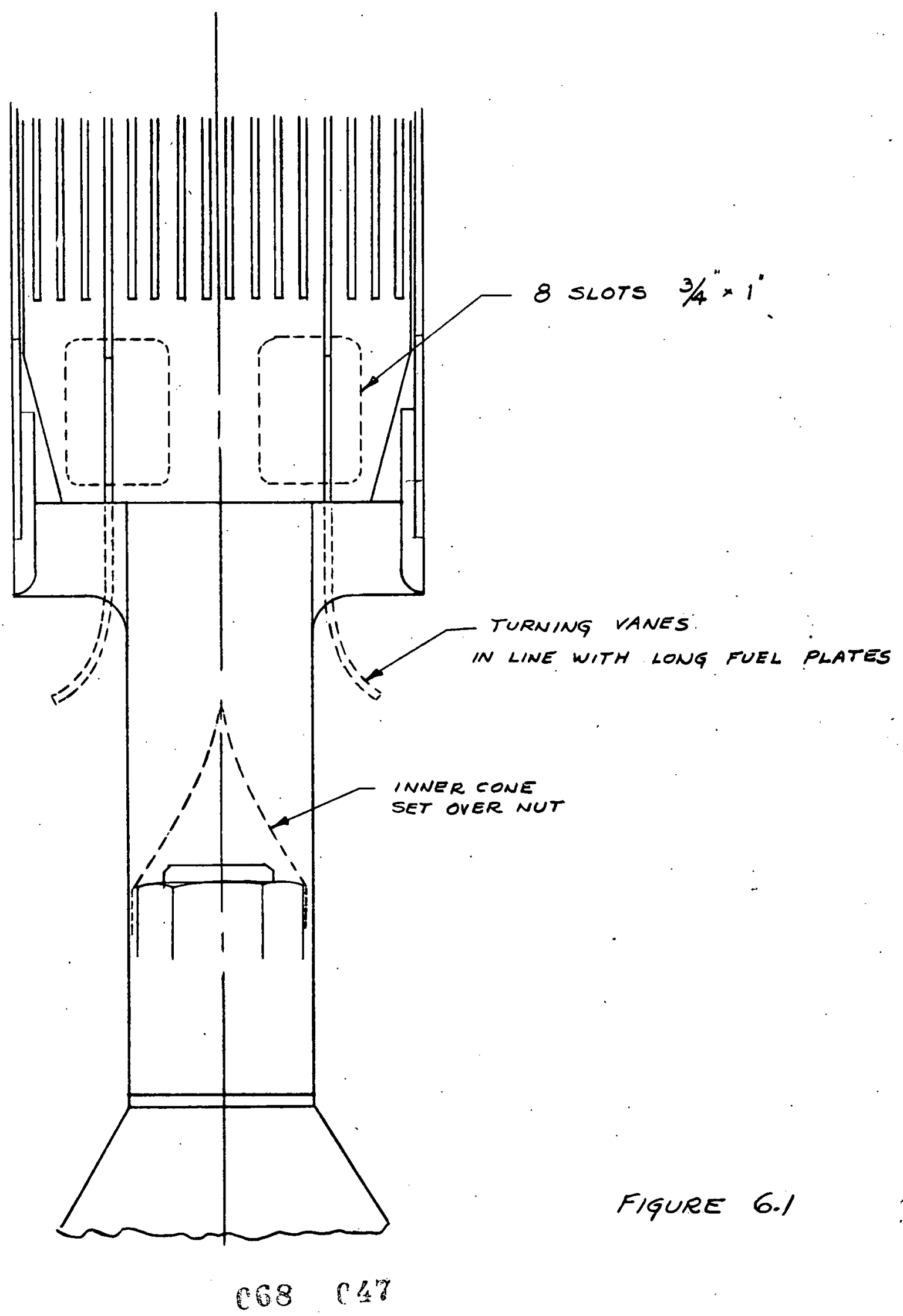


100

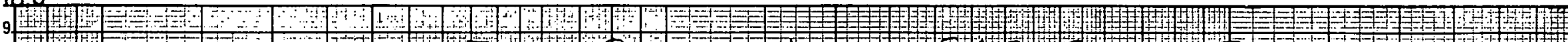
8 Fla

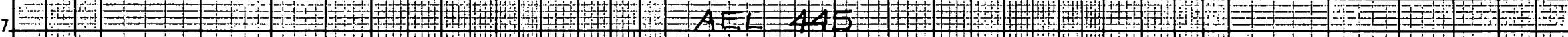
$6 \mathrm{~S}$

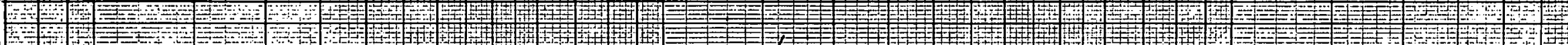
工la $43-1$ tro

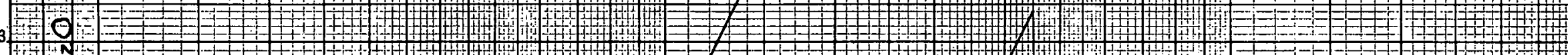
Hin

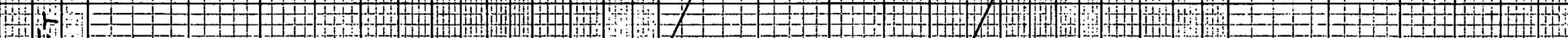

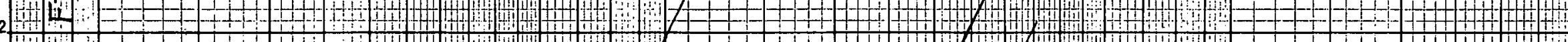
+x+口

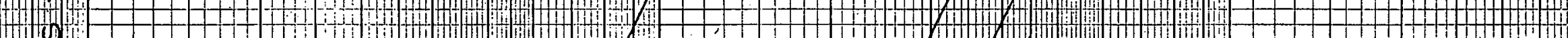
(1)

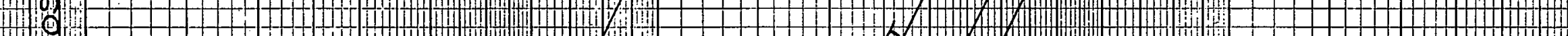
ii 17 -

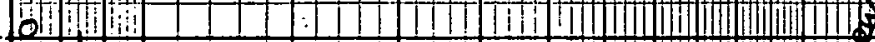

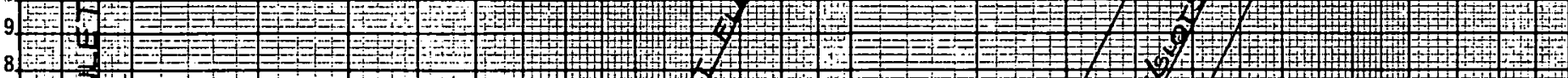
(Ii:

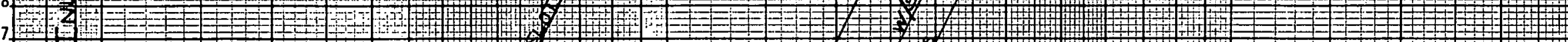

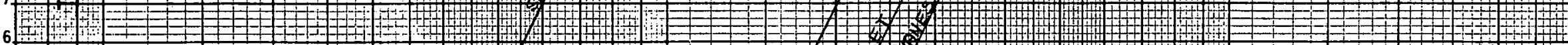

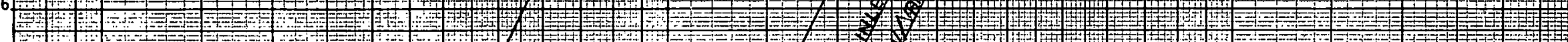
5

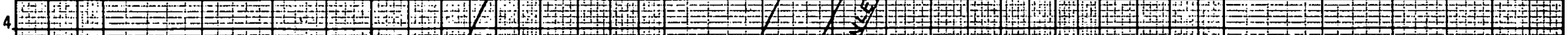

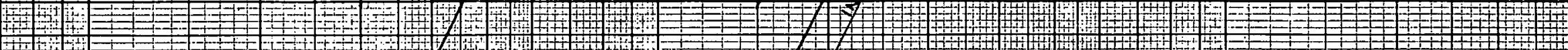
(1) (1)

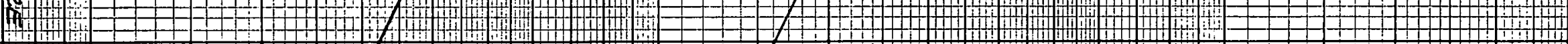
2 of

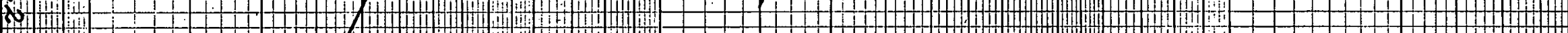

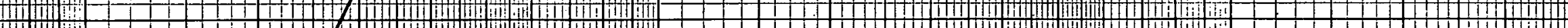
W.6

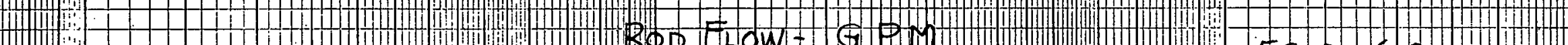
(Ii) 


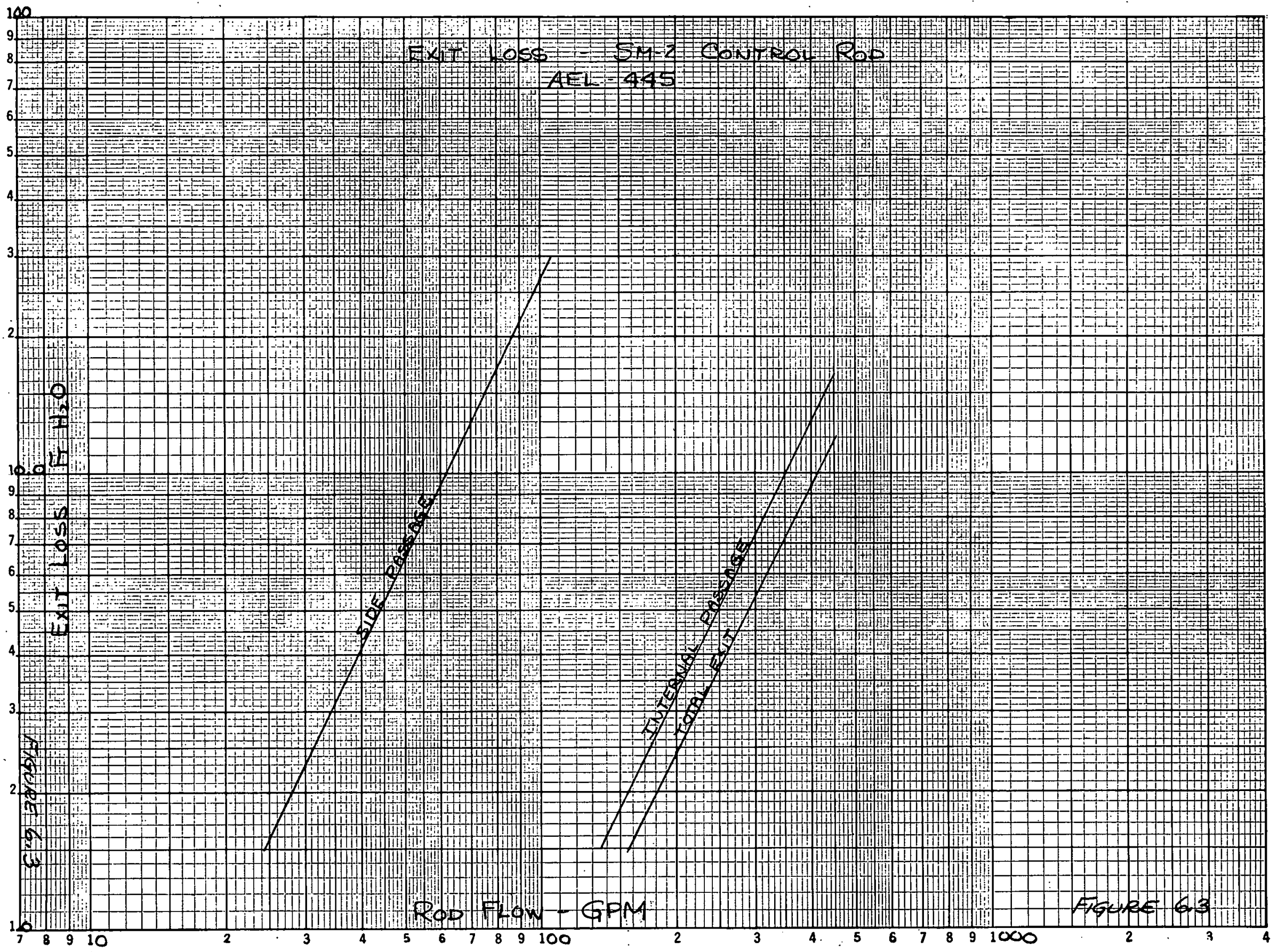




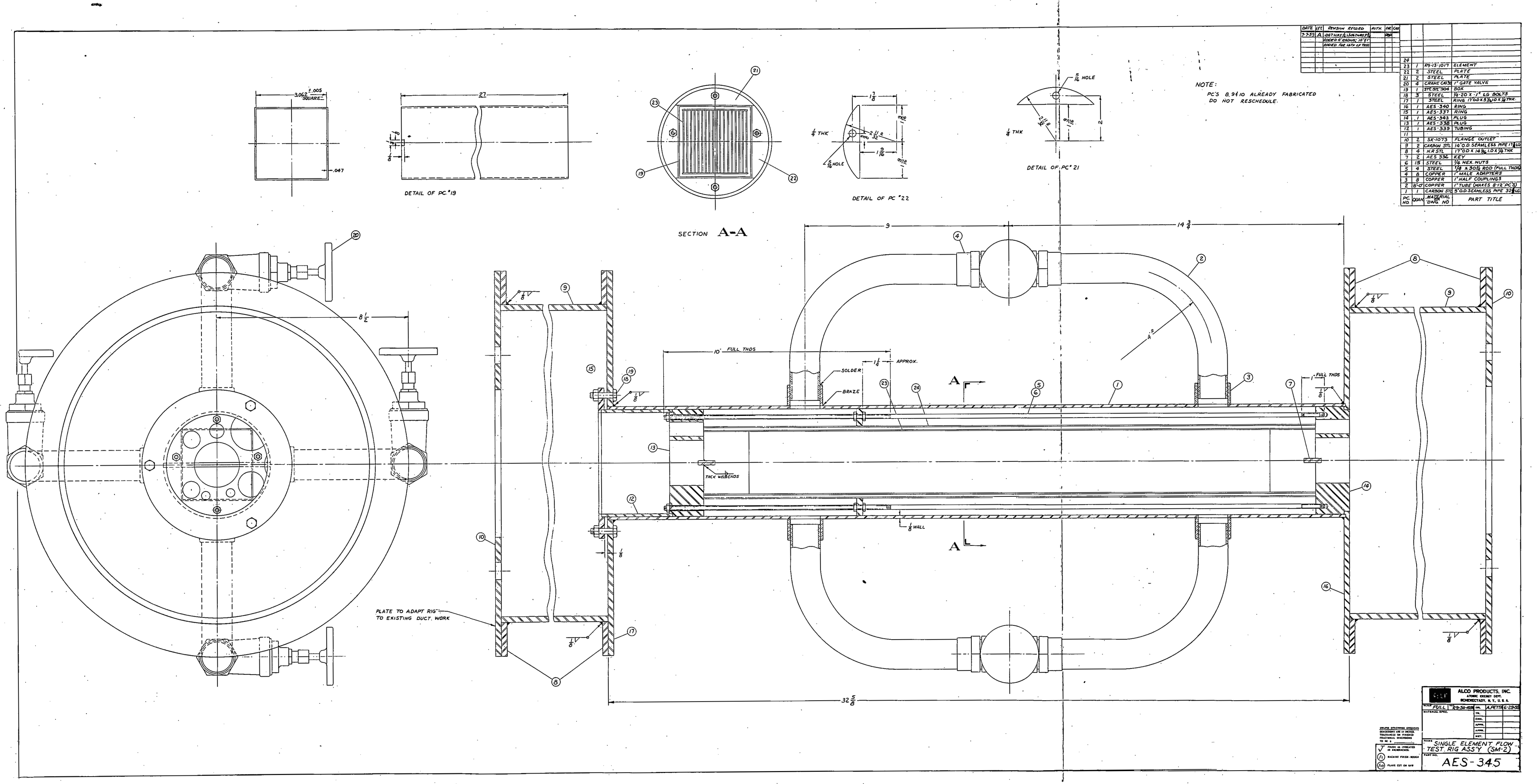




\section{G. CRITICAL EXPERIMENT PROGRAM}

1. Progress Review (Task 7\%0) - J. W. Noaks

The rerun of boron impregnated Mylar tape was received dpring this period and the boron content verified as satisfactory. An additional curve of integrated excess $\mathrm{K}$ versus plate loading was obtained for this boron loading. The preliminary SM-2 midlife mockup was constructed, and planned measurements completed during the report period.

Approximately $80.7 \%$ of the program effort has been completed with an expenditure of $78.2 \%$ of the approved funds:

2. Flexible Critical Experiment (Task 7.6) - Jo W. Noaks

Parametric Studies

A determination of integrated excess $\mathrm{K}^{*}$ in cents as a function of plate loadings per element was obtained for the $7 \times 7 . \mathrm{SM}-2$ core array with a loading of $0.62 \mathrm{gm} \mathrm{B}-10$ per $\mathrm{Kg}$. U 235 . This boron -10 content is based on tape analysis performed by Lucius Pitkin. Cross plots of existing reactivity data for the boron loadings previously reported indicate alternatively a B-10 content of $0.44 \mathrm{gm} \mathrm{B}-10$ perr $\mathrm{Kg} \mathrm{U} \mathrm{U}_{25}$, assuming that the boron analysis for the 1. $6 \mathrm{gm} \mathrm{B}-10$ per $\mathrm{Kg} \mathrm{U}_{23}$ is correct as stated. Since the reactor is a far more sensitive tool for determining boron content, it is clear that appreciable errors may exist in the chemical analyses of these boron impregnated mylar tapes: Therefore, before any credence is tendered the reported boron loadings, one should await the results of reactivity evaluations to be conducted during the next period. Data for a total of four different mylar tape loadings will then be available and some correlation of chemical analyses and reactivity values with errors and "confidence" ratings should be possible.

Figure 7.1 presents the parametric data available to date.

Prelliminary SM-2 Midlife Mockup

The SM-2 midlife mockup with the composition described in Figure 7.2 was critical on the 7 rod bank at 4.602 inches withdrawal. The 7 rod bank has an average worth of $\$ 3.44 \$ 0.10$ per inch of travel between bank positions of 4 and 5 inches. The calibration curve is at its maximum value at 4. 5 inches and has essentially zero slope thru the 4 to 5 inch interval.

Steel reflector and flow divider effects were determined in this mockup. Figure 7. 3 describes the effect on core reactivity of varying flow divider 
thickness. The extrapolated value for a flow divider of 0.093 inch thickness is -96.6 cents. Since the mockup does not allow the variation of center to center fuel element spacing, it was impractical to measure the effect of changing this spacing to accommodate the 0.093 inch flow divider and proper water channels. Therefore, it is assumed by linear extrapolation that the combined core alterations would not introduce a reactivity effect more negative than the -128 . cents so obtained.

Figure 7. 4 describes the reactivity effects of the design lamination of steel and water. side reflectors and solid steel corner reflectors. Since the maximum steel available allows for only $21 / 2 \mathrm{in}$. of steel on all four sides, data were obtained for both four sided - four corner ed reflection, and two adjacent side two corner reflection. The data overlap indicate a descrepancy of almost a factor of two. This factor was therefore, applied in the thick reflector region to yield a design laminated reflector worth not exceeding $f 44$. cents. The nature of the curves presented is such that this treatment should be viewed with reasonable confidence.

It was generally agreed that neutron flux measurements would be influenced strongly by the approximations of this preliminary mockup and consequently should be deferred for investigation during the final SM-2 core mockup. Several fission foil measurements were none theless taken in element 45 at the center and on the fuel edge adjacent to the central control rod at a core elevation of 5.0 inches. Both bare and cadmium covered data were obtained with normalization to 1.00 at the center of element 45 .

\section{Center of Element 45}

Bare U.235

$\mathrm{Cd}-\mathrm{U} \cdot 235$

Cd fraction
1.00

.21

.79
Edge of Element 45

1.87

.22

.88 


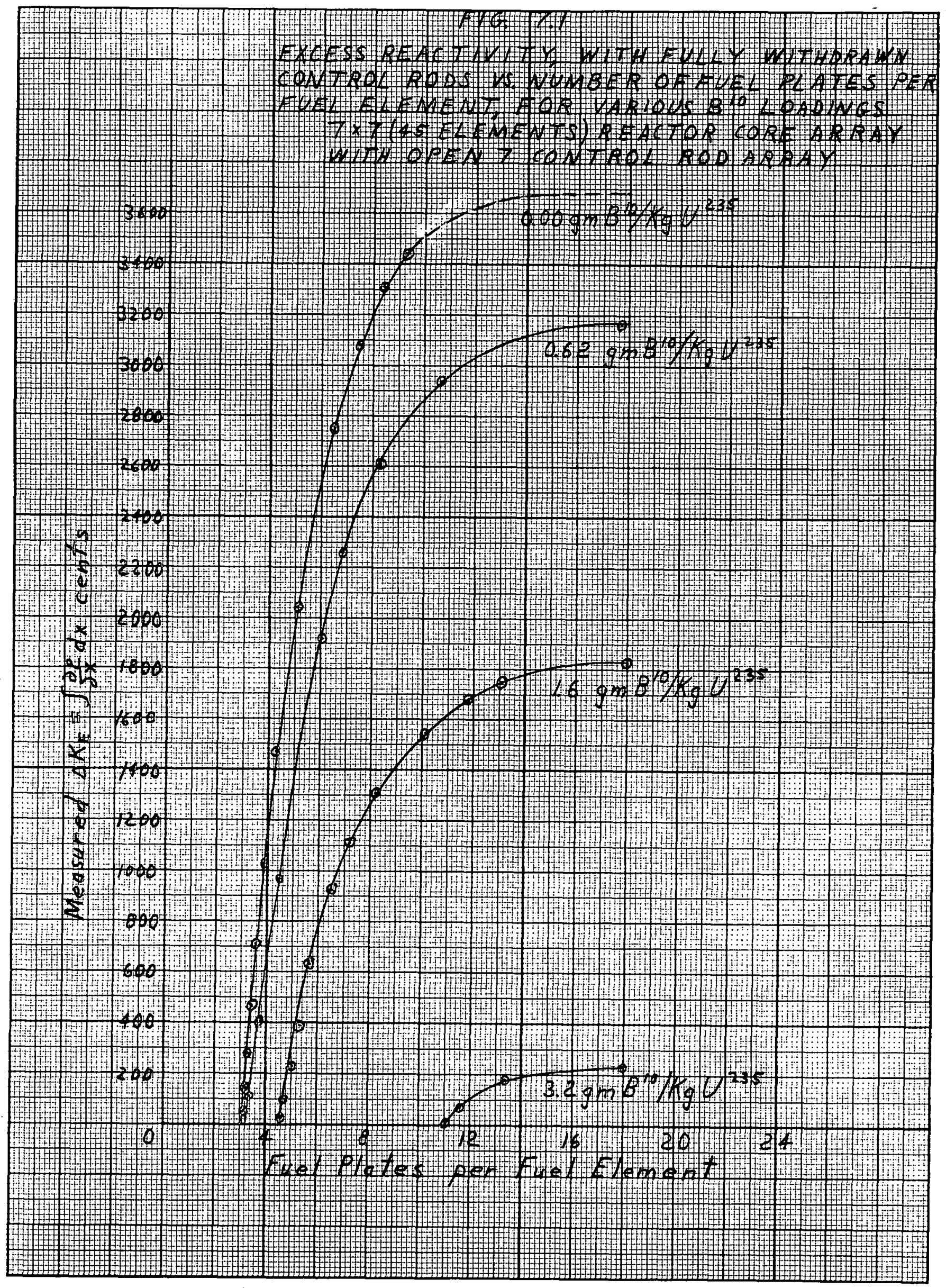




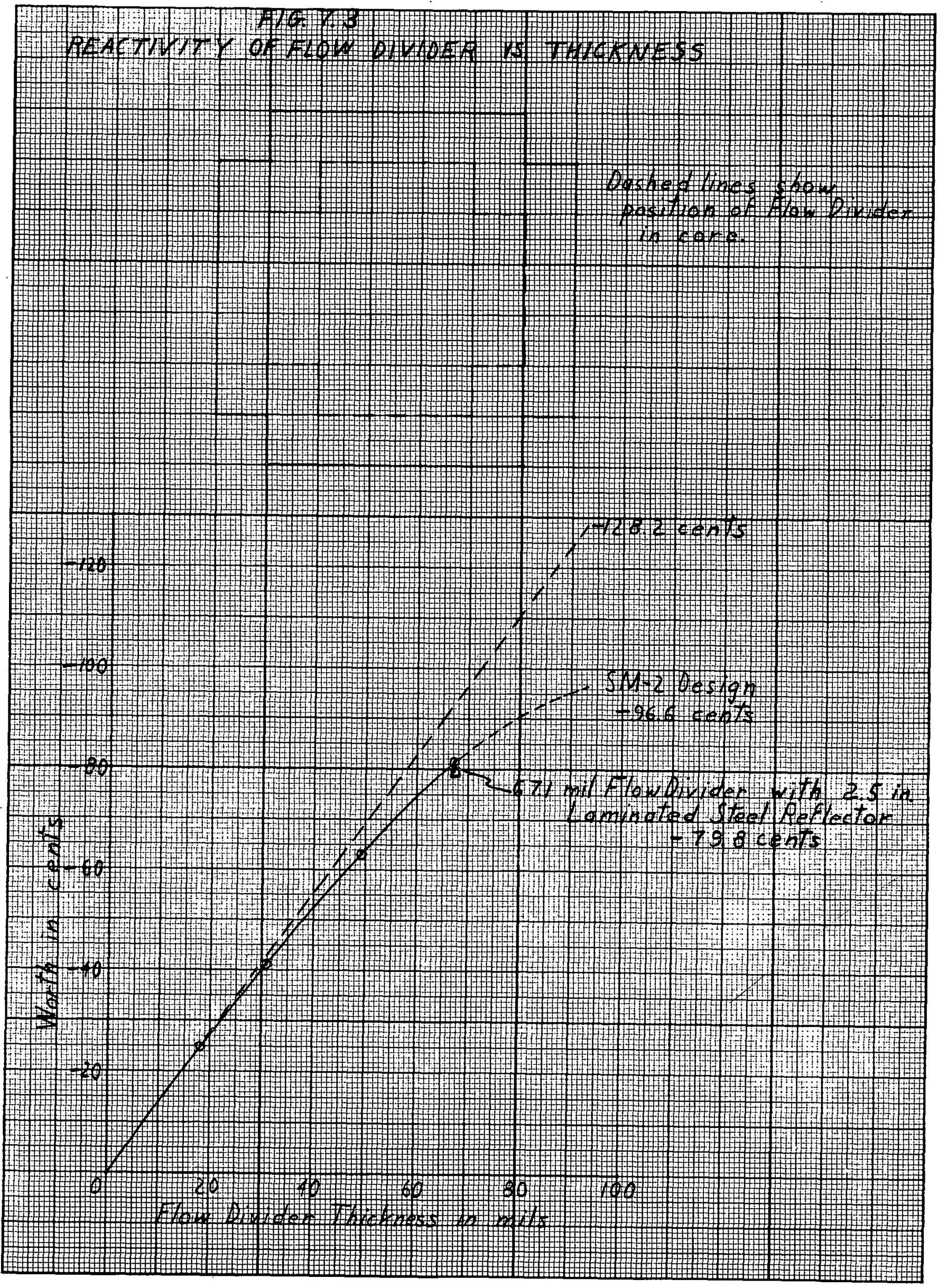

$068 \quad 054$ 


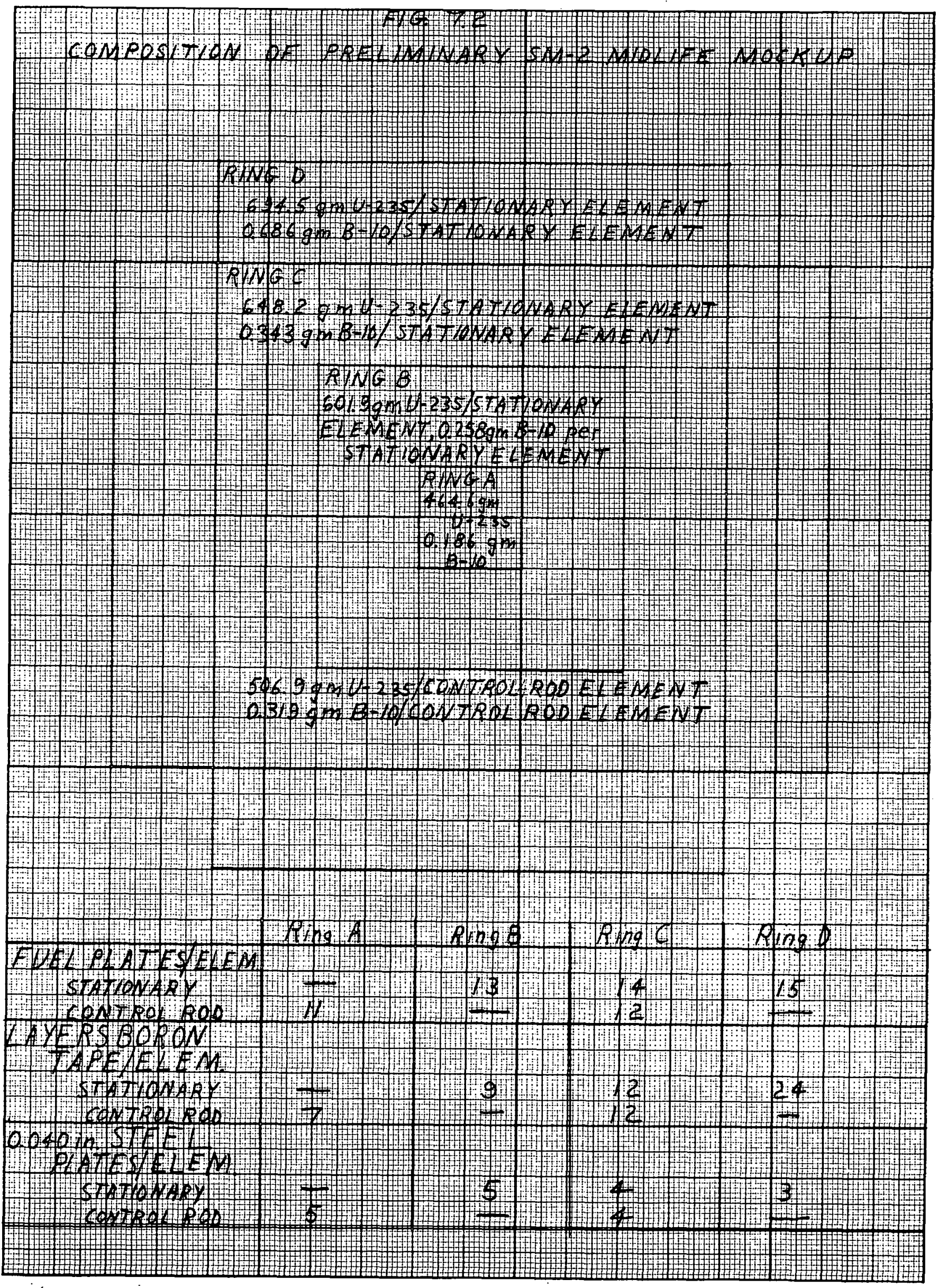




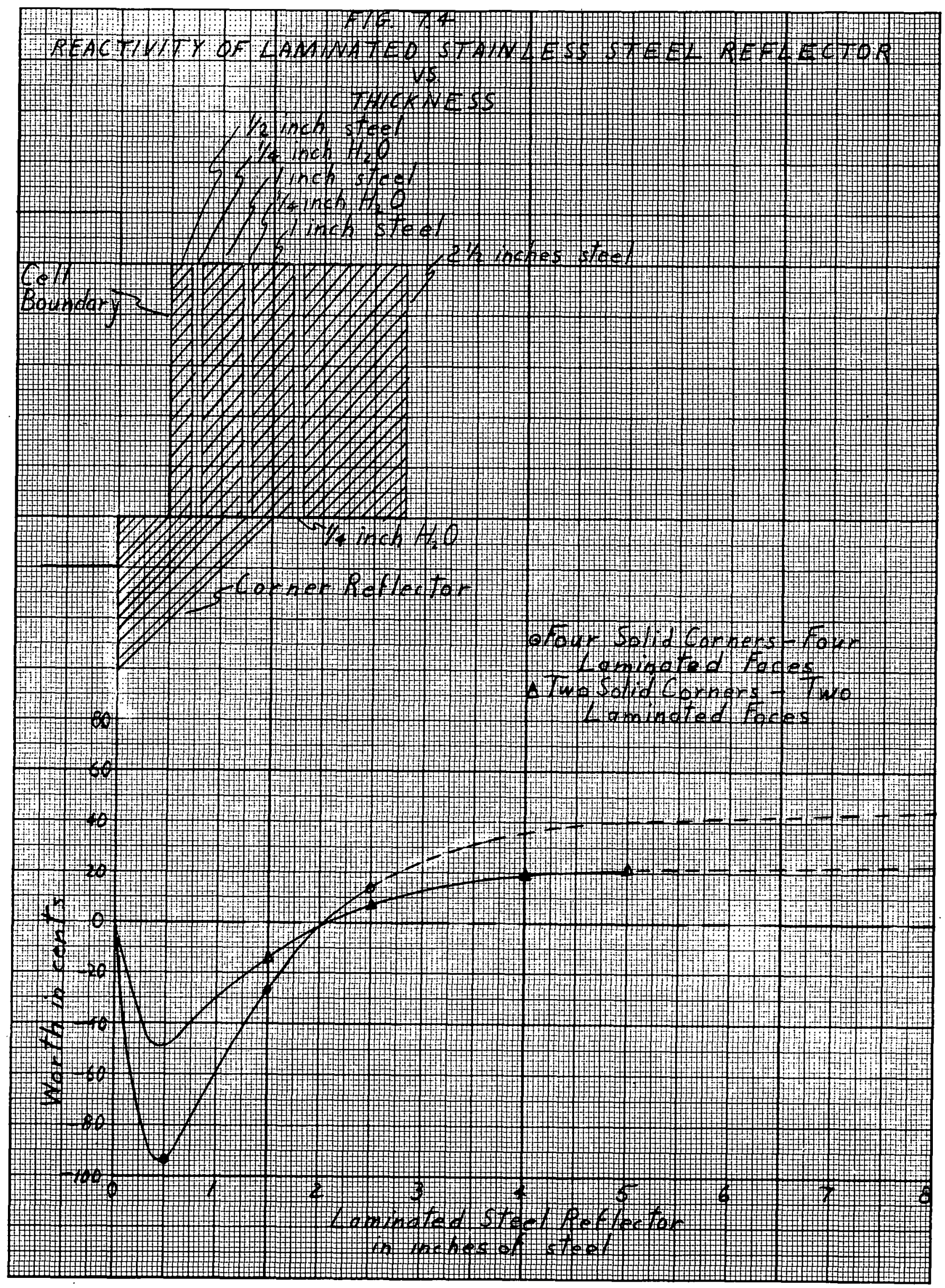

$$
668 \quad 056
$$




\section{H. CONTROL ROD DRIVE DEVELOPMENT}

\section{Progress (Task 11.0) - G. M. Van de Mark}

The pinion, pinion support bearings, and connecting shaft to the seal assembly have been completed to reflect the increased rack size. The seal assembly drawings are complete and material requisition has been started for one seal assembly. Due to the long delivery time on the seal rings and diaphragms, the initial testing will be done with seal rings and diaphragms from previous tests. The seal assembly, less the above mentioned parts, is expected in the Schenectady lab for testing on September 15, 1959 .

The detailing of the clutch assembly is completed, but the prototype is being held back until the test data on release time torque rating is received from the laboratory.

The autoclave has been released for fabrication, and delivery is promised for the end of July, 1959. The internal parts have been drawn and are presently being checked.

The fabrication of the surge tank and horizontal flow test tank has been completed and these items are ready for shipment to Schenectady.

A curve showing static pressure drop across the control rod vs. control rod weight has been plotted, and is included in this report. The present control rod weight is calculated as $95 \mathrm{lbs}$. in air, so that any increase in pressure drop across the control rod will make the present control rod inadequate to balance the hydraulic forces when the core is at room temperature. As reported in Task 6.0, the latest estimate of static pressure drop is $28 \mathrm{ft}$. at room temperature. 


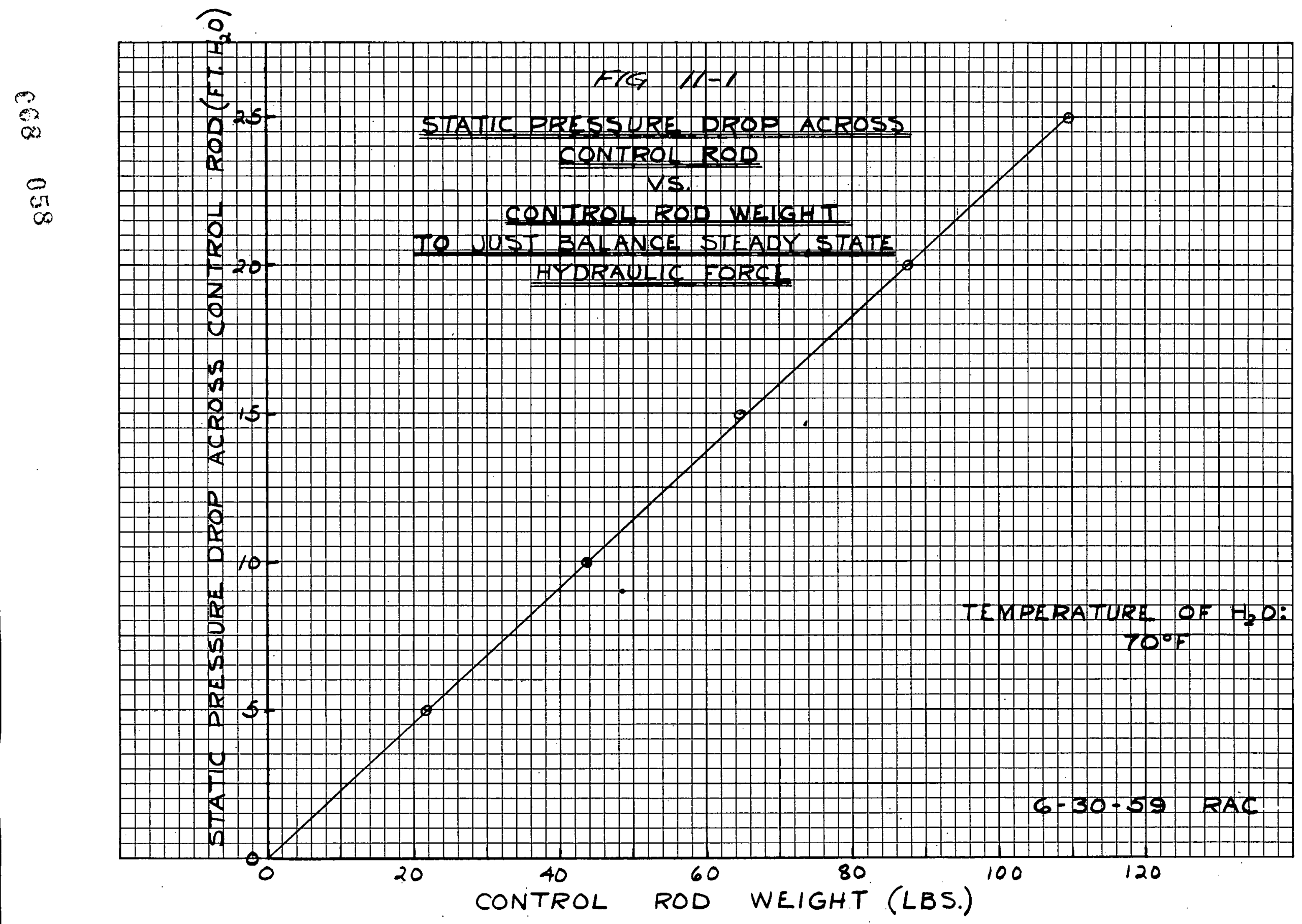

